GA-A15329

UC-77

903095

\title{
CORE SUPPORT BLOCK THERMAL MIXING TEST ANALYSIS REPORT
}

\author{
by \\ E. CHIN
}

Prepared under

Contract DE-AT03-76ET35300

for the San Francisco Operations Office

Department of Energy

GENERAL ATOMIC PROJECT 6400

DATE PUBLISHED: MAY 1979 


\section{DISCLAIMER}

This report was prepared as an account of work sponsored by an agency of the United States Government. Neither the United States Government nor any agency Thereof, nor any of their employees, makes any warranty, express or implied, or assumes any legal liability or responsibility for the accuracy, completeness, or usefulness of any information, apparatus, product, or process disclosed, or represents that its use would not infringe privately owned rights. Reference herein to any specific commercial product, process, or service by trade name, trademark, manufacturer, or otherwise does not necessarily constitute or imply its endorsement, recommendation, or favoring by the United States Government or any agency thereof. The views and opinions of authors expressed herein do not necessarily state or reflect those of the United States Government or any agency thereof. 


\section{DISCLAIMER}

Portions of this document may be illegible in electronic image products. Images are produced from the best available original document. 


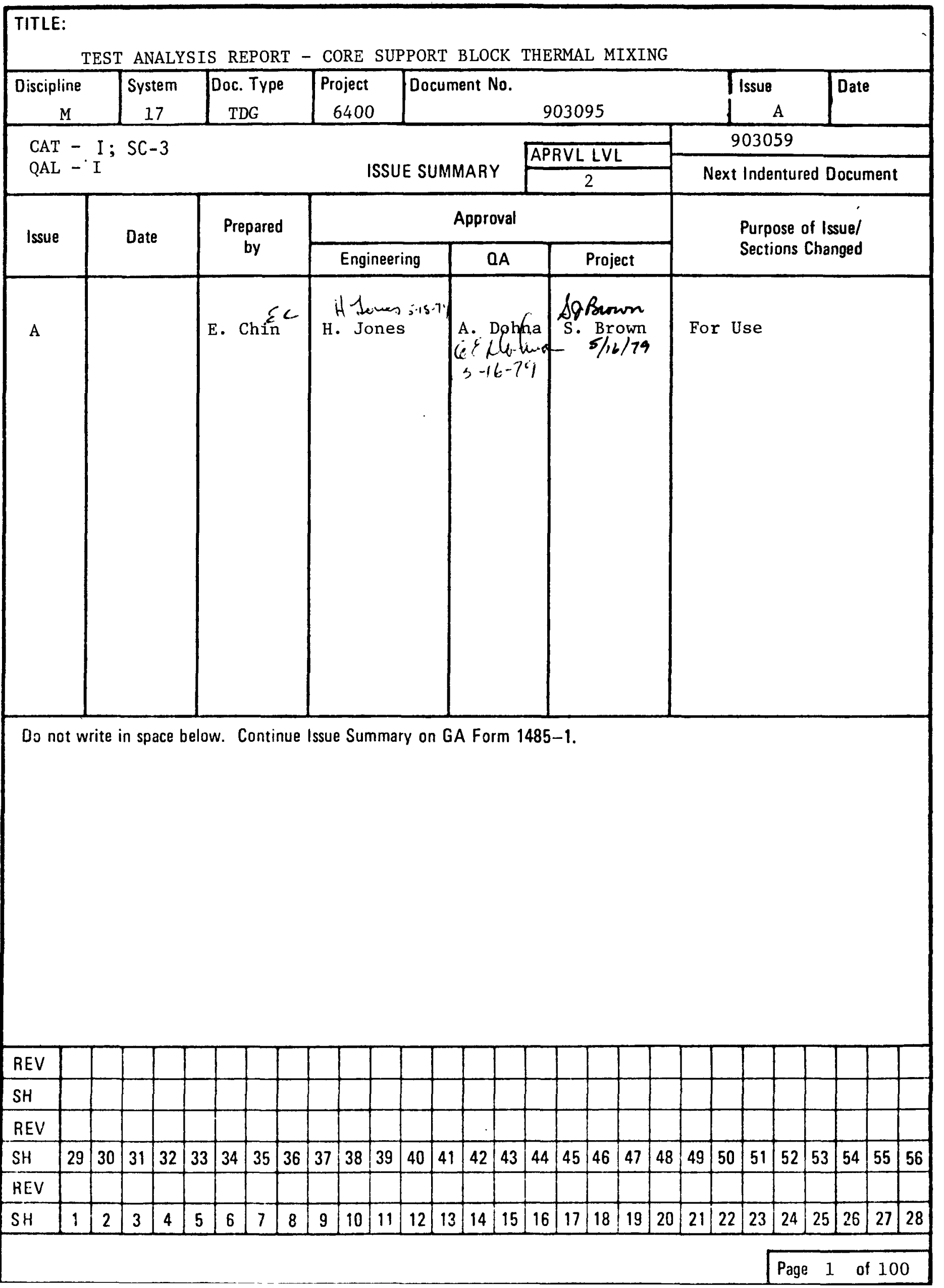




\section{ABSTRACT}

The extent of gas mixing and pressure drop within the core support block was experimentally investigated for various geometric and height configurations. These tests were conducted by the Experimental Engineering Branch of General Atomic Company. As a result of this investigation, the core support block thermal mixing and pressure drop has been quantified. Thermal mixing and the temperature sensor accuracy can be substantially improved at the cost of higher pressure drop.

A 70-degree miter angle configuration is recommended for the reference design of the HTGR core support block (CSB). The recommended CSB height will depend on further evaluation of the possible range of variations in fuel region reactor conditions to be determined by the Systems Engineering Department. The average temperature in a rodded region (a region with control rods in the lowered position) can be measured by the temperature sensor to within a $45^{\circ} \mathrm{F}$ accuracy, a big improvement from an early CSB design tested by the Commissariat a La Energie Atomique at Saclay, France in $1974,75$. 


\section{CONTENTS}

ABSTRACT

List of Figures

2

List of Tables

5

List of Symbols

7

8

1. INTRODUCTION 10

$\begin{array}{lll}1.1 \text { Genera1 } & 10\end{array}$

$\begin{array}{ll}1.2 \text { Objective } & 10\end{array}$

$\begin{array}{lll}1.3 \text { Scope } & 11\end{array}$

2. DESCRIPTION OF APPARATUS 13

2.1 Test Mode1 13

2.2 Model Installation 16

$\begin{array}{lll}2.3 & \text { Facility Equipment } & 17\end{array}$

2.3.1 General 17

$\begin{array}{ll}2.3 .2 \text { Blowers } & 17\end{array}$

$\begin{array}{lll}2.3 .3 \text { Hot Air Supply System } & 17\end{array}$

2.4 INSTRUMENTATION AND MEASUREMENTS 18

$\begin{array}{lll}2.4 .1 \text { Flow Measurements } & 18\end{array}$

2.4.2 Static Pressure Measurements 19

$\begin{array}{ll}2.4 .3 \text { Velocity Measurements } & 19\end{array}$

2.4 .4 Temperature Measurements 21

2.4.5 Data Acquisition System 22

3. TEST RESULTS AND DISCUSSION 24

3.1 General 24

3.2 Preliminary Screening Test Phase 25

3.2.1 Preliminary Results and Discussion 25

3.2.2 Adequacy of Thermal Mixing and 26

Reactor Internals Cost Estimate

3.2.3 Summary of Results from the 29

Preliminary Screening Test Data

3.2.4 Summary of Conclusions from 29

Preliminary Screening Test Data

3.2.5 Recommendations for Final Thermal 30

Mixing Test Phase 
3.3 Final CSB Thermal Mixing Test Phase 31

3.3.1 General 31

3.3.2 Temperature Sensor Test Model 31

3.3.3 7-Column Region - Single Heated Columns 34

3.3 .4 5-Column Region - Single Heated Columns 38

3.3.5 Multiple-Heated Column Tests 39

4. CONCLUSIONS 42

5. RECOMMENDATIONS 43

6. REFERENCES 44

$\begin{array}{ll}\text { 7. APPENDIX } & 87\end{array}$ 


\section{LIST OF FIGURES}

1. Typical Core Support Block and Reflector Block Assembly

2. Core Support Block Mixing Test Model 46

3. Test Configuration Schematic 47

4. Thermocouple Layout for Preliminary Temperature 48 Sensor

5. Simulated Reactor Temperature Sensor Model 49

6. Test Arrangement 50

7. CSB Static Pressure Tap Locations 51

8. Exit Plane Thermocouple Rake 52

9. Data Acquisition System (DAS) Block Diagram 53

10. Normalized Velocity Traverse at 4-Column Region 54 CSB Exit Plane with Circular Flow Area

11. Estimated Cost Optimization of CSB Configurations 55

12. Transient Response of Wooden Sensor 56

13. Transient Response of Titanium Simulated Sensor 57

14. Example of Summation of Influence Coefficients 58

15a. $\theta^{\prime}$ Influence Coefficients for Run 7BZ41(1)-36 59

b. $\theta^{\prime}$ Influence Coefficients for Run 7BZ41(2)-37 60

c. $\theta^{\prime}$ Influence Coefficients for Run 7BZ41(3)-38 61

d. $\theta^{\prime}$ Influence Coefficients for Run 7BZ41(4)-39 62

e. $\theta^{\prime}$ Influence Coefficients for Run 7BZ41(5)-40 63

f. $\theta^{\prime}$ Influence Coefficients for Run $7 B Z 41(6)-41 \quad 64$

g. $\theta^{\prime}$ Influence Coefficients for Run 7BZ41(7)-42 65

16a. $\theta^{\prime}$ Influence Coefficients for Run 7BX48(1)-106 66

b. $\theta^{\prime}$ Influence Coefficients for Run 7BX48(2)-111 67

c. $\theta^{\prime}$ Influence Coefficients for Run 7BX48(3)-112 68

d. $\theta^{\prime}$ Influence Coefficients for Run 7BX48(4)-113 69

e. $\theta^{\prime}$ Influence Coefficients for Run 7BX48(5)-114 70

f. $\theta^{\prime}$ Influence Coefficients for Run 7BX48(6)-115 71

g. $\theta^{\prime}$ Influence Coefficients for Run 7BX48(7)-119 72

17. 5-Column Region CSB Mixing Cavity Flow Area 73

18. Normalized Velocity Traverse at 5-Column Region 74 CSB Exit Plane with Modified Flow Area

19. Multiple Heated Column Test Results \& Predictions/ 75 $7 \mathrm{BX} 48(3,2,4)-110$ 
20. Mu1tiple Heated Column Test Results \& Predictions/ $7 \mathrm{BX} 48(7,2,6)-109$

21. Multiple Heated Column Test Results \& Predictions/ $5 \mathrm{BX} 48(2,3,7)-129$

22. Multiple Heated Column Test Results \& Predictions/ $5 \operatorname{BX} 48(7,2,6)-127$ 
1. Summary of Selected Influence Coefficient Summation, $\sum_{i} \theta_{i}^{\prime}$

2. Summary of Selected Influence Coefficients $/ 52^{\circ}$ miter angle.

3. Summary of Selected Influence Coefficients $/ 70^{\circ}$ miter angle

4. Summary of Miscellaneous Selected Influence Coefficients

5. Summary of Selected Influence Coefficients/ 5-Column Regions

6. Summary of Multiple-Heated Column Influence Coefficients/7-Column Regions

7. Summary of Multiple-Heated Column Influence Coefficients/5-Column Regions

\section{APPENDIX TABLES}

A.1 Preliminary Pressure Loss Coefficients from High Flow 88 Tests Using Large Venturi Meter

A.2 Preliminary Pressure Loss Coefficients for Low Flow 90 Tests Using Small Venturi Meter

A.3 Preliminary Pressure Loss Coefficients (with Increased 94 Reflector Block Height).

A.4 Low Flow Pressure Loss Coefficients for Preliminary Four-Column Regions

A.5 Summary of Selected Preliminary Influence Coefficients 7-Column Regions

A.6 Summary of Selected Preliminary Influence Coefficients (with Increased Reflector Block Height)

A.7 Summary of Selected Preliminary Influence Coefficients 4-Column Regions

A.8 Preliminary Cost Optimization of Core Support Block Configurations 


\section{LIST OF SYMBOLS}

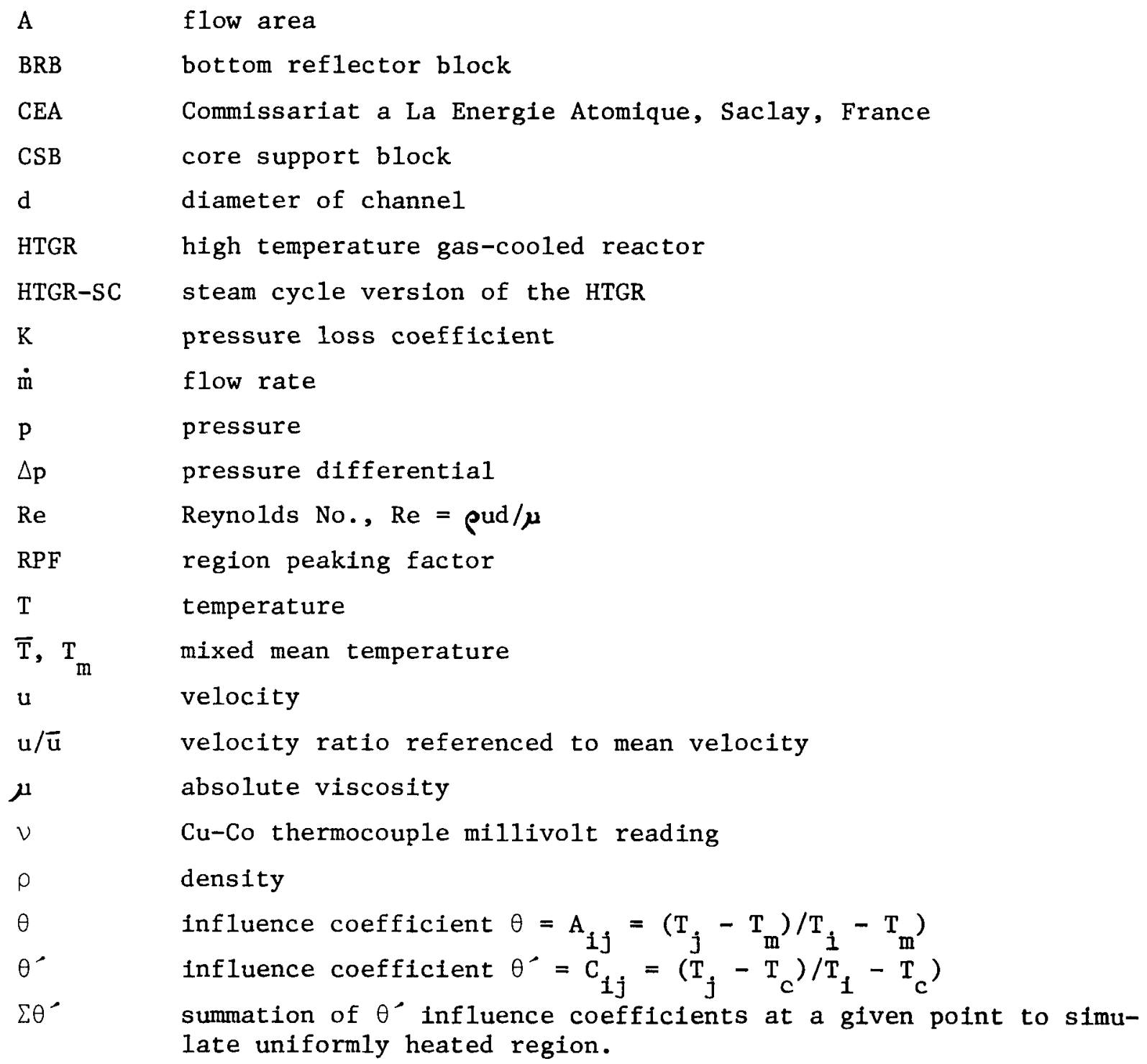




$\begin{array}{ll}\text { Subscripts } & \\ \text { CSB exit } & \text { CSB exit plane location } \\ \text { over-all } & \text { refers to CSB overall pressure drop (exit loss excluded) } \\ \text { sensor } & \text { CSB thermocouple spacer block (refer to Fig. 5) } \\ \text { sleeve } & \text { cylindrical housing in CSB for the spacer block } \\ \text { total } & \text { refers to CSB overall pressure drop with kexit }=0.8 \text { assumed } \\ \text { c } & \text { cold column value } \\ \mathbf{E} & \text { centerline value } \\ \mathbf{i} & \text { hot column value } \\ \mathbf{j} & \text { local value } \\ \text { m } & \text { mixed mean value } \\ \text { spacer A } & \text { data from spacer block A position (see F1g. 5) } \\ \text { spacer B } & \text { data from spacer block B position (see F1g. 5) }\end{array}$




\section{INTRODUCTION}

\subsection{GENERAL}

In the HTGR core, the gas flow within the coolant holes of each fuel region is collected in larger flow channels in the bottom reflector blocks (BRB) as shown in Figure 1. The central control rod BRB flow channel is then fed horizontally to the surrounding six flow channels which coinctdes with the six flow channels in the upper core support block (CSB). A temperature sensor (thermocouple) is located within the CSB to measure the average exit temperature of the region coolant. The temperature sensor located at the outlet of each region in the core is used for control of the region inlet gas flow orifices. Reference 1 specifies that "the indicated temperature sha11 not deviate by more than $45^{\circ} \mathrm{F}$ from the actual region average gas exit temperature during plant power operation." Test results on a previous CSB design (Ref. 2) indicated that the design would not satisfy the criteria for the sensing error. The sensing error is presumed to result from poor thermal mixing of the column streams within the core support block (gas mixing error) and the averaging capability of the sensor itself. No analytical means are available to predict the sensor performance, necessitating this test program.

\subsection{OBJECTIVE}

The primary objective of this test is to optimize the CSB performance by determining the gas mixing error and CSB pressure loss of various alternative CSB designs using a scale model air flow testing technique. The test is to provide a measure of the temperature distribution at the CSB exit and on the surface of the temperature sensor sleeve. The mixing results from each alternative design are to be compared in order to determine their order of mertt in flow stream mixing and pressure loss penalty. 
The sensor data is to be used by the Systems Dynamics Branch of the General Atomic Company to aid in developing a computer simulation of the sensor performance at reactor conditions.

\subsection{SCOPE}

The tests were grouped into two distinct phases. The first phase consisted of a series of preliminary screening tests in which four basic CSB configurations were tested to determine the effects of CSB height and miter angle of converging jet streams on pressure drop and gas mixing. A final phase consisted of a more comprehensive series of tests using two of the four configurations tested in the preliminary phase. The specific objective of this CSB thermal mixing test were as follows:

1. Establish the feasibility of predicting gas mixing at the core support block (CSB) exit plane by deriving temperature influence coefficients from measured gas temperatures.

2. Determine the gas mixing characteristics of the CSB configuration for a partial fuel region (which occurs at the periphery of the core).

3. Obtain distributed temperature data for a simulated CSB temperature sensor sleeve to be used as a boundary condition to calculate sensor temperatures by the General Atomic Company Systems Dynamics Branch.

To achieve these objectives the major test data to be measured were:

1. To measure the fluid temperature distribution on the surface of the temperature sensor housing for various temperature-flow arrangements. 
2. To measure temperature and flow distributions at the exit of the core support block.

3. To measure the pressure drop across the core support block and selected locations in the reflector block assembly.

During both the preliminary screening and final thermal mixing tests, a series of runs were made in which only one inlet flow was heated at a time. The results of this series were used to determine the temperature influence coefficients of the separately heated inlets upon various areas of the sensor and the CSB exit rake. (Refer to Sections 3.2 and 3.3.2. for definitions and use of these influence coefficients.)

A partial reactor power tilt was simulated during the final thermal mixing tests where three inlet streams to the model were heated simultaneously to several different temperatures. These multiple heated column tests were used to determine the extent of predictability of simulating multiple heated column conditions by superimposing the influence coefficients determined from single heated column tests. 


\section{DESCRIPTION OF APPARATUS}

\subsection{TEST MODEL}

The test model consists of a one-half scale simulated core support block configuration and the lower part of the bottom reflector blocks. The six horizontal crossduct channels, which divert the central (control rod) bottom reflector block channel flow to the outer six surrounding channels, is included in the test model.

A composite sketch of the CSB test model is shown in Figure 2. The bottom reflector block (BRB) horizontal crossduct channel is shown at two different vertical positions above the CSB. The individual fuel coolant channels upstream of the horizontal crossduct channel are not simulated in this test mode1.

The core support block is simulated with several interchangeable sections. The upper CSB includes the six miter angle channels which merge into a single larger cavity above the temperature sensor.

The lower portion of the lower CSB includes the temperature sensor and the slightly divergent cavity which simulates the exit region of the CSB. Above the temperature sensor is a lower CSB insert. Inserts of various heights are installed here to simulate CSB's of different heights. (The relative distance between the temperature sensor and the CSB exit plane is fixed and is compatible with items such as spring packs, the peripheral seal, and lower plenum crossducts.)

There are fourteen variations of the four basic CSB test assemblies tested in the preliminary screening test phase. These variations are illustrated in Figure 3. The test parameters include four miter angle CSB 
configurations $(35,52,70$, and 90-degrees), as many as three CSB helghts (35, 41, and 53-in. full scale helght), and, for certain CSB configurations, three positions above the CSB where the central fuel column/reflector block flow is redistributed horizontally to the outer six peripheral fuel/ reflector column flows.

For the final thermal mixing test series, two CSB miter angle configurations (52 and 70-degrees) were more thoroughly tested at three different CSB heights (41, 48.8 and 53 in. full scale height).

The temperature sensor used in the preliminary screening test phase is shown in Fig. 4. It consists of 56 thermocouples on a uniform grid array where the thermocouple wires are routed through the inside of the hollow wood cylinder and maneuvered through an array of holes such that the thermocouple bead barely protrudes above the surface of the wooden sensor. This cylindrical sensor model was originally intended to be used for the final test series also, but it was discovered that much more accurate results could be obtained by using a specially designed simulated reactor CSB temperature sensor shown in Fig. 5 (which was originally designed to be used on a limited number of special tests). Due to other delays in the test program, this special sensor was fabricated in time to be compatible with the entire final test phase. The use of this sensor was to provide data to aid in determining the accuracy of the temperature sensor. The corresponding thermocouple test results were to be used by the Systems Engineering Department of General Atomic to verify their model of the reactor temperature sensor and to check the sensor error.

The final thermal mixing tests use a sensor as illustrated in Fig. 5. The sensor contains a sleeve and spacer geometrically similar to the latest proposed design sensor. The sleeve is instrumented with 28 thermocouples and the spacer is instrumented with 6 thermocouples. The thermal conductivity of the sleeve and spacer material should be as close as practical to 4.0 and $1.0 \mathrm{Btu} / \mathrm{hr} \mathrm{ft}^{\circ} \mathrm{F}$, respectively. This ensures the same ratio of solid conductance to gap and outer surface conductance between reactor and test conditions. 
In an effort to maintain reasonable costs some sensor reactor design features are not duplicated. The thermo-well tubes in the actual sensor are not included in the test sensor. Some compromise is also made on duplicating the ratio of gas-to-solid conductances because the test will be run in air and materials with a thermal conductivity of $1-3 \mathrm{Btu} / \mathrm{hr}-\mathrm{ft}-{ }^{\circ} \mathrm{F}$ do not exist. (A commercially avaflable 90\% titanium-6\% aluminum 4\% vanadium alloy (MIL-9046 Type 3) with a thermal conductivity of about $4 \mathrm{Btu} / \mathrm{hr}-\mathrm{ft}-{ }^{\circ} \mathrm{F}$ is used.) Because of these compromises, the test results may not give directly the sensor error for reactor conditions. The test results will be indicative of the actual sensor error and they will be used to verify the analytical model for calculating the actual temperature sensor error.

The entire model as shown in Fig. 2 is installed on a lower plenum unit which is in turn connected to a blower system. The blower system draws air into the seven inlets (suction mode) so the pressure throughout the mode1 and ducting are below atmospheric pressure. It had been intended to individually adjust the flow rate through the seven inlets by means of the butterfly valves indicated in Fig. 2. However, it was found that a better means of control was to partially block the inlets. This method was used during all the final phase testing. The butterfly valves were locked in position parallel to the tubes axes. The total flow rate is controlled by a single valve which is part of the permanent facility equipment.

Heated air is drawn through any of the seven inlets by connecting an inlet to an electrical heater unit by means of flexible ducting. For the preliminary test phase, only four out of the seven Inlets were individually heated to obtain the necessary data during the preliminary screening tests because of symmetry considerations. For the final mixing tests, up to three inlets are heated simultaneously with two inlets heated to one temperature $\left(\sim 130^{\circ} \mathrm{F}\right)$ and the third heated to a different temperature $\left(\sim 150^{\circ} \mathrm{F}\right)$. For these multiple heated tests, a special manifold is employed to connect two inlets to one electrical heater unit and a second heater 
is used for the third heated inlet. For the final mixing tests, each single column was generally heated individually so that the assumption of symmetry was not required for the major test configurations.

\subsection{MODEL INSTALLATION}

The test arrangement is depicted in Fig. 6. The model is shown installed on a work stand with a plenum located under the work platform. The ducting which connects the model to the blower system includes two venturis and a flow control valve. The 18 in. Simplex venturi is permanently installed in the facility ducting as is the pneumatically operated butterfly valve. Because of the size of the Simplex venturi, it can only be used with reasonable accuracy at the maximum flow rate called for in the Test Specification (Ref. 3). For all other flows, the smaller $12 "$ BIF venturi was used to indicate total flow rate. During testing at the maximum flow rate, the BIF venturi was replaced with a straight section of pipe in order to avoid the pressure loss associated with this venturi.

Also depicted in Fig. 6 is a $100 \mathrm{kw}$ electrical heater system which was used to supply heated air to selected inlets of the model. The heater blower, which is part of the system, was used when required to overcome the flow resistance of the heater and ducting. Also, depicted in Fig. 6 is the $15 \mathrm{kw}$ auxiliary heater which was used when multiple inlet heated tests were specified for the final test phase. The auxiliary heater was used to supply the maximum temperature column hot streak while the $100 \mathrm{kw}$ heater and blower units were used to supply the two adjacent column moderate hot streaks. 


\subsection{FACILITY EQUIPMENT}

\subsubsection{Genera1}

The experimental program was conducted in the General Atomfc Company Experimental Engineering Airflow Building (Bldg 36). The model was located at the east end of the building close to the electrical heater system, which is permanent facility equipment, and also close to the inlet of the $18 \mathrm{in}$. ducts. The model was connected to the lower duct of the dual $18 \mathrm{in}$. ducts. The location of the model also allowed use of the overhead crane for installation and for making configuration changes when necessary.

The data acquisition system which is installed in the Airflow Building was used for this test program and a description of the data acquisition system is given in a following section.

\subsubsection{Blowers}

The primary air supply system consisted of three $250 \mathrm{hp}$ Buffalo Forge blowers connected to a manifold, ducting, valves, and a venturi flowmeter. The specifications for the CSB Thermal Mixing Test (Ref. 3) require that two of the facility blowers be used in a serles configuration. Each blower was rated at $14,000 \mathrm{scfm}$ at $12.5 \mathrm{psia}$ inlet pressure. The line from the manifold to the model consisted of an $18 \mathrm{in}$. duct containing a venturi flow meter and a butterfly valve for flow measurement and control, respectively. This manually operated valve was the primary flow control used to vary the total mass flow rate through the test model.

\subsubsection{Hot Alr Supply System}

The main facility hot air supply system consisted of a 3 hp blower, a $100 \mathrm{kw}$ heater bank, a manifold and ducting. The heater blower was rated at $5000 \mathrm{scfm}$ with 2 in. $\mathrm{H}_{2} \mathrm{O}$ pressure rise. Ambient air was inducted through the blower and discharged through the heater to the manifold. The inlet flow was controlled by a valve arrangement at the blower inlet. 
The heater bank mounted directly downstream of the blower is divided into flve separate sections of $5,10,10,25$ and $50 \mathrm{kw}$ power. It was thus possible to add heat in $5 \mathrm{kw}$ steps over the entire range from 0 to $100 \mathrm{kw}$.

The auxiliary heater is quite similar to the main heater system except it is smaller and does not have a booster blower mounted on its inlet.

\subsection{INSTRUMENTATION AND MEASUREMENTS}

\subsubsection{Flow Measurements}

The total model flow was measured using either the 18 in. Simplex venturi located in the facility ducting or the $12 \mathrm{in.} \mathrm{BIF} \mathrm{venturi} \mathrm{which}$ was connected to the outlet of the model plenum (Fig. 6). The mass flow rate is found from the equations

$$
\dot{\mathrm{m}}=c \frac{\pi}{4} \mathrm{~d}^{2} \frac{\mathrm{Y}}{\sqrt{1-\beta^{4}}} \sqrt{\frac{2 \mathrm{p}_{1} \Delta \mathrm{p}}{\mathrm{RT}_{1}}}
$$

where

$$
\begin{aligned}
& Y=\sqrt{\frac{\gamma}{\gamma-1} r^{2 / \gamma}\left(\frac{1-r^{\gamma-1 / \gamma}}{1-r}\right)\left(\frac{1-\beta^{4}}{1-\beta^{4} r^{2 / \gamma}}\right)} \\
& r=\frac{p_{2}}{p_{1}} \\
& \beta=\frac{d}{D}
\end{aligned}
$$

where values of $d, D$ and $C$ are given in the following Table.

In deriving the equation, it has been assumed that air is a perfect gas with $R=53.34 \mathrm{ft}-1 \mathrm{~b} / 1 \mathrm{bm}-\mathrm{R}$ the gas constant for air and $\gamma=1.4$ the ratio of specific heat capacities for air. 
The measured quantities are the upstream pressure and temperature $\mathrm{p}_{1}$ and $\mathrm{T}_{1}$ and the venturi differential pressure $\Delta \mathrm{p}=\mathrm{p}_{1}-\mathrm{p}_{2}$.

The venturi units used in the test program have the following parameters.

\begin{tabular}{cccccc}
\hline Venturi & TEC No. & (in.) & $\begin{array}{c}\text { d } \\
\text { (in.) }\end{array}$ & \multicolumn{1}{c}{ C } \\
\hline 18 in. Simplex & - & 10.383 & 17.5 & $0.951+1.9 \times 10^{-8}$ Re \\
12 in. BIF & 73099 & 5.800 & 11.973 & 0.9797 & \\
3 in. BIF & 73104 & 1.795 & 2.994 & 0.9797 \\
\hline
\end{tabular}

The 3 in. BIF venturi was used for calibration purposes. Both BIF venturi units have the same flow coefficient, valid over the range of flows for which they were used. The Simplex venturi flow coefficient is a weak function of the throat Reynolds number.

The uncertainty factors for the venturis are estimated to be $0.25 \%$ for the 12 in. BIF, $0.75 \%$ for the $3 \mathrm{in.} B I F$ and $1 \%$ for the Simplex. These are one standard deviation estimates.

The remaining flow measuring devices were located in the model inlet ducts. An orifice plate was inserted in each inlet, and these orifices were calibrated against appropriately sized venturis. (Refer to Fig. 2) The flow is found from the expression

$$
\dot{\mathrm{m}}=\mathrm{k} \frac{\pi}{4} \mathrm{~d}^{2} \sqrt{\frac{2 \mathrm{p}_{1} \Delta \mathrm{p}}{\mathrm{RT}_{1}}}
$$

with $\mathrm{K}$ the flow coefficient found from calibration. The measured quantities are the upstream pressure and temperature, $p_{1}$ and $T_{1}$, and the orifice differential pressure $\Delta \mathrm{p}$. 


\subsubsection{Static Pressure Measurements}

The Test Specification (Ref. 3) calls for static pressure measurements at several axial planes and circumferential orientations; see Figs. 2.1-3 and 2.3-1 of Ref. 3. The locations of static taps in the model are shown in Fig. 7. The overall CSB pressure drop reported herein is measured between static tap locations 3 to $5 \mathrm{in} \mathrm{Fig.} \mathrm{7.} \mathrm{Note} \mathrm{that} \mathrm{the} \mathrm{CSB} \mathrm{exit}$ expansion loss is not included since the lower plenum and other flow regions are not modeled.

A11 static pressure taps were $0.040 \mathrm{in}$. diameter with a depth greater than twice the diameter. The static taps were all inspected and adjusted if necessary to insure a clean, round, burr-free hole.

The estimated static pressure measurement uncertainty due to the static tap itself is the order of $0.3 \%$ of the true reading.

\subsubsection{Velocity Measurements}

The velocity surveys called for in the Test Specification (Ref. 3) were done with a Prandt1 type pitot-static probe. The probe, a United Sensor model PDC-24-G-22-K1, has a 1/8 in. diameter sensor end which will cause a neg1igible blockage error at the exit of the Core Support Block and an error of about $0.1 \%$ in the inlets.

The velocity was evaluated from the equation

$$
u=\sqrt{\frac{2 \gamma}{\gamma-1} \mathrm{RT}\left[1-\left(1-\frac{p_{t}-p_{s}}{p_{t}}\right)^{\gamma-1 / \gamma}\right]}
$$

which is for compressible fluids. Measurements were: air temperature, $T$, total pressure, $p_{t}$, and the difference between total and static pressure, $p_{t}-p_{s}$. 


\subsubsection{Temperature Measurements}

Thermocouples were used to measure air temperature. Seven thermocouples were inserted into the seven inlets to monitor inlet air conditions. The temperature sensor for the preliminary tests had 56 thermocouples arranged in 7 longitudinal stations and 8 circumferential locations; see Fig. 4. A thermocouple rake with 25 thermocouples was installed at the exit plane of the Core Support Block; see Fig. 8. The special simulated reactor sensor used in the final thermal mixing series, Fig. 5, had 34 thermocouples installed to measure the temperature distribution throughout the sensor. In addition to the above, thermocouples were used to measure air temperature at the venturi units.

Type $\mathrm{T}$ (copper-constantan) thermocouples were used for all measurements. These thermocouples were assembled by Experimental Engineering from a single batch of 24 gage, teflon insulated thermocouple wire. All thermocouples were connected to a $150^{\circ} \mathrm{F}$ Pace reference junction, TEC No. 67064 . The air temperature was calculated from

$$
T=32.0873+46.6266 v-1.31251 v^{2}+0.0573506 v^{3}
$$

which is a cubic equation fitted to the standard data over the temperature range of $60^{\circ}$ to $220^{\circ} \mathrm{F}$ by the method of least squares. The equation fits the data with a standard error of $0.01^{\circ} \mathrm{F}$. The limit of error for this thermocouple wire is stated to be $\pm 1-1 / 2^{\circ} \mathrm{F}$ which is assumed to be two standard deviations.

In the above equation

$$
v=v_{R}+v_{O R}
$$

where $\nu_{R}$ is the millivolt reading of a thermocouple when the reference junction is at the temperature $T_{R}$ and $\nu_{O R}$ is the millivolt reading of the same thermocouple sensing the temperature $T_{R}$ while the reference junction is at $0^{\circ} \mathrm{C}\left(32^{\circ} \mathrm{F}\right)$. For example, the Pace reference junction calibration 
gives $\mathrm{T}_{\mathrm{R}}=151.75^{\circ} \mathrm{F}$ so $\nu_{\mathrm{OR}}=2.754 \mathrm{mv}$ for type $\mathrm{T}$ thermocouples. The voltage was measured by the data acquisition system when the thermocouples were hooked up to the Pace reference junction. Prior to the second phase of testing, the reference junction was adjusted to give $T_{R}=150.0^{\circ} \mathrm{F}$ and $\nu_{O R}=2.711 \mathrm{mv}$.

\subsubsection{Data Acquisition System}

The data acquisition system (DAS) used on this test program is an integrated system which is permanently installed in the Airflow Building. A block diagram of the DAS is shown in Fig. 9.

The S-9 data logger and computer of the Non-Linear System Company is the heart of the data acquisition system. This sub-system consists of the following units:

1. NOVA model 1200 mini-computer with $8 \mathrm{~K}$ words of memory augmented by a Plessey model PM-1216 memory board giving an additional $16 \mathrm{~K}$ words of memory.

2. 33ASR teletype terminal (TTY) which is used for programming input and data output.

3. Multi-range A/D converter with $0.04,0.4,4$ and 40 volt ranges.

4. Two multiplexers (cross-bar scanners) with 200 3-wire inputs of which only one was used in this test.

5. Associated displays and power supplies.

The NOVA computer is programmed using a form of the BASIC language called NLS Basic III by the manufacturer. Special programming has been built into the software to integrate the Scanivalve system into the data logging capability. Programs are maintained on paper tape. The mini-computer provides the capability for on-1ine data reduction but not sophisticated data analysis requiring extensive memory. 
The Scanivalve sub-system consists of 5 model 64CBM-048 Scanivalves housed in a cabinet. Each Scanivalve is basically an ultra precision valve with 64 ports and extremely low leakage between ports. The valves are simultaneously actuated by a single stepping motor which drives the valves through timing pulleys. A channel coder identifies the position (port) for the stepping motor and recelves its signal from the NOVA computer. On1y two of the valves were used, numbers 5 and 6 , and the pressure transducers were connected to these two valves in such a way that differential pressures could be measured. The differential pressures may either be the difference between two static taps on the model or one static tap and ambient pressure. The pressure taps were interconnected from the model to fittings on the exterior of the Scanivalve cabinet by means of $1 / 8$ in. I.D. vinyl tubing.

The Druck \pm 1 psid and the Statham \pm 5 psid transducers were connected in parallel between Scanivalves $\$ 5$ and 6 . Therefore, both transducers have the same pressure signal input applied but the Statham output was used whenever the pressure was over 1 psi and the Druck output when the pressure was less than 1 psi. The Druck output signal becomes non-linear above 1 psi and eventually saturates, however, the mechanical action is not harmed with pressures up to $5 \mathrm{psi}$. By connecting the transducers in this manner, the most accurate measurement can be made over the full pressure range that can be generated by the blowers in the Airflow Building.

The signal conditioning units for the Druck and Statham transducers provide accurately regulated power to the transducers and amplification for the signal.

All thermocouples were connected to the Pace unit which provides a constant $150^{\circ} \mathrm{F}$ thermocouple reference function. From the Pace, the thermocouple output voltage was fed to the $5-9$ data logger through regular 2-wire connectors. 


\section{TEST RESULTS AND DISCUSSION}

\subsection{GENERAL}

The core support block thermal mixing test program was divided into two separate phases; (1) the preliminary screening test phase, and (2) the final thermal mixing test phase. The preliminary screening test phase cover four basic design configurations which were tested at a QAL-III level. Hence, these data should not be used directly for design purposes. For this reason, the preliminary screening test data has been placed in Appendix I. The final core support block thermal mixing test was a QAL-I level test where a more extensive test series was conducted on two basic design configurations. 


\subsection{PRELIMINARY SCREENING TEST PHASE}

The objective of the preliminary screening test phase was to test a relatively wide range of possible CSB configurations with unheated test conditions and with relatively few, simple, single heated column tests. From these results, two CSB miter angle configurations would be re-tested thoroughly in the final thermal mixing test phase.

\subsubsection{Preliminary Results and Discussion}

In the preliminary screening test phase, overall CSB pressure loss coefficients

$$
\mathrm{K}_{\text {overa11 }}=\Delta \mathrm{P}_{\text {overa11 }}\left[\dot{\mathrm{m}}_{\text {tota1 }}^{2} /\left(2 \rho \mathrm{gA}_{\mathrm{CSB}}^{2} \text { exit }\right)\right]
$$

were determined for the various CSB configurations over a range of unheated flow conditions from $1.7 \mathrm{lb} / \mathrm{sec}$ to about $6.0 \mathrm{lb} / \mathrm{sec}$ (15\% reactor $\mathrm{Re}$ No. to $53 \%$ reactor Re No.). Some of the tests went up to about $10 \mathrm{1b} / \mathrm{sec}(140 \%$ reactor $\operatorname{Re}$ No., or $100 \%$ reactor $\operatorname{Re}$ No. in a region with a region peaking factor $(\mathrm{RPF})=1.4)$. As indicated in Section 2.4.2, Eq. 6 does not include the CSB exit loss. These data are shown in Tables A. 1 and A. 2 of the Appendix of this report. Note that the preliminary screening test data are not QAL-I level and should not be used directly for design purposes.

All of the seven column region heated tests in this preliminary screening phase were conducted at about $3.2 \mathrm{lbs} / \mathrm{sec}$ (about 28\% reactor Re No.) with only one column heated. Multiple heated column tests were not conducted in this test phase. The CSB pressure loss coefficients for the heated single column tests are also shown in Tables A.2 and A.3. Corresponding pressure loss coefficients for a four-column region (assuming such regions could exist) are shown in Table A.4. For these four-column regions, three outer adjacent flow columns were blocked while the CSB was kept in an identical configuration as used in the seven-column region tests.

* Reynolds Number 
A summary of selected influence coefficients on the wooden sensor model and at the CSB exit plane are shown in Tables A.5 and A.6 for the seven-column region tests, and in Table A.7 for the four-column region tests where the influence coefficient using the ambient temperature $T_{c}$, as the reference temperature is defined as

$$
\theta^{\wedge}=C_{i j}=\frac{T_{j}-T_{c}}{T_{1}-T_{c}}
$$

while the influence coefficient using the mixed mean temperature, $\mathrm{T}_{\mathrm{m}}$, as a reference is defined as

$$
\theta=A_{i j}=\frac{T_{j}-T_{m}}{T_{i}-T_{m}} .
$$

The extent of thermal mixing within the CSB can be judged by noting the maximum temperature influence coefficient determined from the CSB exit plane thermocouples. Note that relatively large variations exist for the $\theta_{c}$ sensor for the four-column region data shown in Table A.7. The expected sensor errors resulting from these large variations are unacceptable. Also, note that in Fig. 10 the CSB exit velocity maldistribution is large for the four-column region test. One might speculate that if the CSB cavity cross-sectional area were changed from a circular shape to a truncated circle (truncated next to the flow columns that are blocked), that the sensor error might be substantially improved.

\subsubsection{Adequacy of Thermal Mixing and Reactor Internals Cost Estimate}

A detailed discussion of the preliminary test data is given in Ref. 4. A summary of the seven-column preliminary screening test data from A.5 is given in Table A.8, with the assumed cost information taken from Ref. 5. The data are tabulated in a generally decreasing order of thermal mixing as determined by the CSB exit plane influence coefficients. Starting from the bottom of Table A.8, the AIG influence coefficients are probably very 
similar to the 35-in. high CSB tested by the CEA and reported in Ref. 2 as having insufficient thermal mixing. Test AZG is only slightly better.

As the CSB miter angle is increased to $52^{\circ}$ for the 35 and 41-in. high $\mathrm{CSB}$, the thermal mixing (as evidenced by the smaller CSB exit influence coefficients) is improved, but it is doubtful that the temperature sensor inaccuracies discussed in Ref. 2 could be reduced by a factor of at least 2. On the other hand, by moving the control rod fuel column crossduct channel upwards (further away from the CSB), the thermal mixing seems to be further improved. Also, based on a limited number of test results the B2G $52^{\circ} \mathrm{CSB}$ with a 53-in. high CSB appears to rate fairly high for the test configurations tested. It appears that all of the $70^{\circ}$ and $90^{\circ}$ miter angle CSB configurations give reasonable thermal mixing, although the 35-in.-high CSB with a $70^{\circ}$ miter angle has less thermal mixing and higher CSB pressure drop than the 41-in.-high CSB.

Shown in the far right column of Table A.8 is the total estimated cost increase of the reactor internals ( per cost estimate information in Ref. 5) compared to a 35-in.-high CSB with a $35^{\circ}$ miter angle (similar to an old $3000 \mathrm{MW}(t)$ HTGR reference design). This cost information from Table A.8 is also shown in Fig. 11 as a function of CSB pressure drop (with CSB exit loss excluded). The numbers from 1 to 14 in Fig. 11 represent the order of decreasing thermal mixing indicated in column 1 of Table A.8. For each CSB miter angle, there is a representative sma11 range for the CSB pressure drop as indicated along the abscissa reference axis. The diagonal straight dotted lines indicate lines of constant CSB height. The test configurations (indicated by the thermal mixing order from 1 to 14) at or above the curved solid line represent configurations which appear to have good thermal mixing. The configurations below the curved dotted line have very questionable or poor thermal mixing. From Fig. 11, it is possible that a 48.8-in. high CSB with a $52^{\circ}$ miter angle (representing the low point on the good-mixing curve) may provide adequate thermal mixing and also be approximately $\$ 400,000$ cheaper than the $B 2 G$ configuration (No. 4 thermal mixing order). 
The present HTGR designs already allow for a CSB height of approximately 41-in. and a maximum reactor CSB pressure drop of $1.5 \mathrm{psi}$. This associated cost of $\$ 2.5$ million is shown in Fig. 11 (data pts. 5, 6, and 7). Thus, any adjusted total costs falling below this value represents a potential cost savings.

There are three other factors involved in the selection of the optimum core support block configuration in addition to pressure drop, CSB height and thermal mixing considerations. These are: (1) the feasibility (and possibility of increased costs) to manufacture a 70-degree miter angle core support block, (2) the probability for increased erosion (if any) in the block as the miter angle is increased, and (3) the uncertainty of whether a further increase in CSB height is practical.

The present 40.94-in. CSB height would be acceptable from the thermal mixing point of view if the reference reactor CSB design were changed to include 70-degree miter angle flow channels in the CSB. In prior estimates of CSB pressure drop, it was assumed that the maximum pressure drop is $\Delta \mathrm{p}_{\max }=1.5 \mathrm{psi}$ (Ref. 5). Test uncertainties could raise the actual maximum CSB pressure drop to 1.8 psi.

It is anticipated that a 52-degree miter angle CSB with a 48.8-in. height is acceptable with respect to mixing and at a reduced CSB pressure drop of close to 1.0 psi. If the Change Request listed in Ref. 6 is approved, then it may be possible to achieve this CSB increase without needing an additional core cavity height increase if the radiation shielding immediately above the CSB can be moved upwards by $1 / 4$ of a standard fuel block height. A substantial cost savings of over $\$ 0.8$ million could result from decreased pressure drop by using the 52-degree miter angle/ 48.8-in. high CSB. 


\subsubsection{Summary of Results from the Preliminary Screening Test Data}

The results of the preliminary screening tests show the following:

1. The CSB pressure loss coefficients range from $1.2<\overrightarrow{\mathrm{K}}_{\text {overall }}<5.5$ for CSB miter angle configurations ranging from 35 to 90-degrees, respectively. (Note that $\overline{\mathrm{K}}_{\text {overall }}$ does not include the CSB exit loss to the lower plenum.) Otherwise, the CSB pressure loss coefficients presented herein are conservative, in that they actually include part of the reflector block.

2. The influence coefficients indicate several CSB configurations give acceptable mixing for seven-column regions (refer to Fig. 11).

3. Relatively large variations in temperature sensor influence coefficients were measured for the four-column regions when the same $\operatorname{CSB}$ was used as for the seven-column regions ( 3 flow passages blocked).

4. Increased mixing resulted from the following:
a. Increased CSB height.
b. Increased miter angle within the CSB.
c. Increased height between the temperature sensor and the reflector block horizontal cross-over channel.

\subsubsection{Summary of Conclusions From Preliminary Screening Test Data}

1. Conservatively assuming that the exit loss is $K_{\text {exit }}=0.8$, the CSB pressure drop, $\triangle \mathrm{P}$, (excluding the bottom reflector block $\Delta \mathrm{P}$ ) will probably be a maximum of 1.0 to $1.8 \mathrm{psi}$ (based on a maximum HTGR-SC region flow rate, $\dot{m} \simeq 50 \mathrm{lbs} / \mathrm{sec}$ ), depending on whether a 52 or a 70-degree miter angle CSB is finally selected. 
2. Influence coefficlents which are comparable to or better than the values suggested by G. Niblock in Ref. 7 were measured for the first $10 \mathrm{CSB} /$ Reflector Block configurations listed in Table 2. However, they may not all be acceptable since no guideline exists for reducing hot streaks within the CSB.

3. To avoid large potential errors in sensor measurement, the partial fuel regions must have a special CSB with a reduced cavity size or modified shape to help guide flow uniformly over the temperature sensor.

4. The best cost optimized configuration with good mixing appears to be the 53-in. high CSB with a 52-degree miter angle. A close second choice is the 41-in. high CSB with a 70-degree miter angle.

5. There is reason to hope that the most optimized version could be a 48.8-in. high CSB with a 52-degree miter angle.

\subsubsection{Recommendations for Final Thermal Mixing Test Phase}

It was recommended that the following be implemented into the final thermal mixing test phase of the test program:

1. The 48.8-in. high CSB with a 52-degree miter angle be thoroughly tested along with several other promising candidates (both 52 and 70-degree miter angle CSB's only).

2. To avoid fabricating new parts, rearrange the sequence of the tests so that the tests with the largest insert blocks are run first, then the inserts can be cut down to a different size for the remainder of the tests.

3. The lower CSB cavity must be redesigned for partial fuel regions to reduce large potential sensor errors. 


\subsection{FINAL CSB THERMAL MIXING TEST PHASE}

\subsubsection{Genera1}

For the final thermal mixing test phase the designation used for the CSB Configuration/Test No. is demonstrated in the following example:

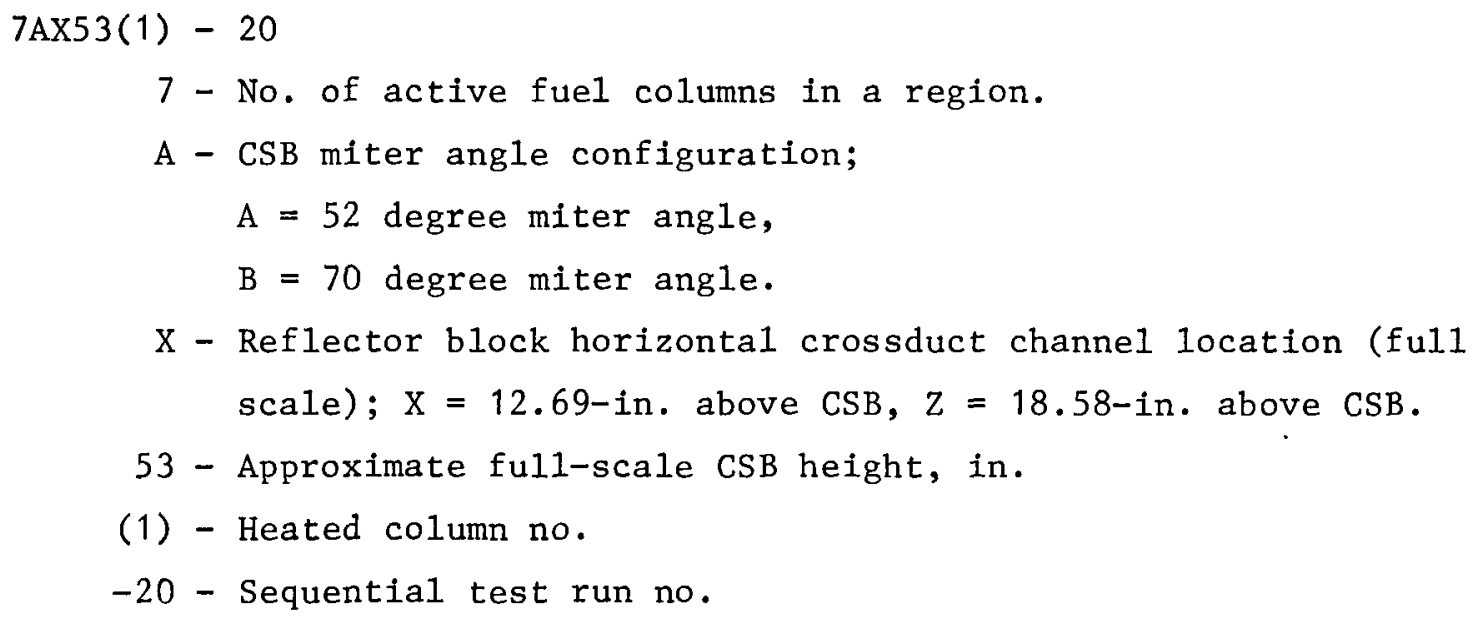

Note that the simulated temperature sensor model shown in Fig. 5 was used for all of these final phase tests.

\subsubsection{Temperature Sensor Test Mode1}

The sensor temperature data from the preliminary screening test was originally to be given to the Systems Dynamics Branch to help develop a computer model for predicting sensor accuracy. Influence coefficients were not originally expected to be useful on the sensor surface since Ref. 2 reported difficulty in trying to apply the CEA test data. More recent1y, however, the Systems Dynamics Branch has gone back to the original CEA test data and found that superposition of single heated column results on the sensor were fairly good, e.g., $\sum_{i} \theta_{i, j}^{-} \approx 1.0 \pm 0.12$ for each sensor thermocouple location. A check of the preliminary screening test data (assuming symmetry for the unheated single columns) showed that superposition of this data give values of $\Sigma \theta^{-}$as low as 0.28 . 
At this point (between the preliminary screening and the final test phases) some checks were made to ascertain whether or not the large discrepancies in the current summation of influence coefficients could be due to not reaching steady state conditions. Figure 12 shows the rapid increase and leveling-off of the region inlet temperature and the corresponding response in several selected sensor locations at the sensor surface. Several modifications were made to expose the thermocouples by lifting them about $1 / 16$ in. to improve the response of this wooden sensor. This attempt made only a slight improvement.

Meanwhile, as the preliminary screening test phase was being completed, the Systems Dynamics Branch had a detailed simulated temperature sensor block fabricated from a special titanium alloy (as shown in Fig. 5). This sensor was designed to be used on a relatively few tests to help gather data to verify a computer model of the sensor.

Since this latter simulated sensor (Fig. 5) was already fabricated, it was also tested to determine its response to a rapid increase in temperature. The results are shown in Fig. 13. A large improvement is noted when compared to the wooden sensor response of Fig. 12. Within 30 minutes of turning on the heater, the upper centerline temperature appears to have reached a steady state (about $6^{\circ} \mathrm{F}$ below the heated air inlet temperature) while the lower centerline temperature is only $2^{\circ} \mathrm{F}$ below the upper centerline temperature. (Note that for the wooden sensor in Fig. 12, after 60 minutes (twice as 1ong) the upper centerline temperature, $\mathrm{T}_{72}$, was stil1 increasing and was $10^{\circ} \mathrm{F}$ below the heated air temperature, while the lower centerline temperature was $8^{\circ} \mathrm{F}$ below $\mathrm{T}_{72}$.)

These two sensor response tests were conducted using the permanent auxiliary heater/blower and thus the flow rates involved were lower than the flow rates used for most of the preliminary screening and final test runs. The temperature response shown in Fig. 13 for the titanium simulated sensor merely indicates that it is superior to the wooden sensor response (Fig. 12) in reaching a steady state condition in about 30 minutes for a relatively low flow rate. At higher flow rates, the response time should be even shorter. 
The decision was then made to use the titanium simulated sensor for a11 of the final thermal mixing tests. As a result of using this sensor the superposition of the single heated columns was greatly improved and the accuracy was comparable to the CEA results which the Systems Dynamics Branch reviewed.

A summary of the summation of selected influence coefficients from the final thermal mixing test phase is tabulated in Table 1. These influence coefficient summations are based on unmodified test data. Note that the seven column region test data, $\Sigma \theta^{-}$, for the spacer block locations (last two columns of Table 1) are consistently close to the ideal value of 1.0. The five column region data is not as close to 1.0 for the spacer block largely because of more difficulties encountered in trying to get a steady state condition. The spacer block data was not originally intended to be used for superposition of individual heated jet data, but the data in Table 1 implies that the method can be used (with some modifications described below) for the seven-column region test data and with less accurate results for the five-column region test data.

Under reactor conditions, for the same CSB configuration tested herein, the temperature sensor sleeve and CSB exit plane influence coefficients should be the same as the test results reported herein. This is largely due to the fact that the convective heat transfer coefficient in both the test and reactor conditions on the outer surface of the temperature sensor sleeve is large. Thus, differences in gas and surface temperatures will be small since the thermal resistance between the gas and the surface is small.

For the test, the cylindrical spacer block rests essentially along a line contact at the bottom inside surface of the sleeve as indicated in Fig. 5. An air gap exists between the sleeve and the spacer at all other boundaries of the spacer block. This air gap serves as a relatively large thermal resistance in the test model. Under reactor conditions, this gap will be filled with helium which will have a much higher thermal conductivity (than ambient air) and hence a smaller thermal resistance. This factor is 
accounted for in the selection of the simulated sensor sleeve and spacer block material by the Systems Dynamics Branch of General Atomic Company. For test and reactor similarity, the thermal conductivity of the sleeve and spacer material should be as close as practical to 2.7 and 1.3 $\mathrm{Btu} / \mathrm{hr} \mathrm{ft}{ }^{\circ} \mathrm{F}$, respectively. This ensures the same ratio of solid conductance to gap and outer surface conductance between reactor and test conditions. The material selected for the simulated sensor sleeve and spacer block has a thermal conductivity of about $4 \mathrm{Btu} / \mathrm{hr} \mathrm{ft}^{\circ} \mathrm{F}$. Therefore, the air test results on the sensor spacer block can not be used directly for predicting exact reactor sensor results, but should prove valuable in checking out the computer thermal model of the sensor.

A typical distribution of the summation of influence coefficients $\Sigma \theta^{\prime}$, is shown in Fig. 14. The maximum $\Delta \theta^{\prime}$ on the sensor sleeve occurs at the centermost upstream position, while the minimum values are located on the downstream side of the end-most locations. In the immediate vicinity of the sensor sleeve (the three center-most columns on Fig. 14), the $\Sigma \theta^{-}$ values are in good agreement with a range of $0.94 \leq \Sigma \theta^{\prime} \leq 1.18$. At the $\mathrm{CSB}$ exit plane, $0.92 \leq \Sigma \theta^{\prime} \leq 1.14$. In genera1, the range of values of $\Sigma \theta^{\prime}$ at the CSB exit plane is smaller (more predictable) than the values of $\Sigma \theta^{-}$at the temperature sensor sleeve and spacer blocks as indicated in Table 1 .

\subsubsection{Seven-Column Region - Single Heated Columns}

A summary of important temperature influence coefficients and overall CSB pressure loss coefficients for the single heated column is given in Tables 2 through 5 for the final test phase. Some of the test runs (e.g., shown in Table 5) represent not-quite steady state conditions, especially in the thermocouples mounted in the spacer. The objectives of this part of the test program (the single heated column tests) did not include obtaining spacer thermal data. Since the sensor data were recorded anyhow the results are tabulated even though the spacer block may not always have reached steady state. 
A summary of some selected maximum influence coefficients for the 52-degree miter angle CSB is tabulated in Table 2. The maximum $\theta^{-}$influence coefficient (refer to Eq. 7 where $\theta^{-}$is referenced to the cold column temperature) is shown for the sensor and CSB exit plane positions. The maximum value of $\theta^{\prime} \mathrm{CSB}$ exit is indicative of the amount of thermal mixing taking place within the CSB. A comparison of $\theta^{\prime}$ sens max to $\theta^{\prime}$ CSB exit gives an indication of which flow column most directly impinges onto the sensor sleeve. From Table 2, hot streaks originating from columns 2, 3, 5, and 6 (see Fig. 2 for relative location) apparently do not impinge directly onto the sensor sleeve as evidenced by the significantly lower values of $\theta^{-}$at the sensor location as compared to that for the CSB exit plane. Also to be noted in Table 2 is that in general the maximum values of $\theta^{-} \mathrm{CSB}$ exit get smaller (indicating greater mixing) as the CSB height is increased.

Maximum and minimum values of $\theta_{E \text { sleeve }}(\theta$ is defined in Eq. 8 and is referenced to the mixed mean temperature) are also shown in Table 2 . (These values are at or near steady state, since the test procedure included monitoring the sensor sleeve temperatures to ensure steady state values.) Test No. $7 \operatorname{AX} 53(7)-15$ indicates that $\theta_{E \text { sleeve/max }}=0.266$. This means that if column 7 initially had a hot streak of $100^{\circ} \mathrm{F}$ above the mixed mean average and all of the other columns were uniform in temperature, then the maximum centerline sleeve surface temperature would be $26.6^{\circ} \mathrm{F}$ above the mixed mean temperature. The simulated sensor spacer block indicates that from $\theta_{E \text { spacer } A}=0.226$ there could be a $22.6^{\circ} \mathrm{F}$ sensing error for an initial $100^{\circ} \mathrm{F}$ column 7 hot streak. Refer to station 1 Fig. 5 for the location of this reading. This is a relatively large sensing error which should be carefully considered.

Similar data is shown in Table 3 for the 70-degree miter angle CSB. Here, single heated column tests were conducted for each individual flow column for each of three CSB heights. Because of the steeper convergence angle which causes opposite jets to impinge more directly than for the 52-degree miter angle CSB, the temperatures of the flows from columns 2 and 5 can be seen to be more readily sensed by the sensor sleeve. The thermal mixing within the 70-degree $\operatorname{CSB}$ is better than that for the 52-degree CSB, 
with the mixing improving as the $\operatorname{CSB}$ height is increased (as evidenced by values of $\theta^{\prime}$ CSB exit/max').

Because of some relatively large differences in $\theta^{\prime}$ sens max and $\theta^{\prime}$ CSB exit max, one might draw the conclusion that relatively large errors might exit when the hot streak is concentrated in columns 2, 3, 5 or 6 . However, when one examines the values at $\theta_{E}$ sleeve max/min or $\theta_{E}$ spacer $A / B$ in Tables 2 and 3 , the error is less than 13 percent of the difference between the maximum CSB inlet and the true mixed mean temperatures. Thus, an original column $2,3,5$ or 6 hot streak of $\left(\mathrm{T}_{\max } \operatorname{CSB}\right.$ inlet $\left.-\overline{\mathrm{T}}\right)=100^{\circ} \mathrm{F}$ would result in an error of less than $13^{\circ} \mathrm{F}$ (no uncertainties included in this estimate). Generally, from these four columns, the measured temperature will be lower than the true mixed mean temperature. The opposite is generally true for hot streaks emanating from columns 4 and 7 where the indicated mixed mean temperature is higher than the true mixed mean temperature.

When one compares the 52-degree and the 70-degree miter angle CSB results for $\theta_{\mathscr{E}}$ spacer, errors up to $30 \%$ may occur in the $\mathrm{T}_{\max }-\overline{\mathrm{T}}$ readings for the tests tabulated in Table 2 (52-degree CSB) while the maximum error shown in Table 3 (70-degree CSB) is 14 percent.

The influence coefficients along the centerline of the sleeve and spacer block are all generally smaller than the $\theta_{f}^{\prime}$ 's for the 52-degree CSB. Thus, the temperature sensor should be more accurate for the 70-degree CSB. From the test data in Table 3 the largest sensor error due to a single column hot streak of $100^{\circ} \mathrm{F}$ above the mixed mean temperature is $13.2^{\circ} \mathrm{F}$ for test $7 \mathrm{BX} 48(4)-113$. Similarly, if the initial column hot streak was $200^{\circ} \mathrm{F}$ above the mixed mean temperature, then the expected error could be $26.4^{\circ} \mathrm{F}$. From past experience in looking at column temperatures, a hot streak in one column is generally followed by a relatively cold column on the opposite side of the same region; hence, some of the sensing error tends to negate itself. This observation should be confirmed by the systems Engineering Department when the CSB influence coefficient data is used in the COLUMN and PLENUM computer codes. 
Influence coefficient test data for the 70-degree miter angle CSB are shown in Figs. 15a through $15 \mathrm{~g}$ for the 41-in. high CSB, and in Figs. $16 \mathrm{a}$ through $16 \mathrm{~g}$ for the 48.8-in. high CSB.

The discussions have been concentrated around the maximum values of influence coefficients either in the temperature sleeve and block or at the CSB exit plane. Furthermore, only single heated column flows have been discussed in this section thus far. The reader is reminded here that the location of the maximum influence coefficient is different for each heated column. As the mixing improves, the maximum influence coefficient gets smaller, but the presence of the hot streak is also more broad. Thus for a given location which originally was affected only by one particular heated column for a CSB with poor mixing, better mixing may cause that same location to be affected by other heated columns. It may be possible that the combined effect of multiple heated columns is not significantly different between a CSB configuration which promotes poor mixing, and one which promotes good mixing. This will not be determined until the data is actually used by the Systems Engineering Department for various realistic reactor conditions.

Other miscellaneous seven-column region test results are shown in Table 4. Some of these test results were conducted while the spacer block temperatures were still changing, some were conducted at different total flow rates, and some were taken where the heated column flow rate was either increased or decreased from the nominal specified flow rate. These results indicate that

1. There is no obvious Reynolds Number (Re No.) effect on the influence coefficients or pressure loss coefficient due to flow rate variation for a fuel region in the range of 15 to 44 percent reactor $\operatorname{Re}$ No.

2. As a single column heated flow increases relative to the remaining column flow rates, the maximum influence coefficients also increases. This effect is more prominent on the sensor sleeve than at the CSB exit plane 
3. The sensor sleeve temperatures reach a steady state value much faster than the spacer block located inside the sleeve.

\subsubsection{5-Column Region - Single Heated Columns}

Comparable selected influence coefficients are summarized in Table 5 for five-column regions representative of some peripheral core regions in an HTGR. Note that the CSB cavity shape for these regions has been changed from a circular cross-sectional area to the shape shown in Fig. 17. This change in shape for the five-column tests was a result of poor sensing accuracy indicated by the four-column tests conducted in the preliminary screening test phase of this program. With the circular cross-sectional area used in the preliminary test phase, large velocity maldistributions occurred as indicated in Fig. 10. A velocity ratio of $u / \bar{u}=1.0$ would represent a local velocity equal to the average velocity through the CSB cavity. Note that the velocity distribution varies from 0.05 to 2.39 for this configuration.

Figure 18 shows the velocity distribution for a five-column region using the CSB cavity cross-sectional area shown in Fig. 17. The flow distribution is seen to be much more uniform than in Fig. 10 with a minimum and maximum velocity ratio of 0.62 and 1.16 , respectively in the free flow area. The baffle plate used in the simulated CSB cavity was intended to provide a simple modification which would cause a minimal effect on the flow paths of the active flow columns (compared to a seven-column region), e.g. one-third of the flow area is removed from the CSB cavity region by the baffle to conform with two blocked flow passages out of six in a normal full CSB region.

Because the baffle was inserted in an attempt to make the flow pattern for the five-column CSB similar to the flow pattern for the seven-column region, the influence coefficients are expected to be much closer to that for the seven-column region test results than for the four-column region test results shown in Table A.5 in the Appendix. The summary of selected influence coefficients given in Table 5 verifies this expectation. Note, 
however, that the influence coefficients for the spacer are also higher (a maximum of $\theta_{E \text { spacer } A}=0.215$ ) thus the greatest sensor inaccuracies may be expected to occur in partial regions. Since there are only six such regions in a medium size HTGR it may be beneficial to lower the average temperature from these regions by slightly over-cooling them. The sensor accuracies under reactor conditions will have to be checked out with actual expected reactor conditions by the Systems Engineering Department.

The pressure loss coefficients given in Table 5 for the 5-column region are approximately 30 percent higher than those for the 7-column region given in Tables 2 and 3 . This fact must be accounted for in the design and operation of the HTGR. The additional pressure drop in these 5-column regions may hinder the ability to always over-cool these regions.

\subsubsection{Multiple-Heated Column Tests}

In addition to having an extensive single heated column test series in the final thermal mixing test phase, a number of multiple heated column tests were also conducted. The purpose of these tests was to provide experimental data for some simulated region power tilts and to see how close superimposed single heated column results would match with these data. It should be pointed out here that the only influence coefficients which can be superimposed and satisfy the boundary conditions for superposition are the $\theta^{-}$values defined in Eq. 7 .

Selected values of influence coefficients determined from the multiple-heated 7-column tests are shown in Table 6 . The predicted values of $\theta^{-}$are also shown based on the superposition of the corresponding single heated column results. The predicted results are based on the actual test data, i.e., the data has not been made symmetric (e.g., $\theta^{\prime}{ }_{6}=\theta_{3}^{\prime}$ ) nor normalized (e.g., $\sum_{i} \theta_{i}^{\prime}=1.0$ ). 
The most accurate values of $\theta^{-}$in Table 6 should be $\theta^{-}$sens. max. and $\theta^{\prime}$ CSB exit max. ${ }^{-}$Some of the predicted values of $\theta^{\prime} €$ spacer may be lower than experimentally measured due to the possibility that steady state for the sensor spacer may not have reached for each single heated column test. (Note that the original objectives of this test program did not include measurement of this data.) Nevertheless, in many cases the agreement between experimental and predicted results is good. Not only are the maximum values well predicted, but Figs. 19 through 22 show that the distributions are well predicted. In Figs. 19 through 22, the experimental multiple heated test results for several 5 and 7 -column regions are shown on a computer printout with the superimposed single hot streak predictions written above the test data. Other predictions are contained in the calculation file for this report. In all cases the predicted distributions are similar to the experimental values.

An indication of the temperature sensor error may be deduced by studying the "max" and "min" values of $\theta_{E}$ sleeve in Tables 6 and 7 . In general, the 7A-series (52-degree miter angle CSB) has a larger mixed mean temperature error than the 7B-series (70-degree miter angle, as evidenced by the values of $\theta_{E}$ sleeve of $\mid \theta_{E}$ sleeve $\mid \approx 0.22$ (an error of $22^{\circ} \mathrm{F}$ for an initial hot streak of $\mathrm{T}_{\max }-\overline{\mathrm{T}}=100^{\circ} \mathrm{F}$ ). Although the value of $\theta_{E \text { spacer }}$ in the last two columns of Tables 6 and 7 indicate better agreement with the true mixed mean temperature, it should be remembered that the test material used for the simulated sleeve and spacer block could not exactly duplicate the reactor thermal sensor thermal conductivity in a helium environment so that the test model $\theta_{E}$ spacer data should not be used directly. These values of $\theta_{€}$ spacer are mainly useful in checking out the computer code model used to simulate the temperature sensor.

The reader is reminded at this point that as discussed in Section 3.3.3, cold streaks usually exist in the opposite side of the 7-column fuel region. The multiple heated 7-column tests described herein only contain half of the normal region power tilt. If the "cold" streaks were also included, the tendency would be to improve the accuracy of the temperature sensor. 
Based on the relatively good agreement in the summation of all single heated column flow results and the multi-heated column test predictions with experimental results, one may conclude that this superposition technique could be applied satisfactorily to a computer program to predict the reactor CSB temperature sensor sleeve and spacer block temperatures. One may want to make the data symmetrical and perhaps normalized, but this is not done in this report. 


\section{CONCLUSIONS}

Conclusions which can be drawn from the final test phase results are as follows:

1. The multiple heated columns test results can be reasonably predicted from the single column heated jet test data. This good correlation occurs both at the CSB exit plane and along the temperature sensor sleeve.

2. The thermal mixing and the CSB pressure drop for the 52 and 70-degree miter angle CSB configurations have been quantified. The thermal mixing data for the 52-degree miter angle CSB was not as good as indicated by the preliminary screening test phase.

3. The accuracy of the temperature sensor for a five-column region can be greatly improved when the 19 in. diameter circular crosssectional area is modified to the truncated circular shape as shown in Fig. 17. With this cavity shape modification, the sensor accuracy for these peripheral fuel regions is expected to meet the design criteria specified in Ref. 1. 


\section{RECOMMENDATIONS}

As a result of the CSB thermal mixing test program, the following recommendations are made:

1. The recommended CSB configuration should have a 70-degree miter angle to ensure good thermal mixing and adequate temperature sensor accuracy. Although the 48.8-in. high CSB has better mixing than the 41 in. high CSB, further application of the test data may show that both designs will satisfy the temperature sensing accuracy requirements. If so, the 41 in. $\operatorname{CSB}$ will be less expensive.

2. General use of the influence coefficients and pressure loss coefficients should have an uncertainty of \pm 10 percent added to the test data. The temperature sensor sleeve data should prove extremely useful for current and subsequent sensor spacer block designs by providing good estimates of reactor boundary conditions for a thermal model of the temperature sensor.

3. A pressure loss coefficient of $K=3.8$ should be used for the 70degree miter angle $\operatorname{CSB}$, excluding the $\operatorname{CSB}$ exit loss, or $\mathrm{K}=4.6$ if one assumes an exit loss of $\mathrm{K}_{\text {exit }}=0.8$. These loss coefficients are based on the C.SB exit flow area and should be used in design analyses. 
6. REFERENCES

1. Design Criteria DC-18-1, Reactor Core," General Atomic Company, unpublished data, December 11, 1975.

2. Niblock, G. A., "Analysis of Testing of the Temperature Sensor and Gas Mixing in the Core Support Block," General Atomic Company, unpublished data, July 20, 1976.

3. Hussmann, C., and E. Chin, "Specification for Core Support Block Thermal Mixing Test, General Atomic Company, unpublished data, May 13, 1977.

4. Chin, E., "Preliminary Thermal/Fluid Mixing Test Results on Core Support Block", General Atomic Company, unpublished data, January 20, 1978.

5. Brown, S. J., "Core Cavlty Redesign Study - Final Report," General Atomic Company, unpublished data, July 5, 1977.

6. Brown, S. J., "Increase in Core Cavity Height," General Atomic Company, unpublished data, February 9, 1977.

7. Niblock, G. A., "Lead Plant Core Support/Reflector Block Estimated Influence Coefficients for Gas Mixing," General Atomic Company, unpublished data, September 3, 1976. 


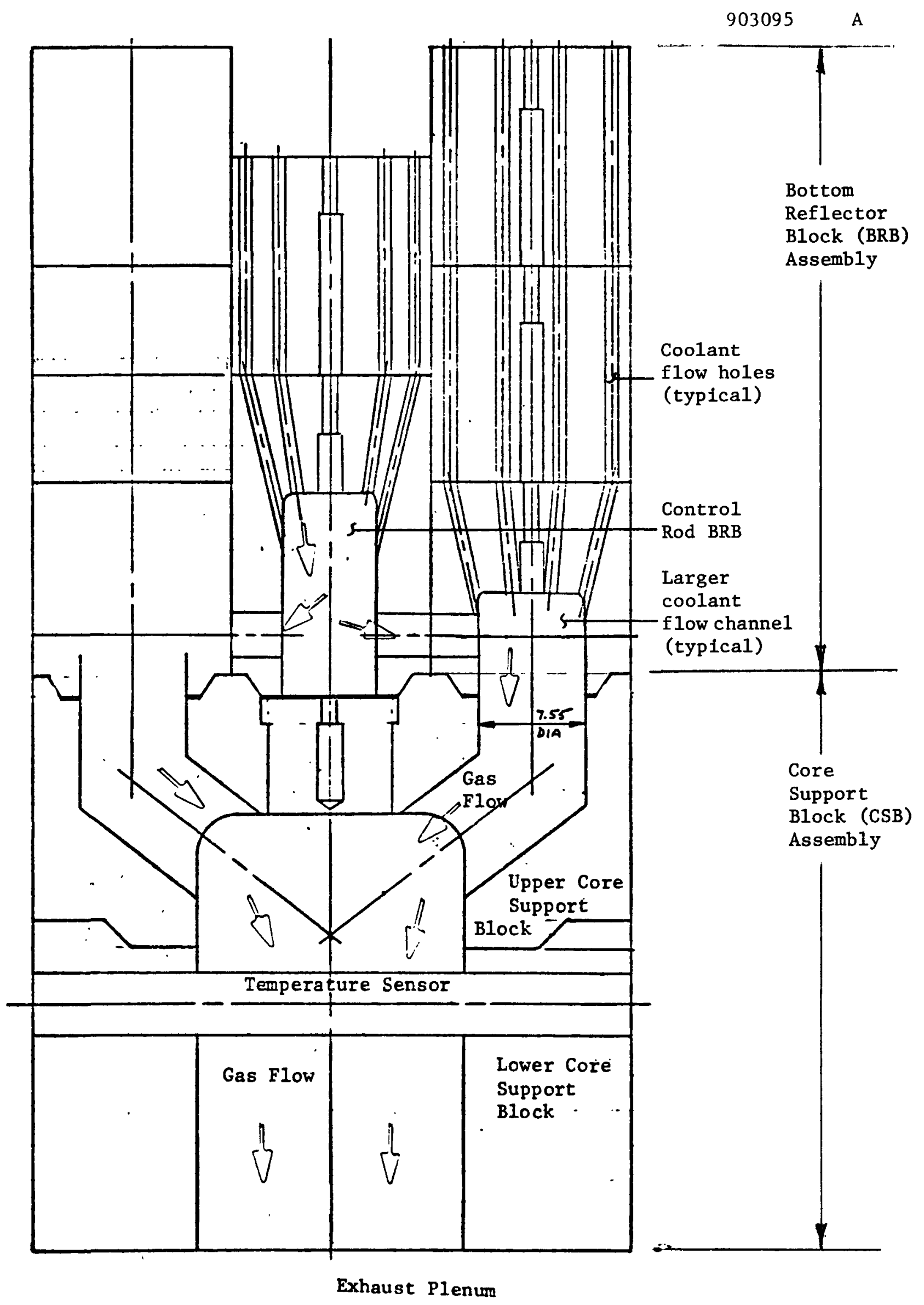

Figure 1. Typical Core Support Block and Bottom Reflector Block Assembly 


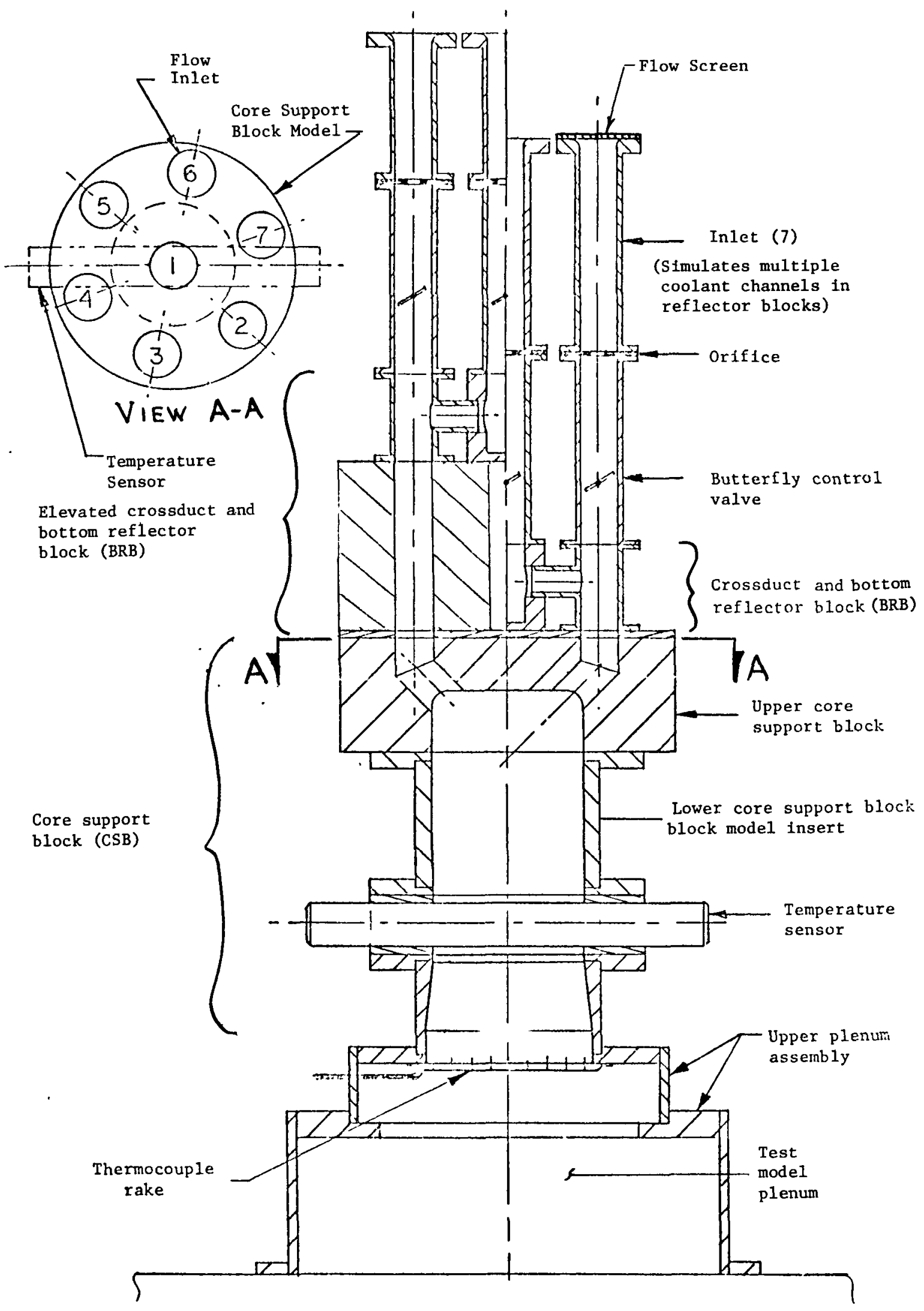

Figure 2. Core Support Block Mixing Test Mode1 

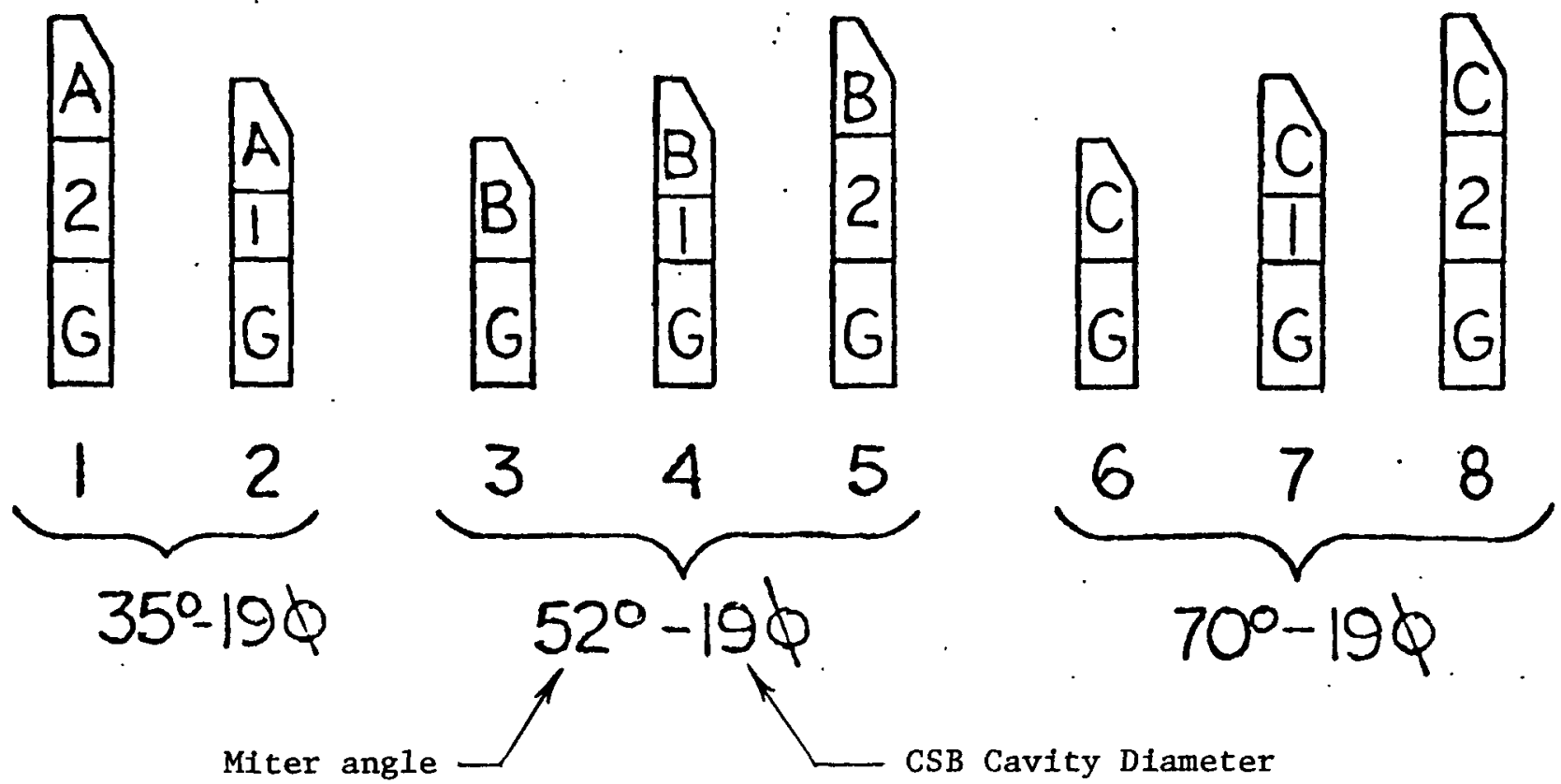

Miter angle

CSB Cavity Diameter

(19-inch full scale)
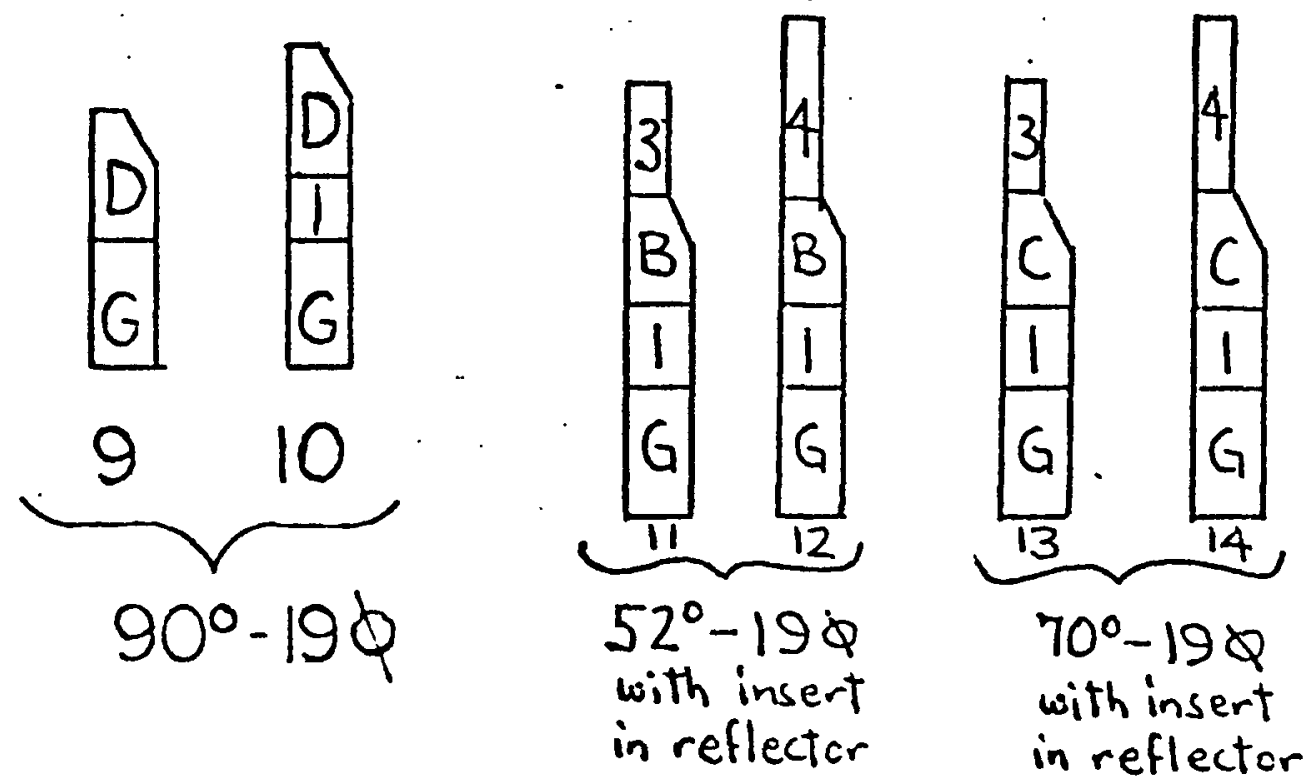

A, B, C \& D indicate different upper CSB miter angles.

$G$ indicates the lower CSB which includes the temp. sensor

1 \& 2 indicate different heights of the insert block in the CSB

3 \& 4 indicate different heights of the BRB crossduct channel 
Flow
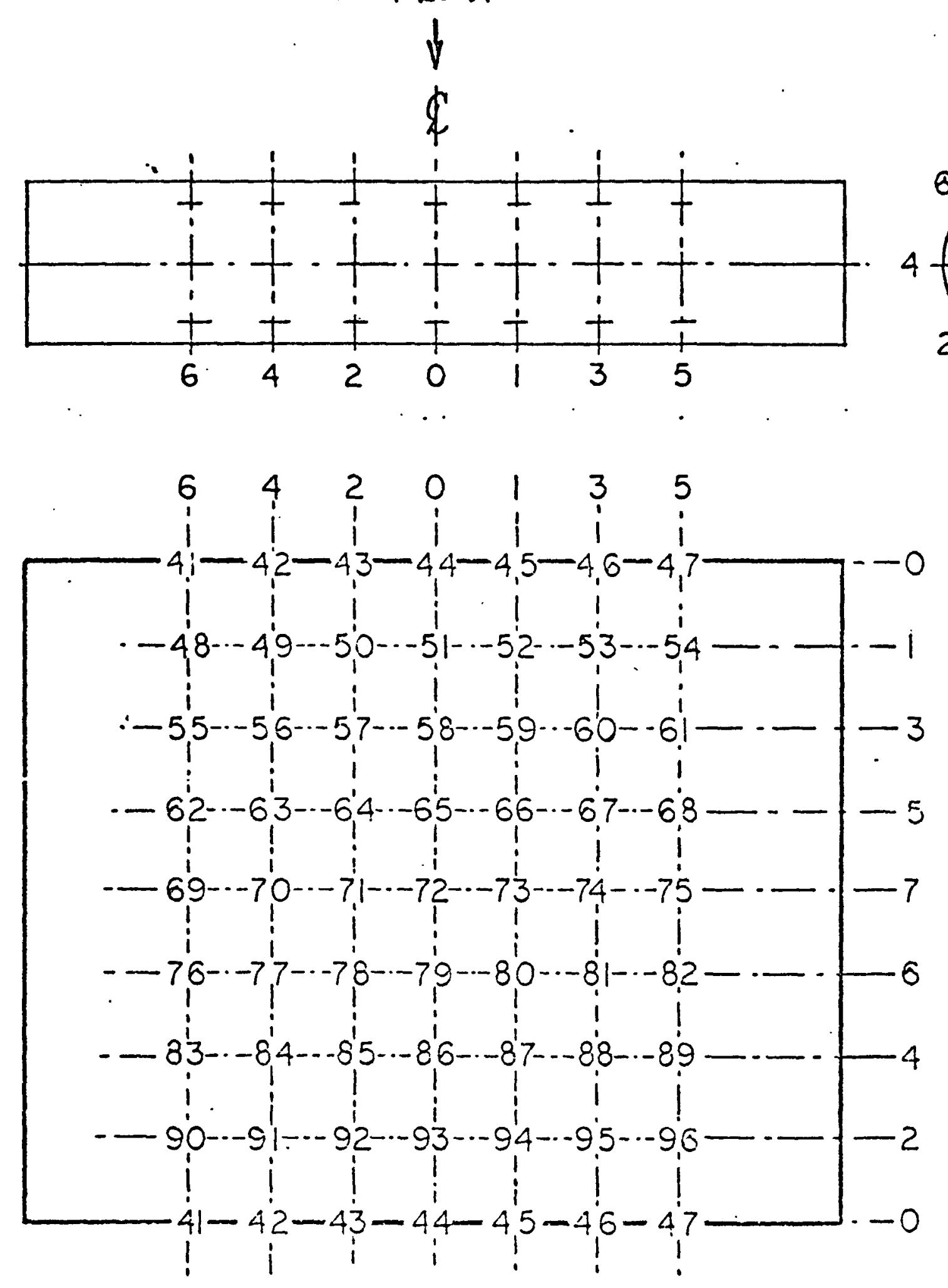

FLOW

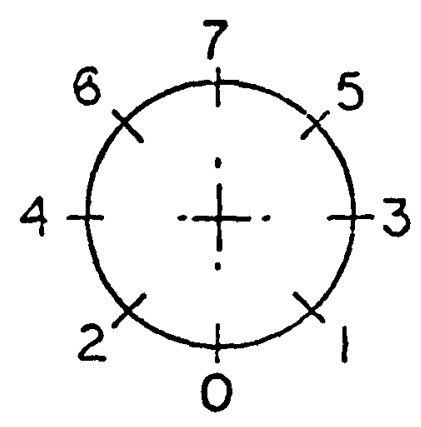



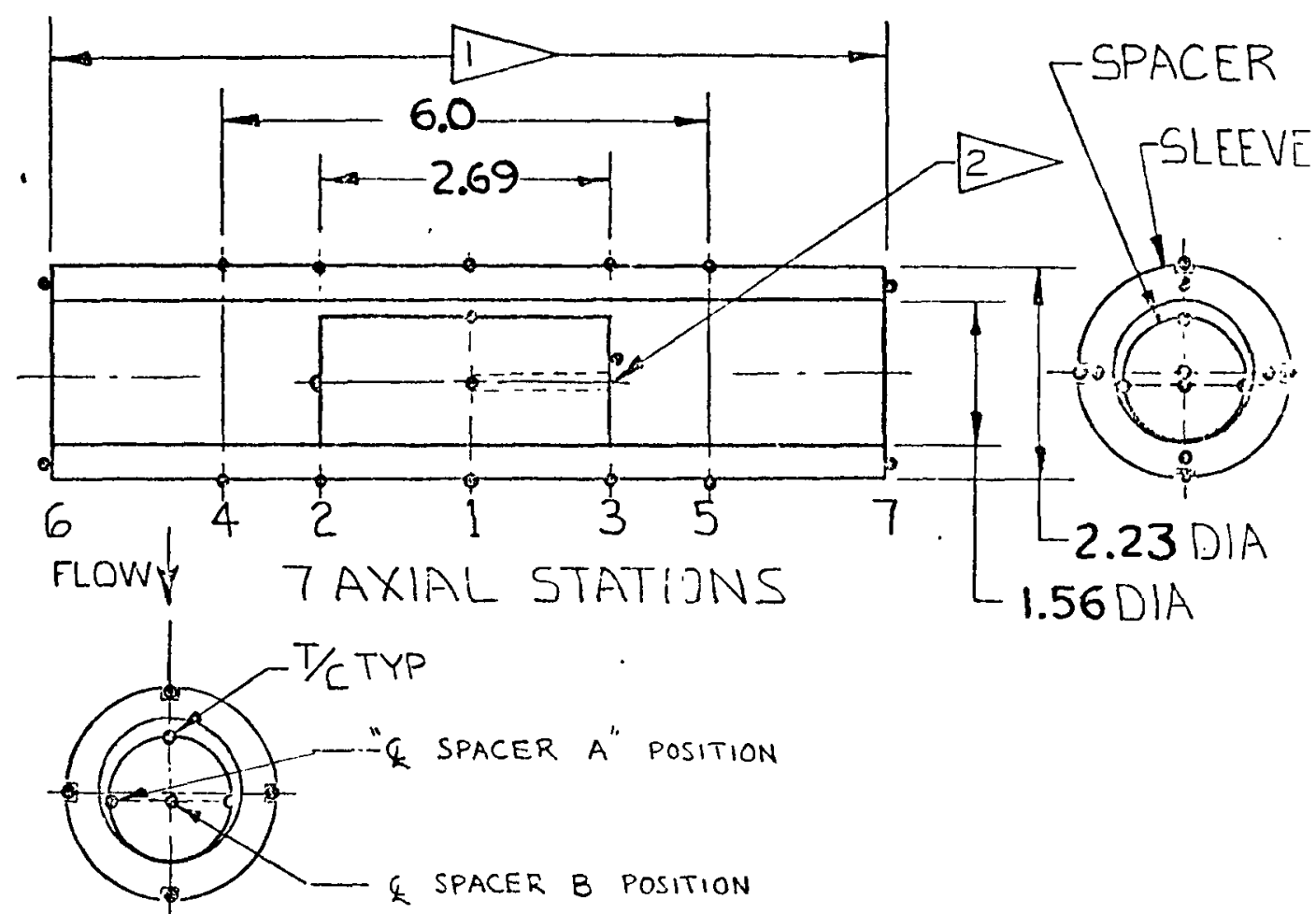

STATION 1

1 LENGTH TO BE

DETERMINED DURING

FABRICATION.

2 D DKILL HOLE FORT $/ C$.

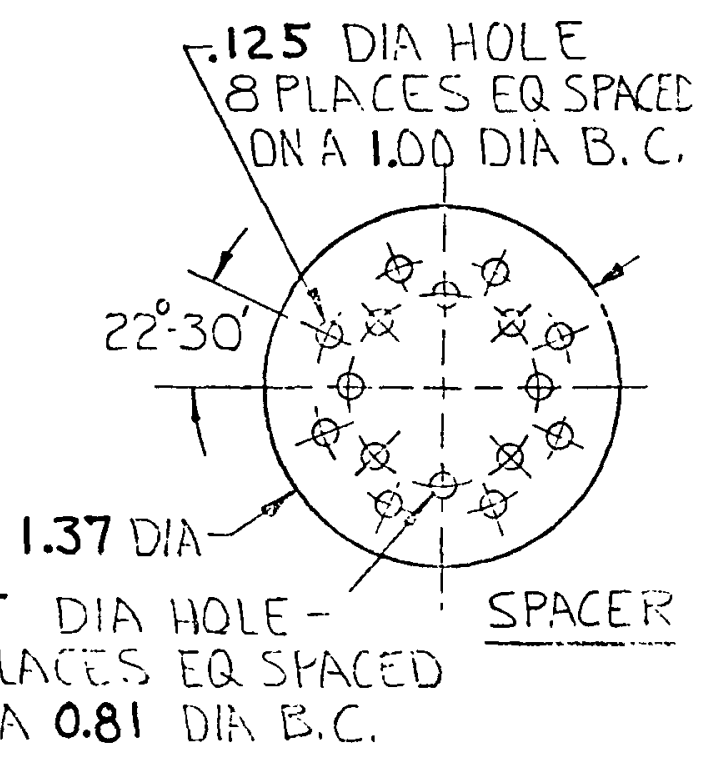

Figure 5. Simulated Reactor Temperature Sensor Model 


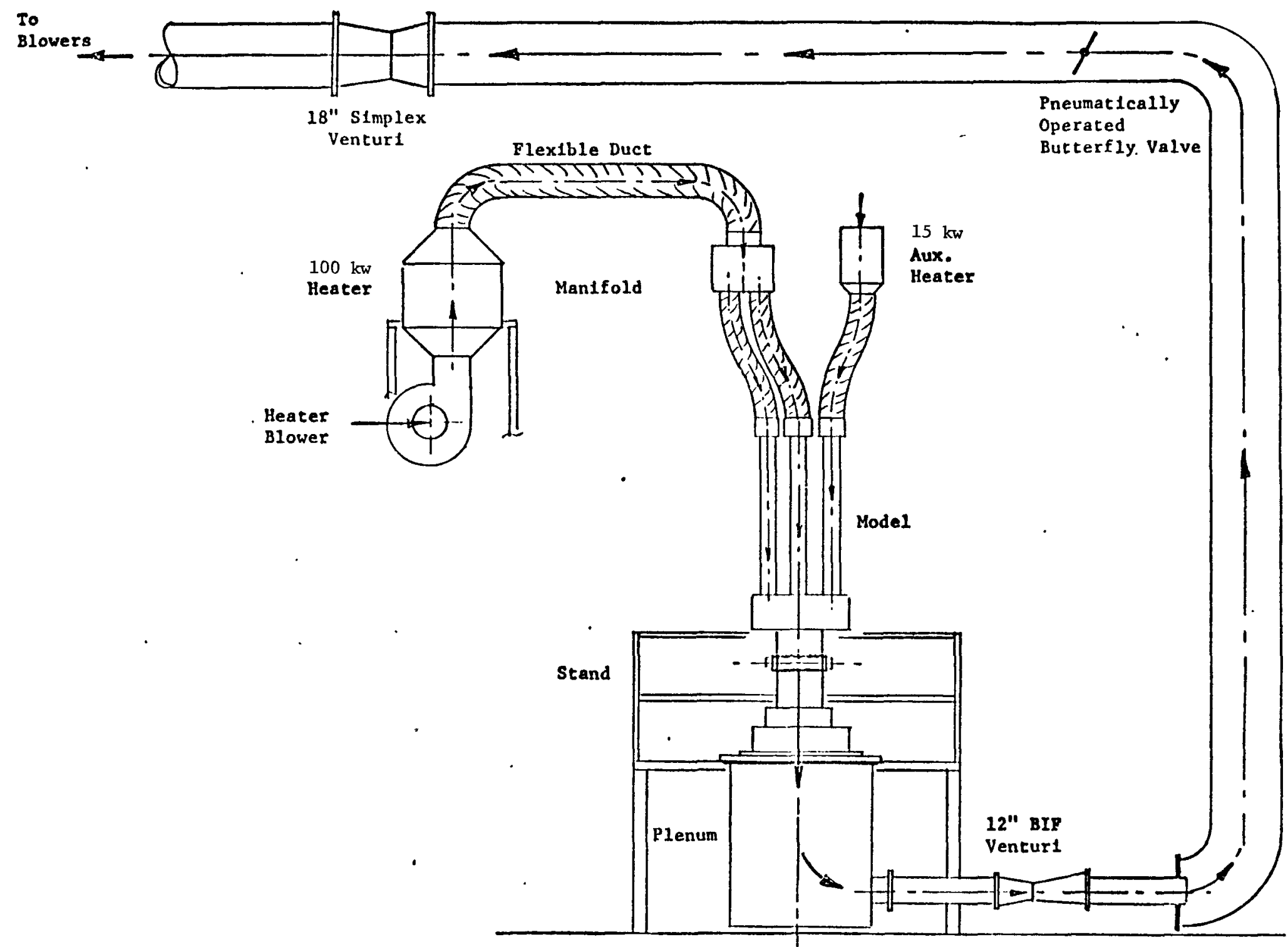


No. Static Pressure TAP

(1) Orifice upstream

(2) Orifice downstream

(3) Crossover upstream

(4) Crossover downstream

(5) CSB outlet
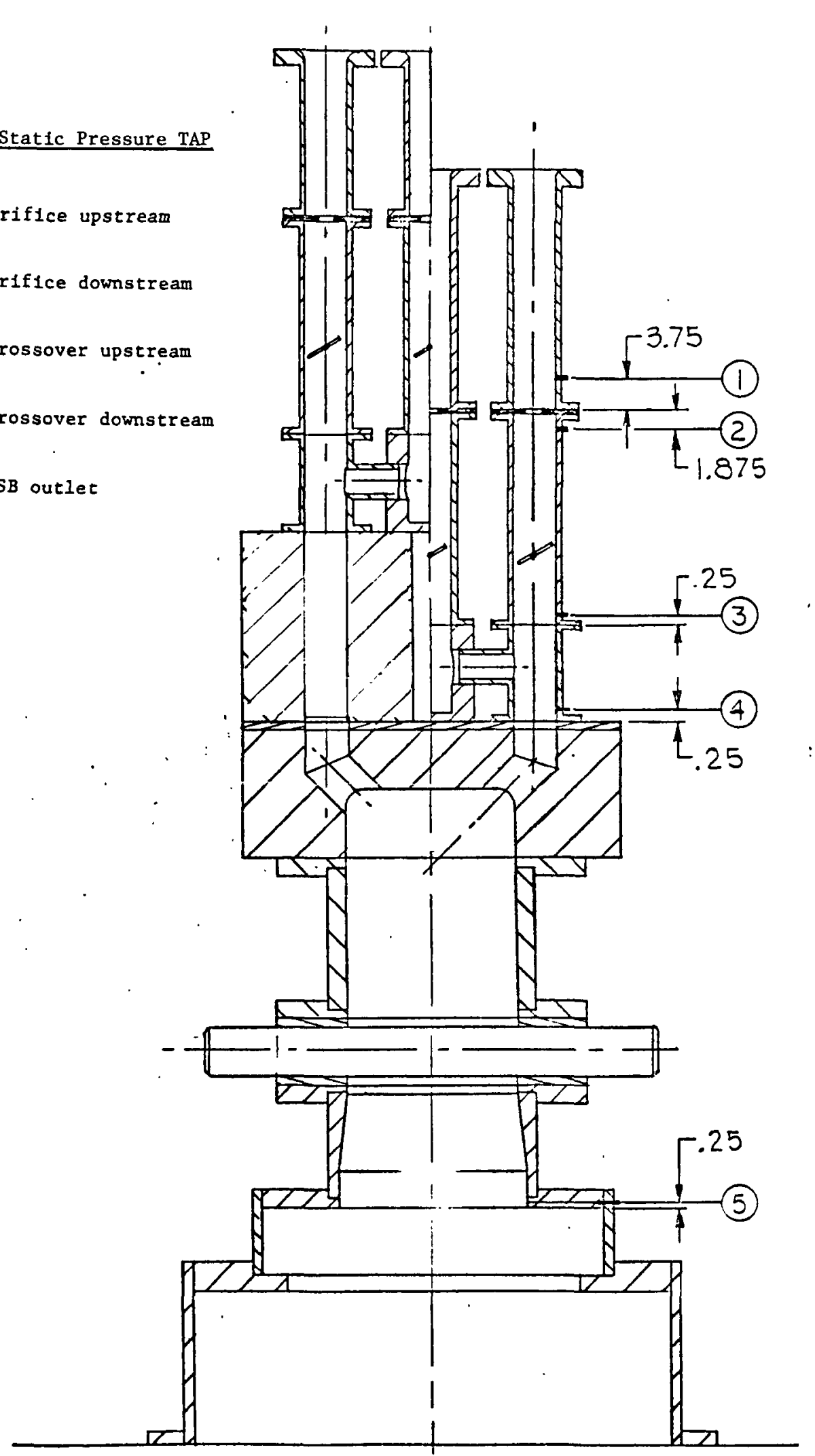

Figure 7. CSB Static Pressure TAP Locations 


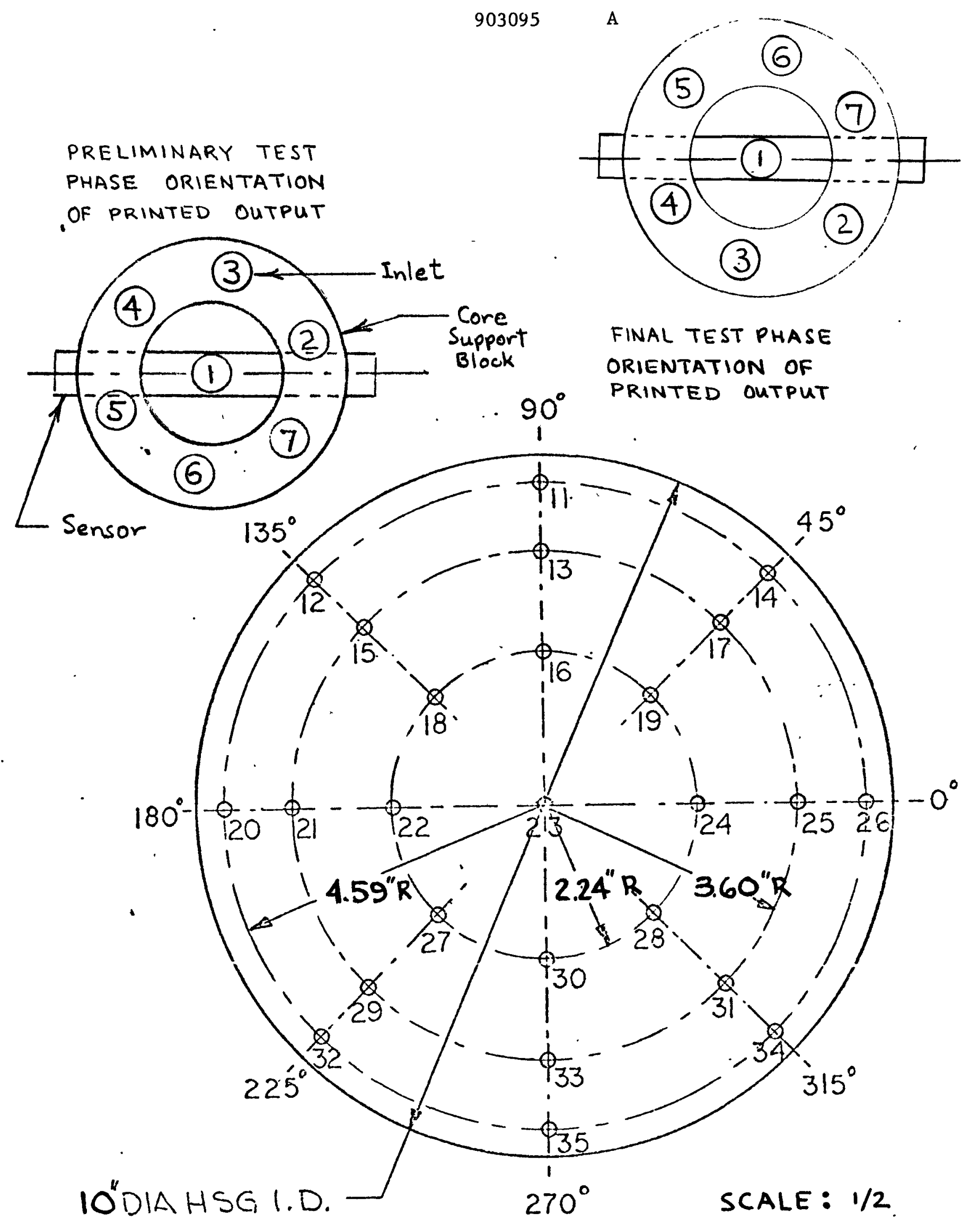

Figure 8. CSB Exit Plane Thermocouple Rake 


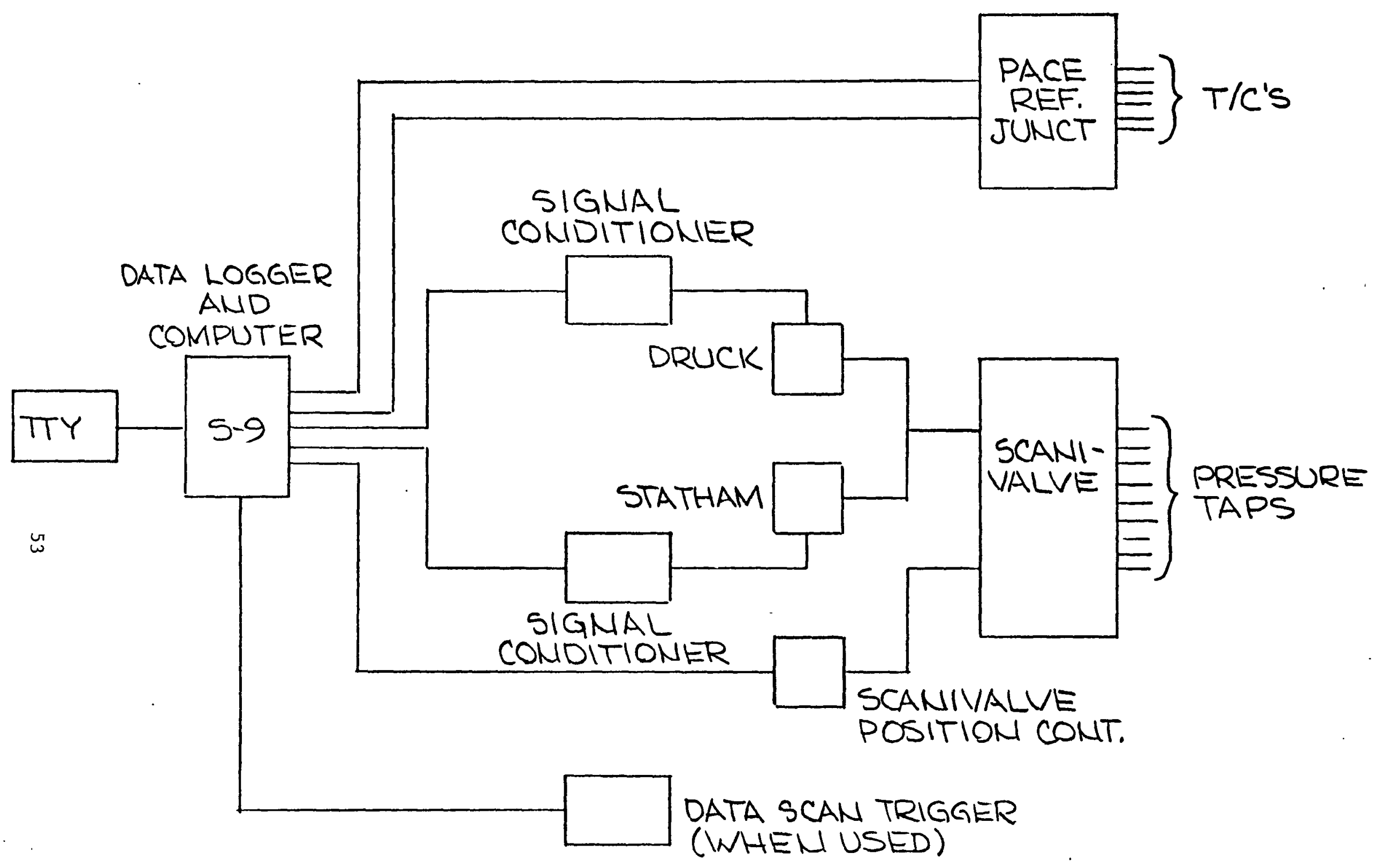

FIGURE 9- Data Acquisition System (DAS) Block Diagram 


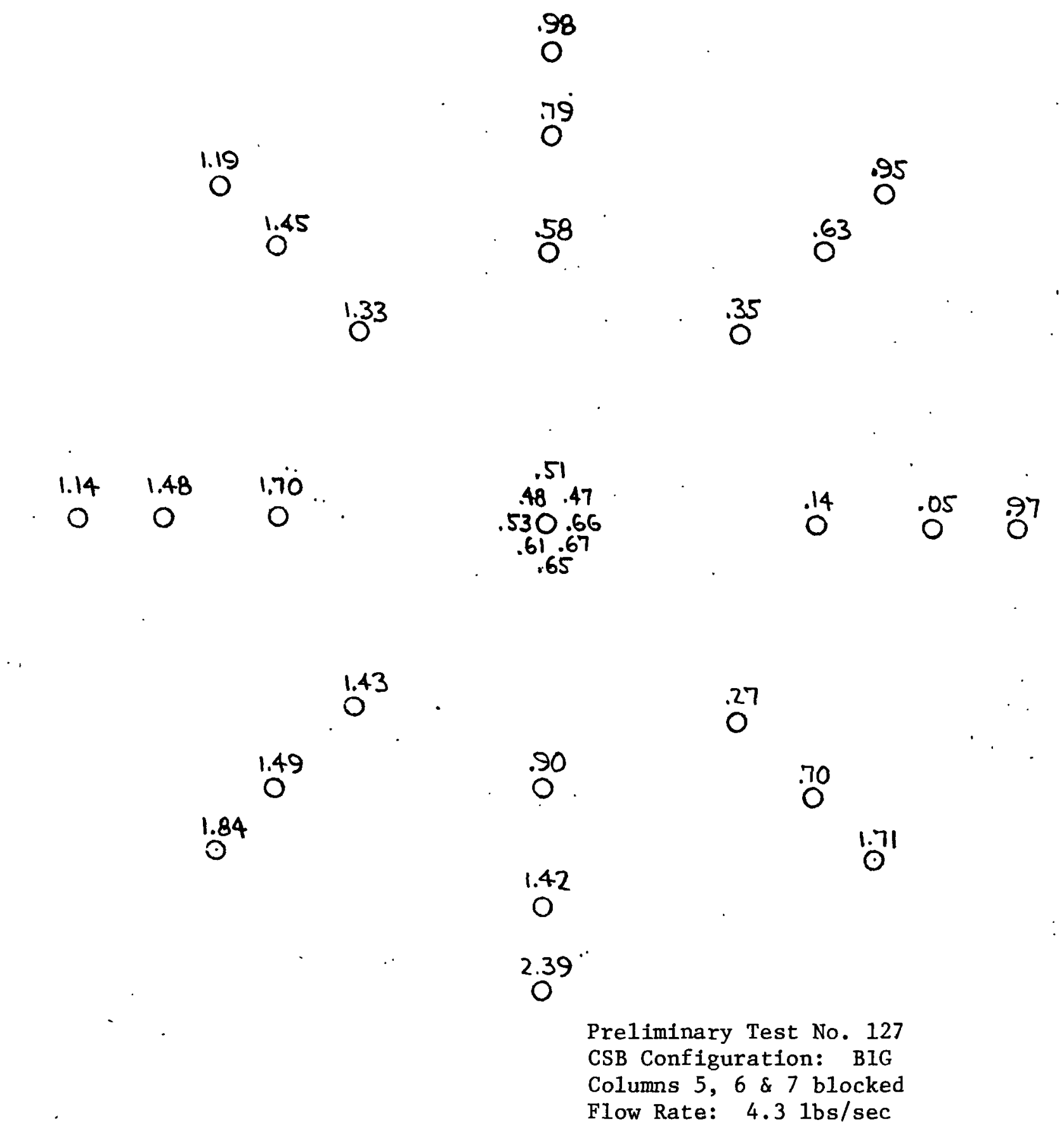

Figure 10. Normalized Velocity Traverse at a 4-Column Region CSB Exit Plane with Circular Flow Area 

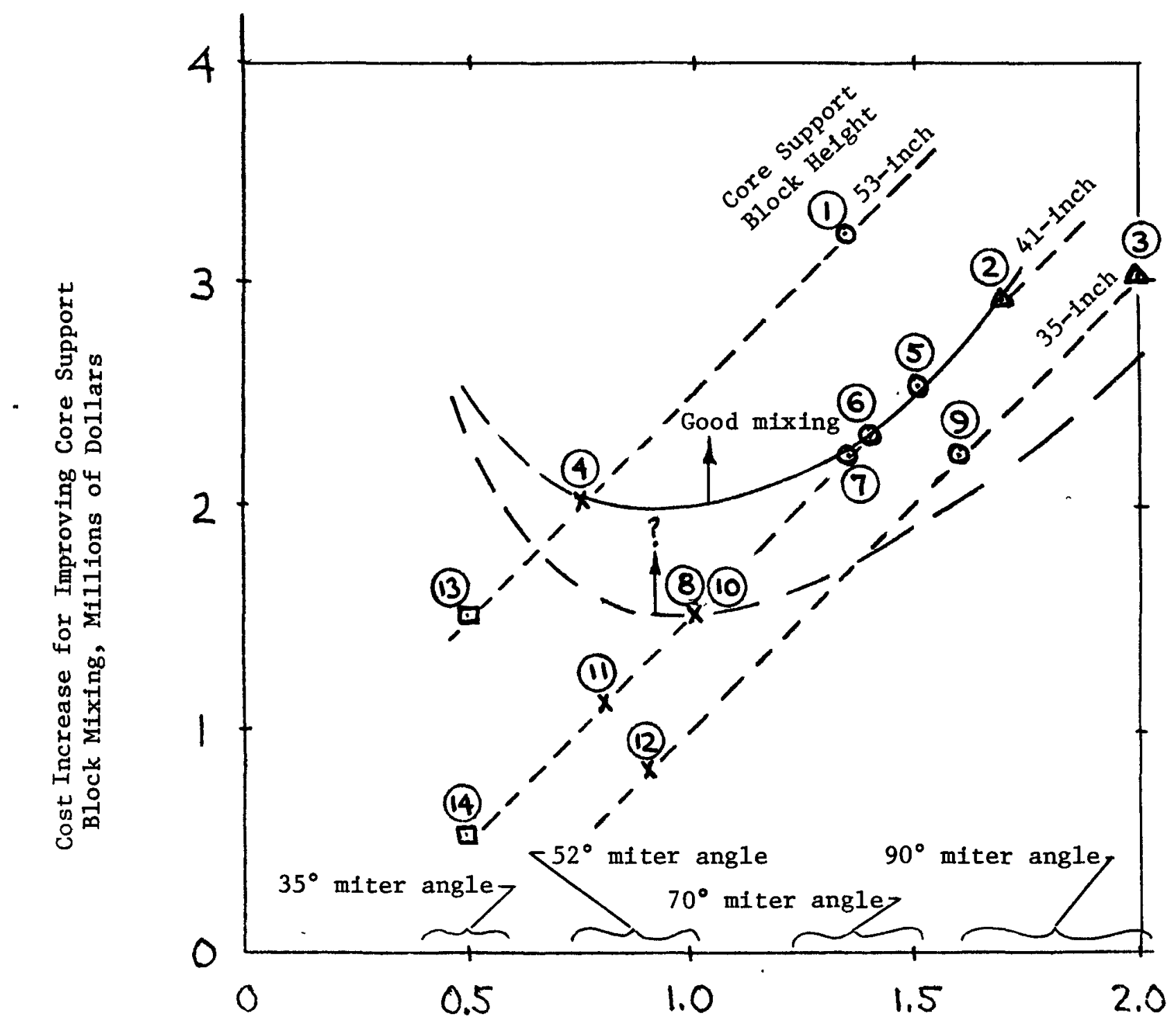

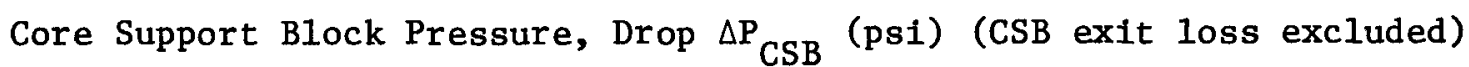

Figure 11. Estimated Cost Optimization of CSB Configurations 


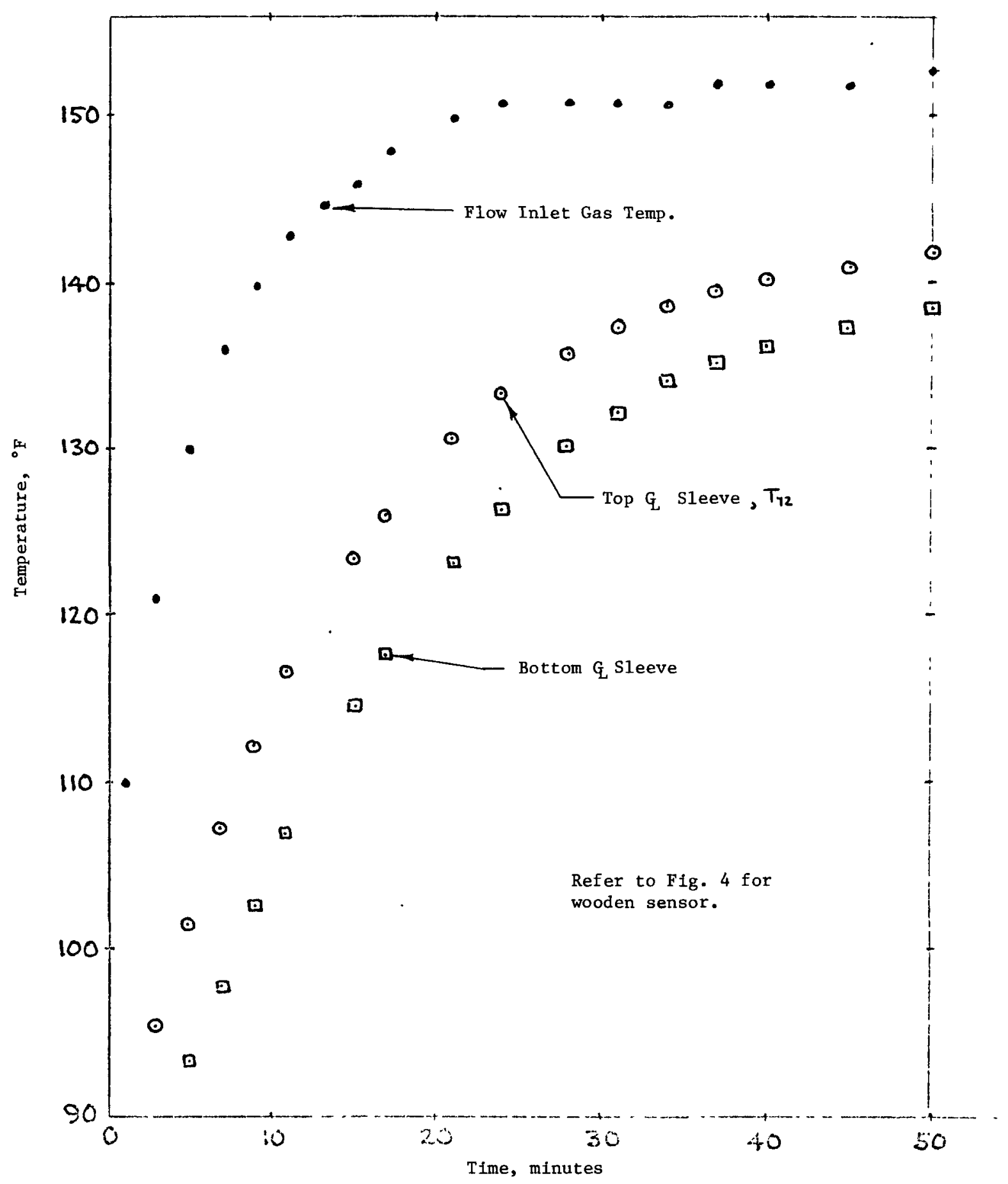

Figure 12. Transient Response of Wooden Sensor 


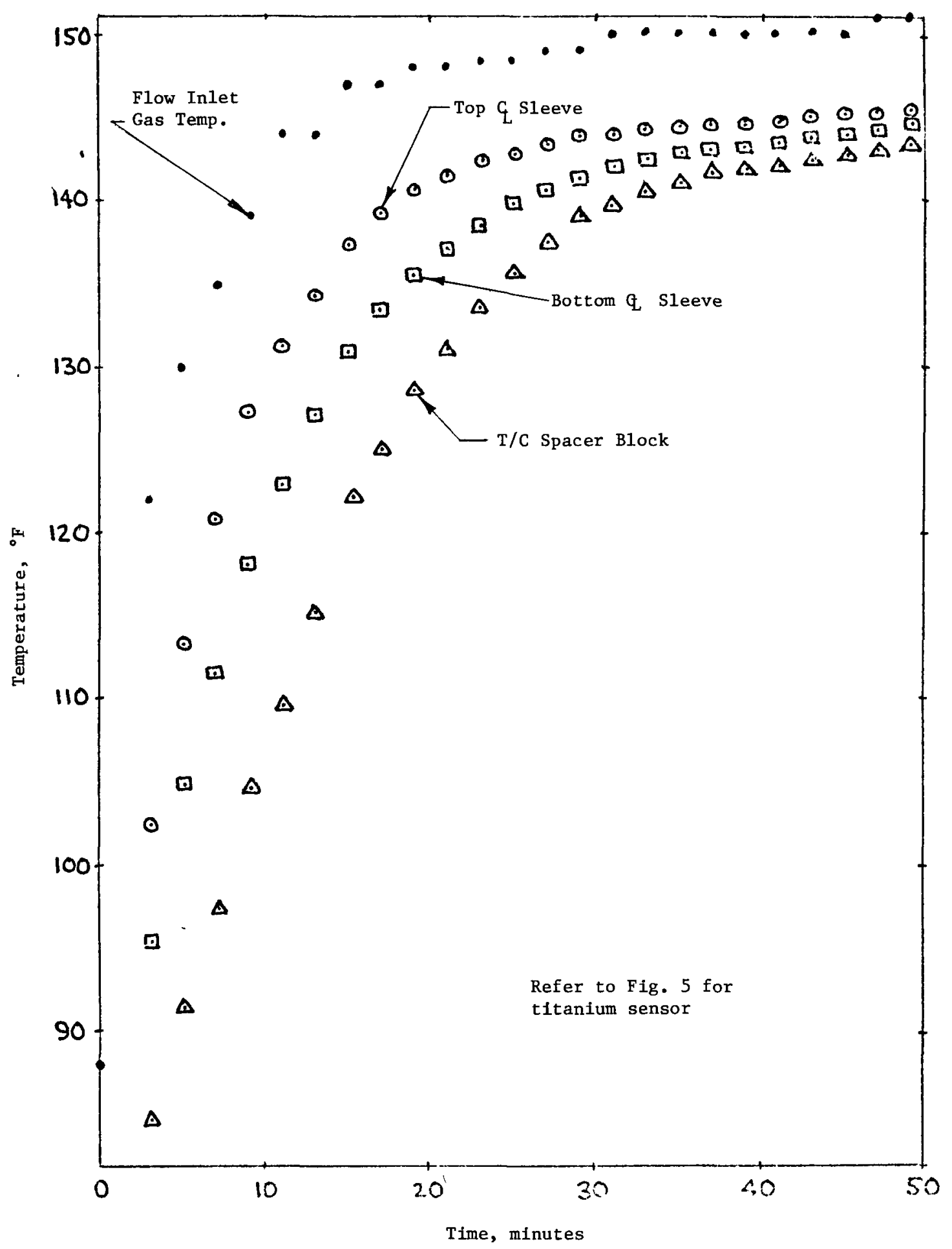

Figure 13. Transient Response of Titanium Simulated Sensor 


Sleeve $\left\{\begin{array}{ccccccc}.878 & .946 & .996 & .950 & .843 & \ldots . . \text { Bottom } \\ .935 & 1.006 & 1.054 & .998 & .887 & \\ 1.045 & 1.127 & 1.179 & 1.124 & .998 & \ldots . . & \text { Top } \\ .916 & 1.013 & 1.066 & 1.012 & .891 & & \\ .878 & .946 & .996 & .950 & .843 & \ldots . . . \text { Bottom }\end{array}\right.$

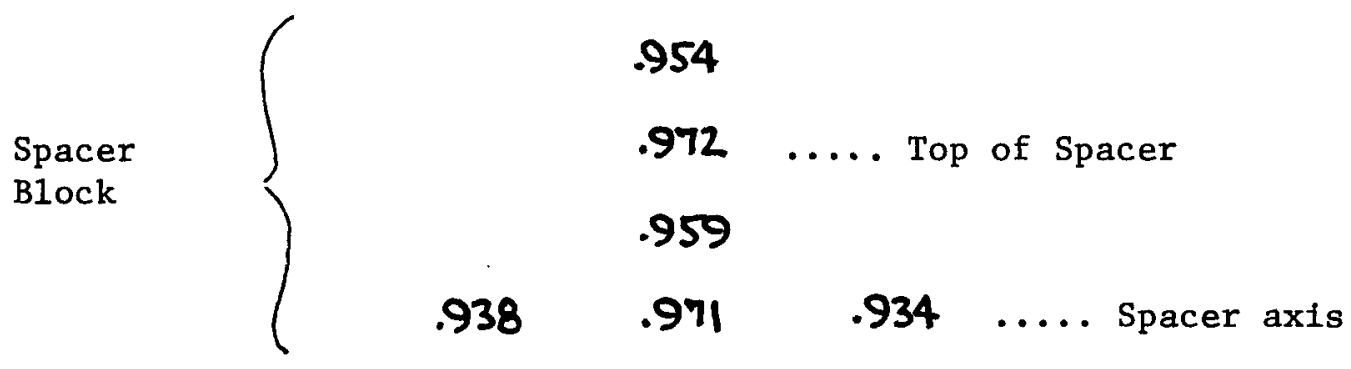

Temperature Sensor Sleeve and Spacer Block

.953

.952

1.005

.964

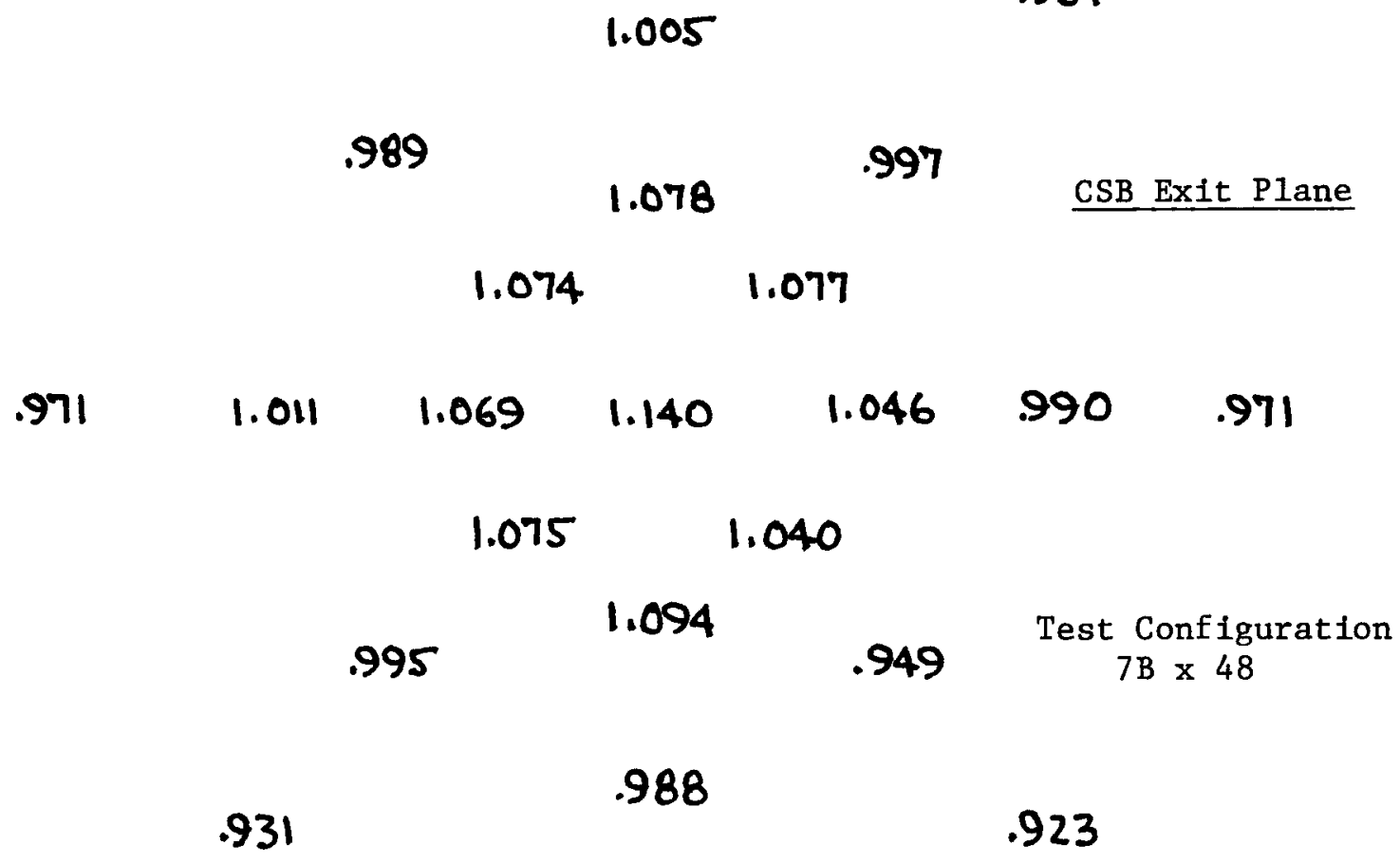

.934

Figure 14. Example of Summation of Influence Coefficients 
INFLUENCE COEFFICIENTS (AMB. TEMP. REF.)

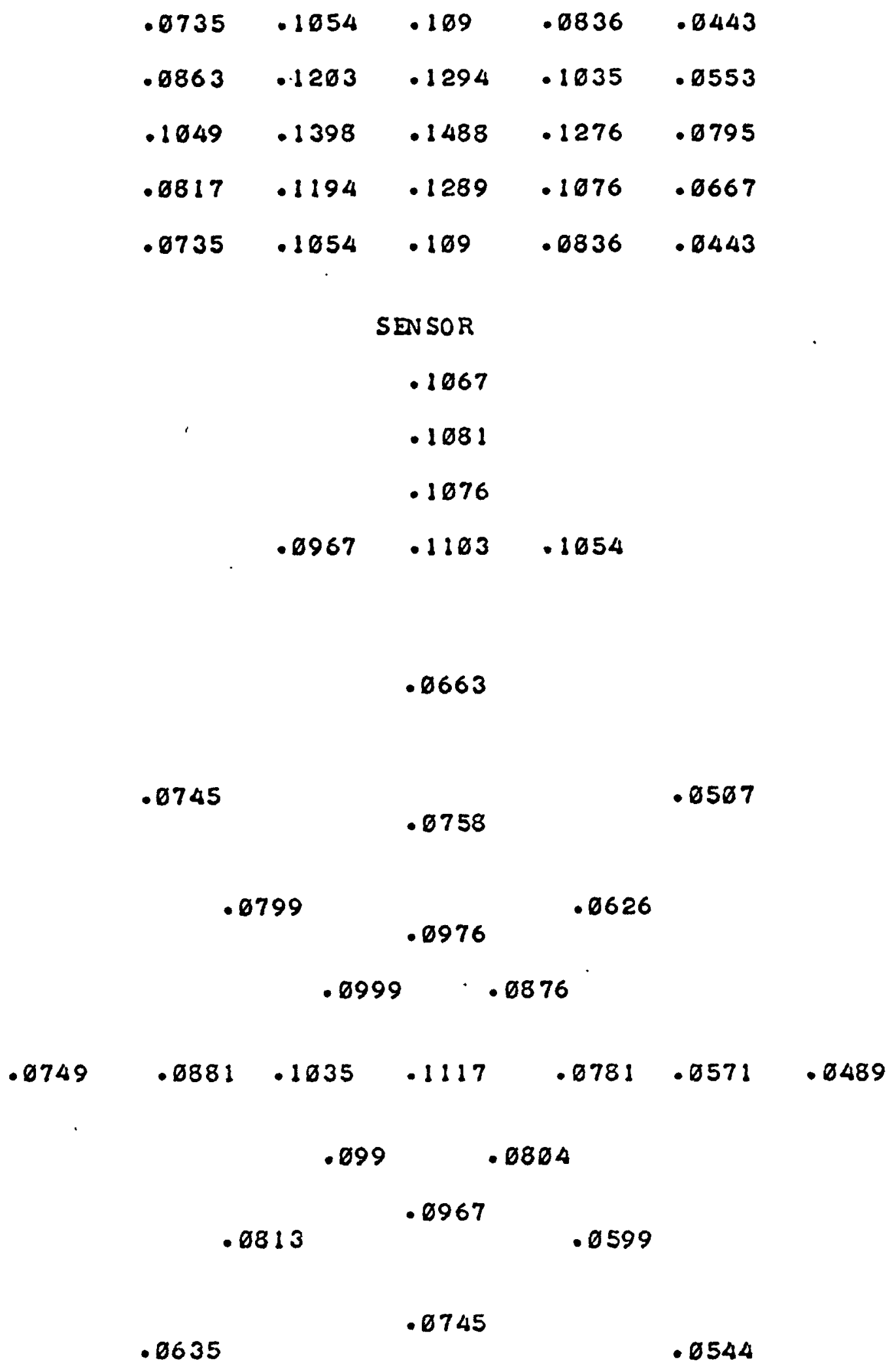

.0635

Figure 15a. $\theta^{\prime}$ Influence Coefficients for Run 7BZ41(1) - 36 
TEST NO.:

INFLUENCE COEFFICIENTS (AMB. TEMP. REF.)

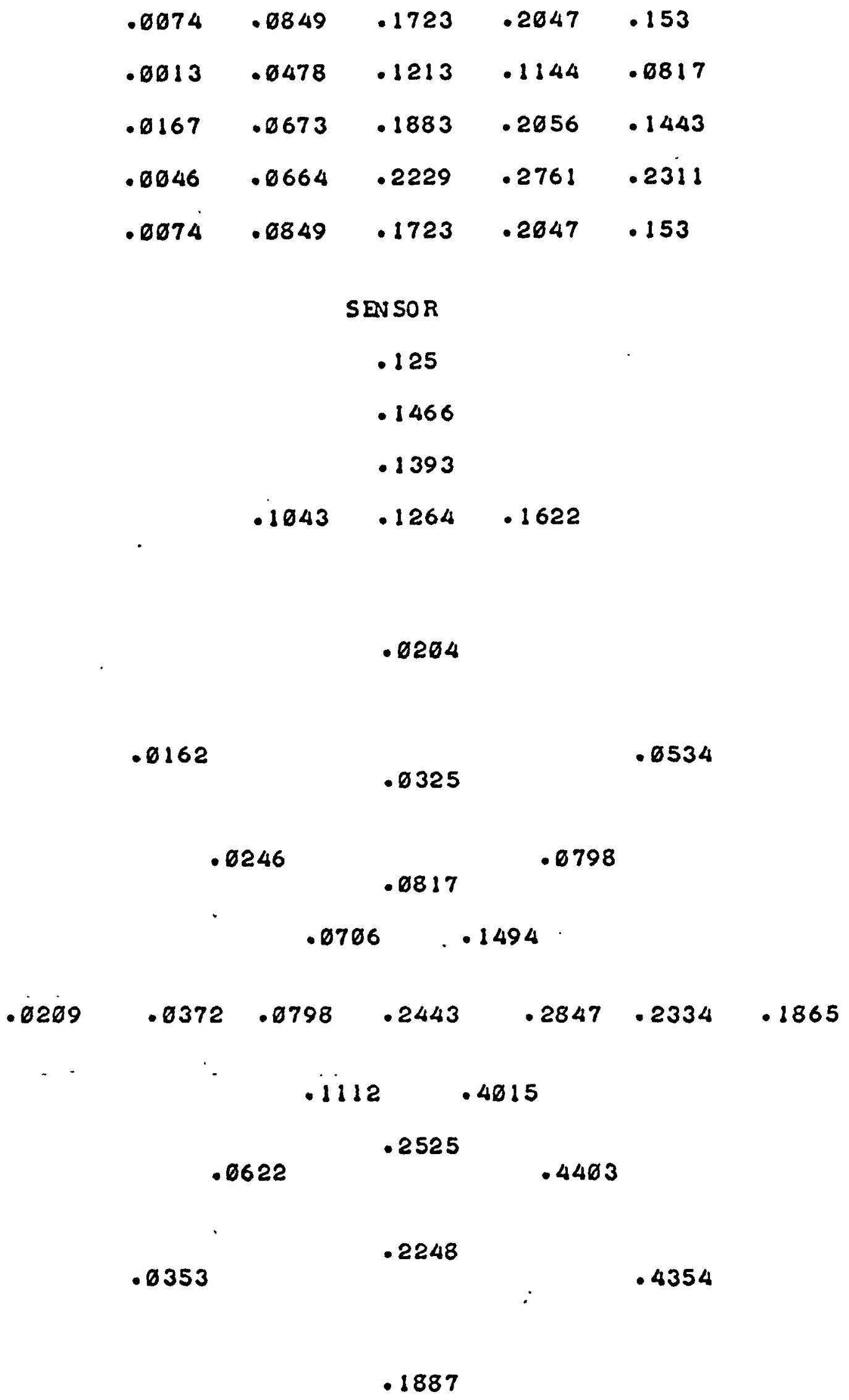

Figure 15b. $\theta^{\prime}$ Influence Coefficients for Run 7 BZ4I(2) - 37 
INFLUENCE COEFFICIENTS CAMB. TEMP: REF.

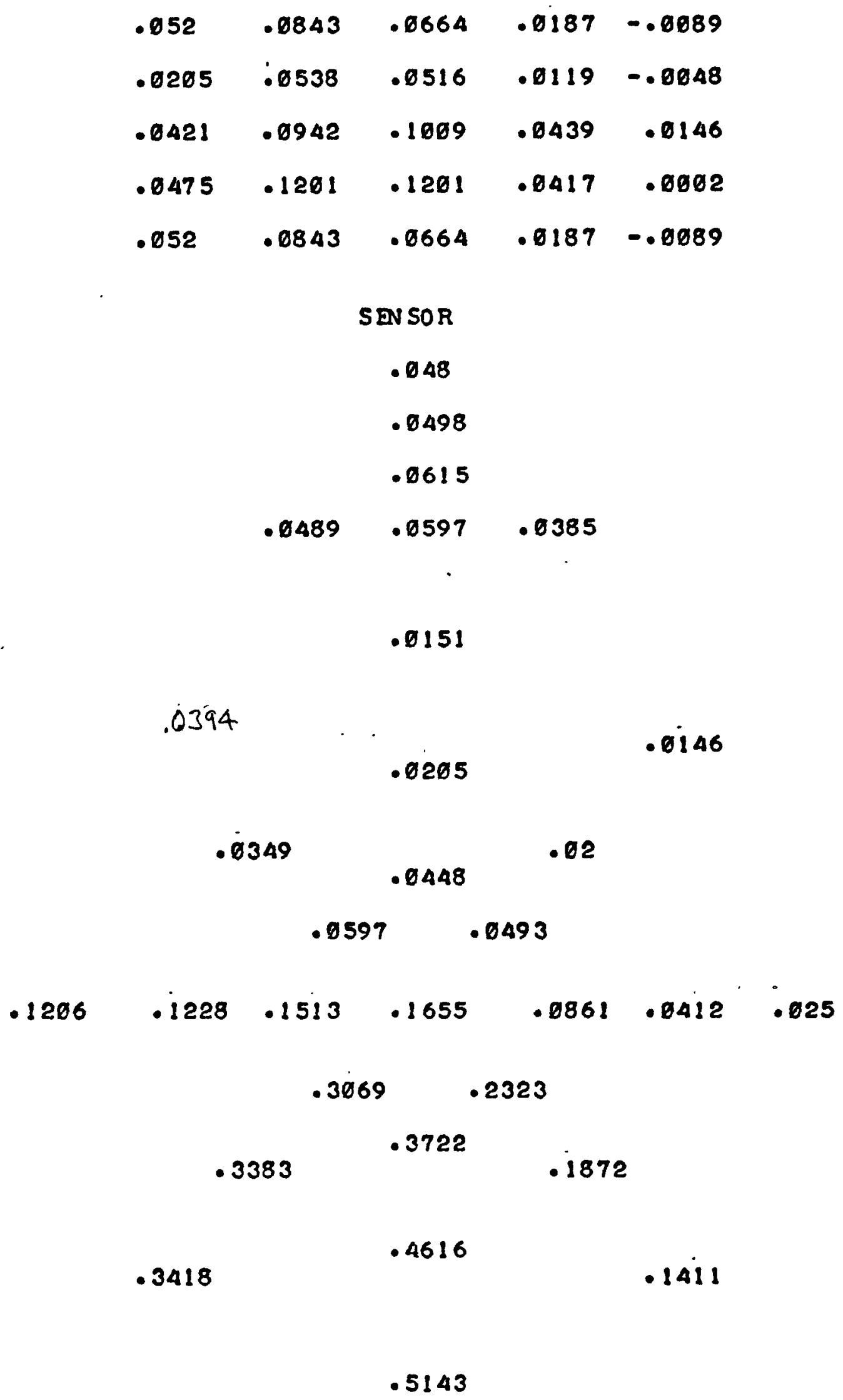

Figure 15c. $\theta^{\prime}$ Influence Coefficients for Run 7BZ41(3) - 38 
TEST NO.:

INFLUENCE COEFFICIENTS (AMB. TEMP. REF.)

$\begin{array}{lllll}.5202 & .3066 & .1368 & .0198 & -.0157 \\ .4859 & .0146 & .0958 & .0115 & -.0087 \\ .6097 & .4053 & .1278 & .0289 & .008 \\ .6289 & .4257 & .1265 & .0171 & -.0074 \\ .5202 & .3066 & .1368 & .0198 & -.0157\end{array}$

\section{SENSOR}

.2226

.2106

.2123

$.2765 \quad .2421 \quad .145$

.0359

.3159

.0402

.0045

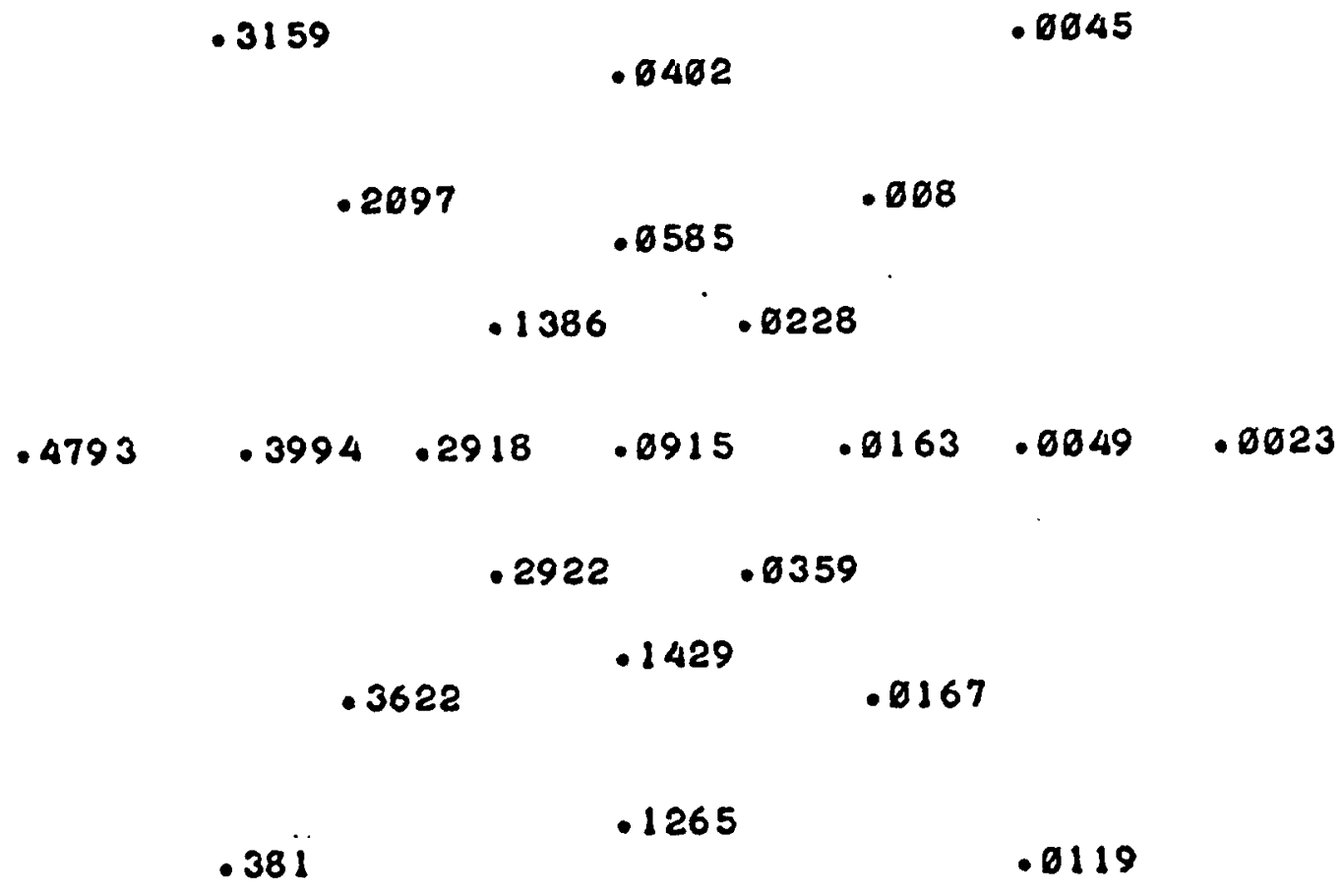

.1144

Figure 15d. $\theta^{\prime}$ Influence Coefficients for Run 7BZ4I(4) - 39 
TEST NO.A

INFLUENCE COEFFICIENTS (AMB. TMMP. REF.)

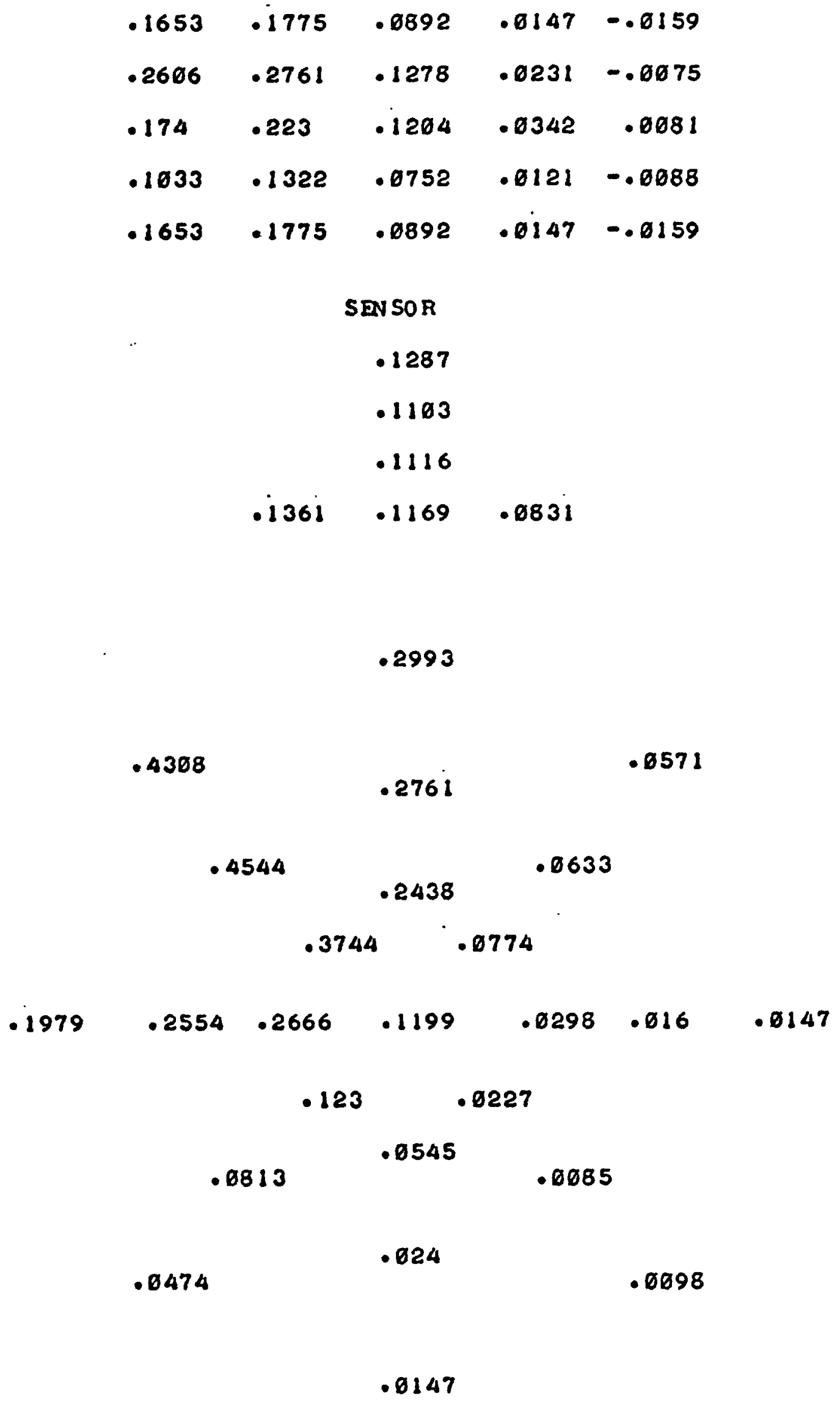

Figure 15e. $\theta^{\prime}$ Influence Coefficients for Run 7BZ41(5) - 40 
INFLUENCE COEFFICIENTS (AMB. TEMP. REF•)

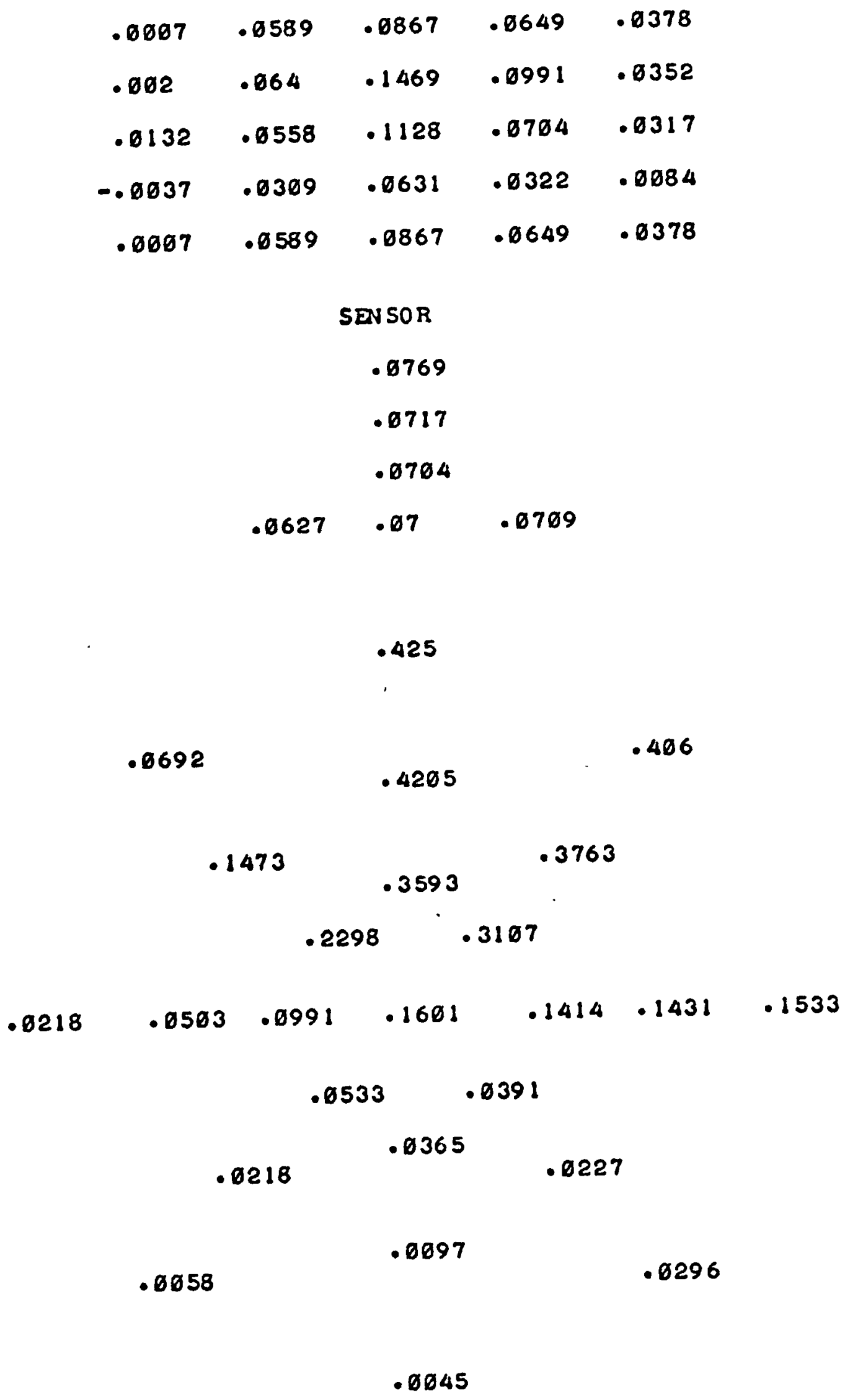

Figure 15f. $\theta^{\prime}$ Influence Coefficients for Run 7BZ41(6) - 41 64 


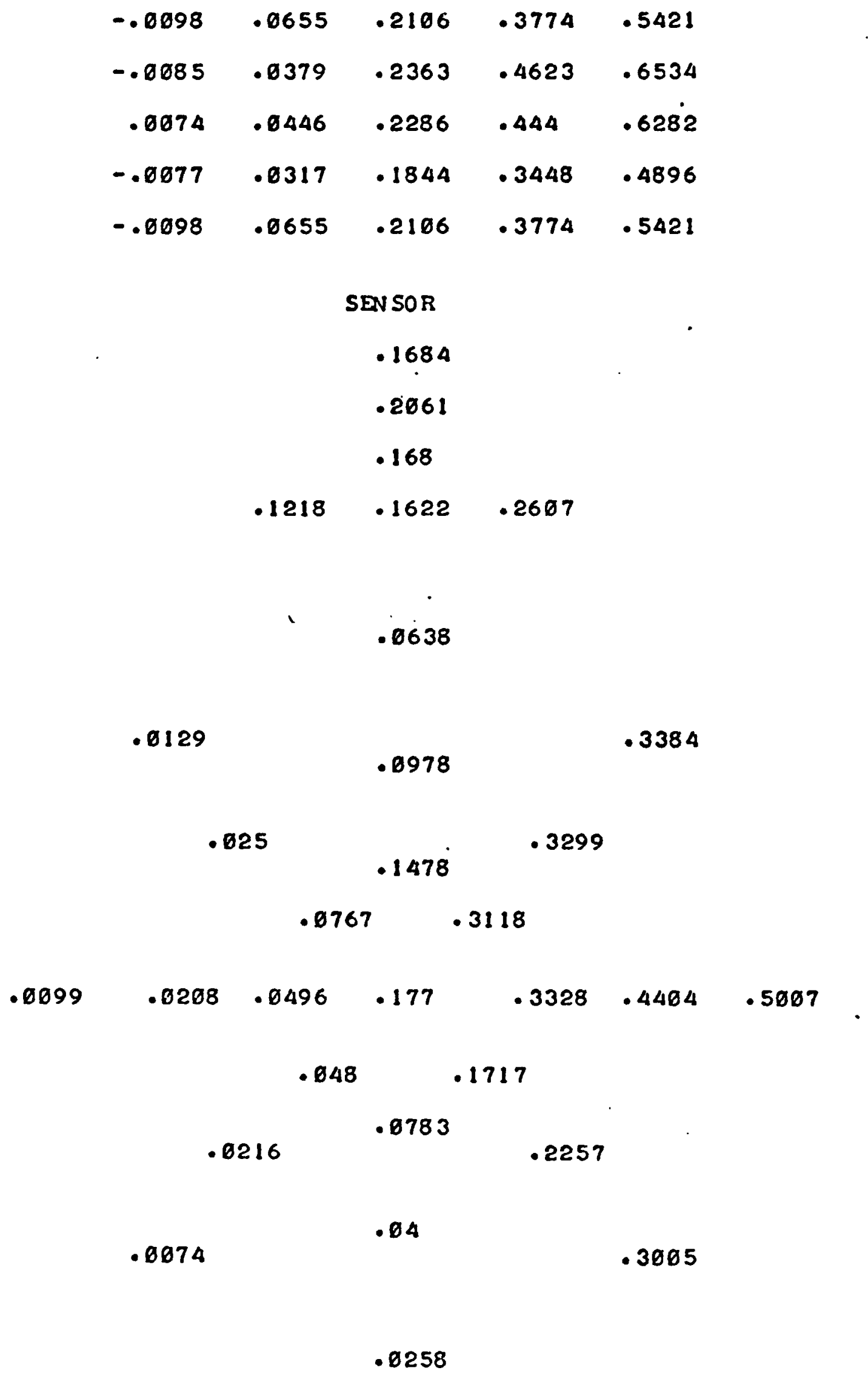

Figure 15g. $\theta^{\prime}$ Influence Coefficients for Run 7BZ41(7) - 42 
INFLUENCE COEFFICIEUTS (AIT3. TEIP. REF.)

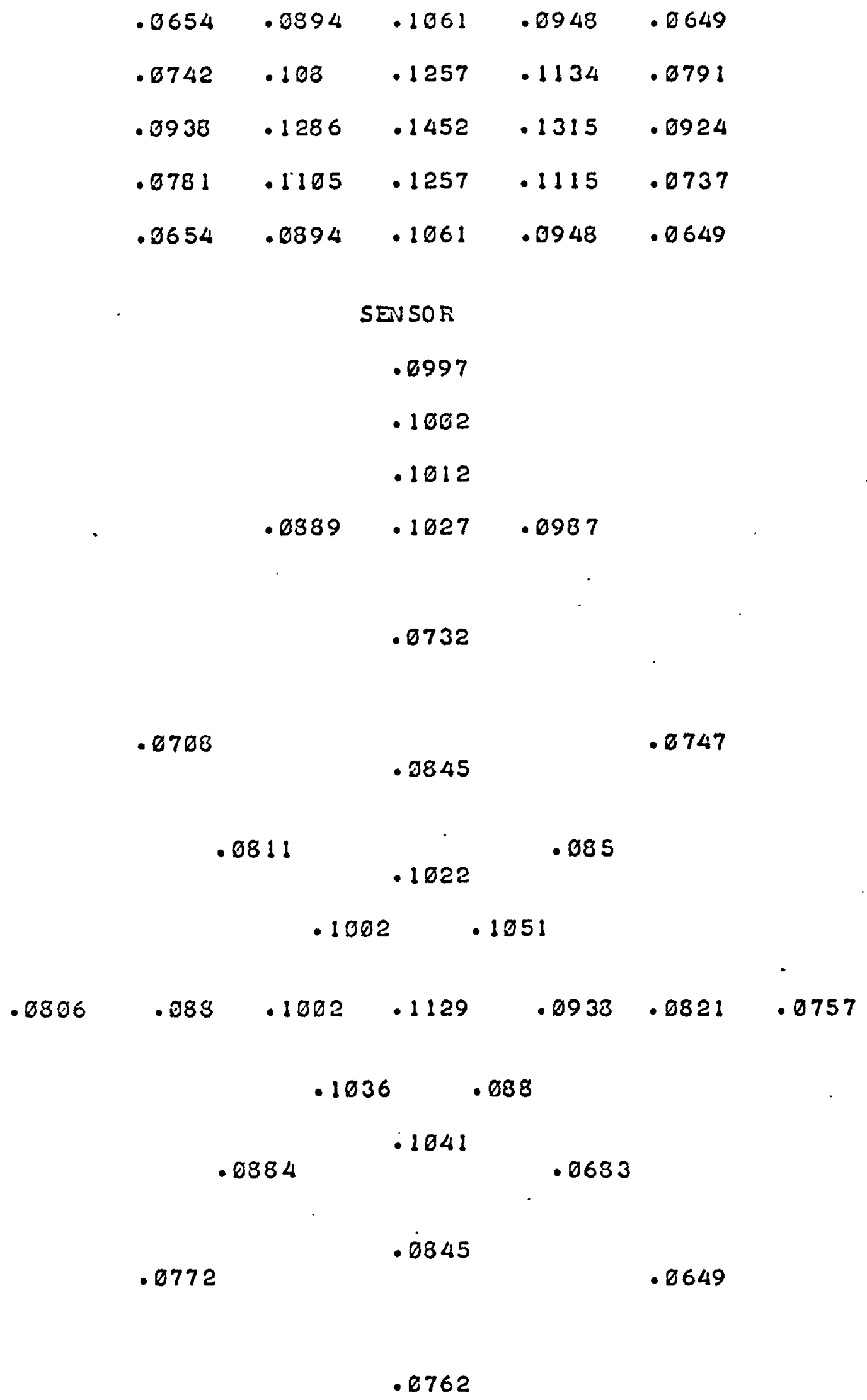

Figure 16a. $\theta^{\prime}$ Influence Coefficients for Run 7B x 48(1) - 106 
TE.T NOE

INELUENGE COEFICIEITS (AUTE. TEYP. TEF.)

$$
\begin{aligned}
& \begin{array}{lllll}
.0007 & .6327 & .1151 & .1828 & .202
\end{array} \\
& \begin{array}{lllll}
.003 & .034 & .1168 & .1635 & .1637
\end{array} \\
& \begin{array}{lllll}
.0194 & .0552 & .1623 & .2461 & .2397
\end{array} \\
& \begin{array}{lllll}
.0352 & .0464 & .1689 & .2587 & .2699
\end{array} \\
& \begin{array}{lllll}
.0007 & .0327 & .1151 & .1828 & .202
\end{array} \\
& \text { SES SOR } \\
& .8736 \\
& .0913 \\
& .0883 \\
& .0552 \quad .0817 \quad .1221
\end{aligned}
$$

.0172

.8033

$$
.93
$$

.068

$$
\begin{array}{cccc}
.0172 & & .0663 & .0883 \\
& .046 & .1405
\end{array}
$$

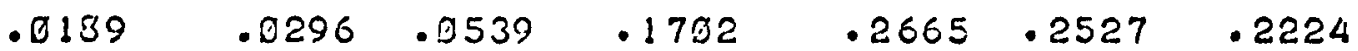

$$
\begin{aligned}
& .1142 \quad .3643 \\
& .0777 \quad .2509-.4843
\end{aligned}
$$
. 8495
.3972

.2734

$$
.2721
$$

Figure 16b. $\theta^{\prime}$ Influence Coefficients for Run $7 B \times 48$ (2) - 111 


\begin{tabular}{lllll}
\multicolumn{6}{c}{ INRUUNCE COEFEICIEJTS } & (AIE. TEIP. REF.) \\
.0816 & .1017 & .1875 & .0713 & .0214 \\
.0461 & .0794 & .1004 & .0637 & .0214 \\
.0699 & .116 & .1397 & .0906 & .038 \\
.0365 & .1339 & .1463 & .0397 & .0236 \\
.0816 & .1017 & .1075 & .0713 & .0214
\end{tabular}

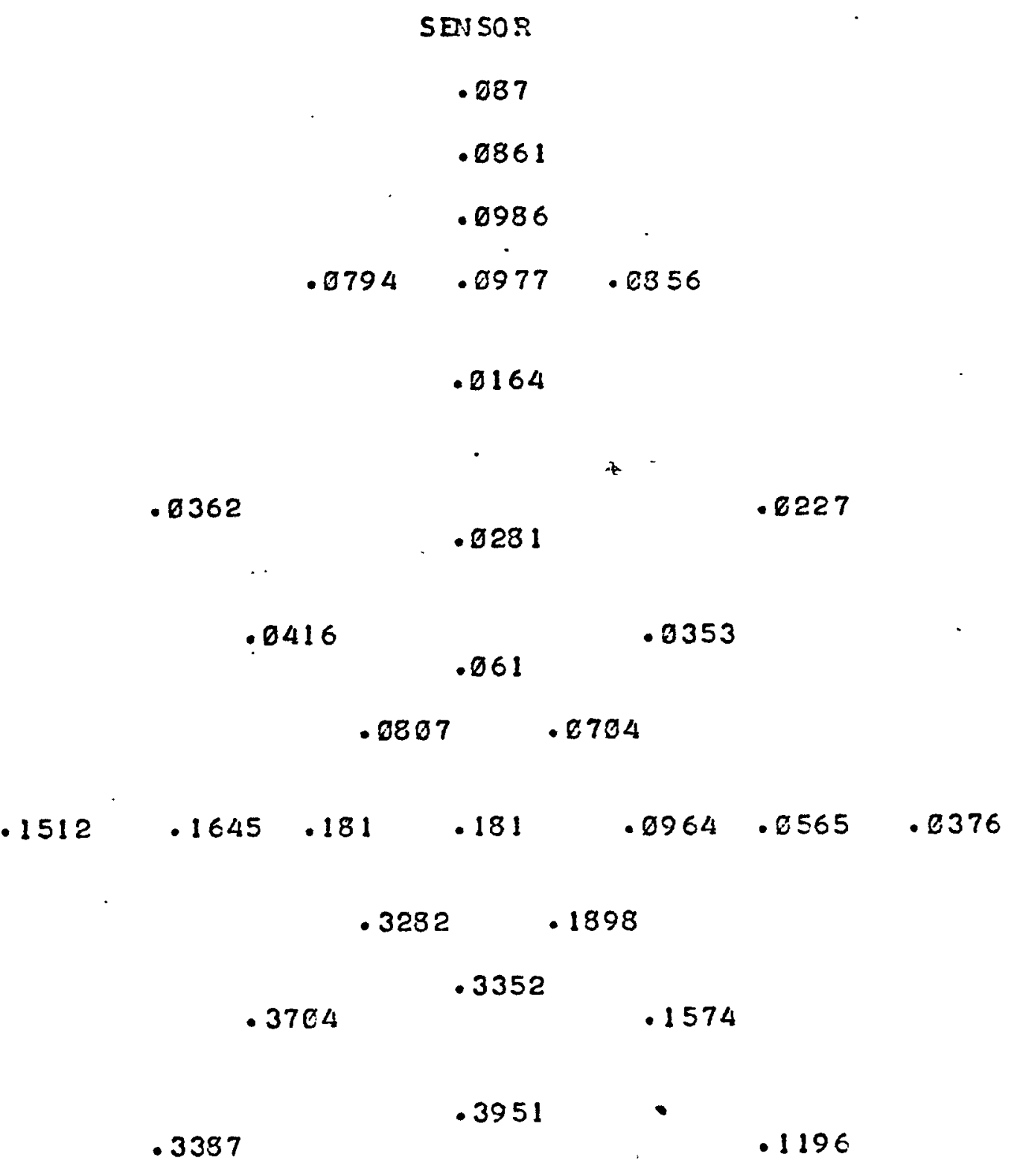

.4172

Figure 16c. $\theta^{\prime}$ Influence Coefficients for Run 7B x 48(3) -112 
INFLUMNE COEEFICIEITS (AMB. TEI?. REF.)

$$
\begin{array}{rrrrr}
.4222 & .3559 & .2263 & .0998 & .0127 \\
.3998 & .3269 & .1376 & .0723 & .0132 \\
.4547 & .3798 & .2147 & .092 & .0238 \\
.4689 & .3933 & .2039 & .0769 & .0123 \\
.4222 & .3589 & .2263 & .0998 & .0127
\end{array}
$$

\section{SES SOR}

.2434

.2293

.2463

$.2703 \quad .2612 \quad .1721$

$$
.0345
$$

.2084

$$
.0523
$$

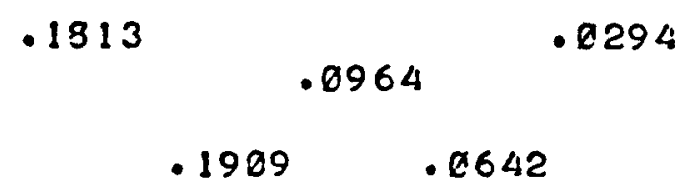

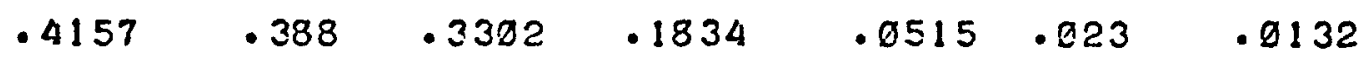

$\begin{array}{ccc} & .3075 & .0612 \\ .3466 & .1704 & \\ & & .0243\end{array}$

$$
.1203
$$

$$
.136
$$

$$
.8993
$$

Figure 16d. $\theta^{\prime}$ Influence Coefficients for Run 7B x 48(4) - 113 
TEST NO.: INFLUANCE COEFICI INTS (AME. TEMP. REF.)

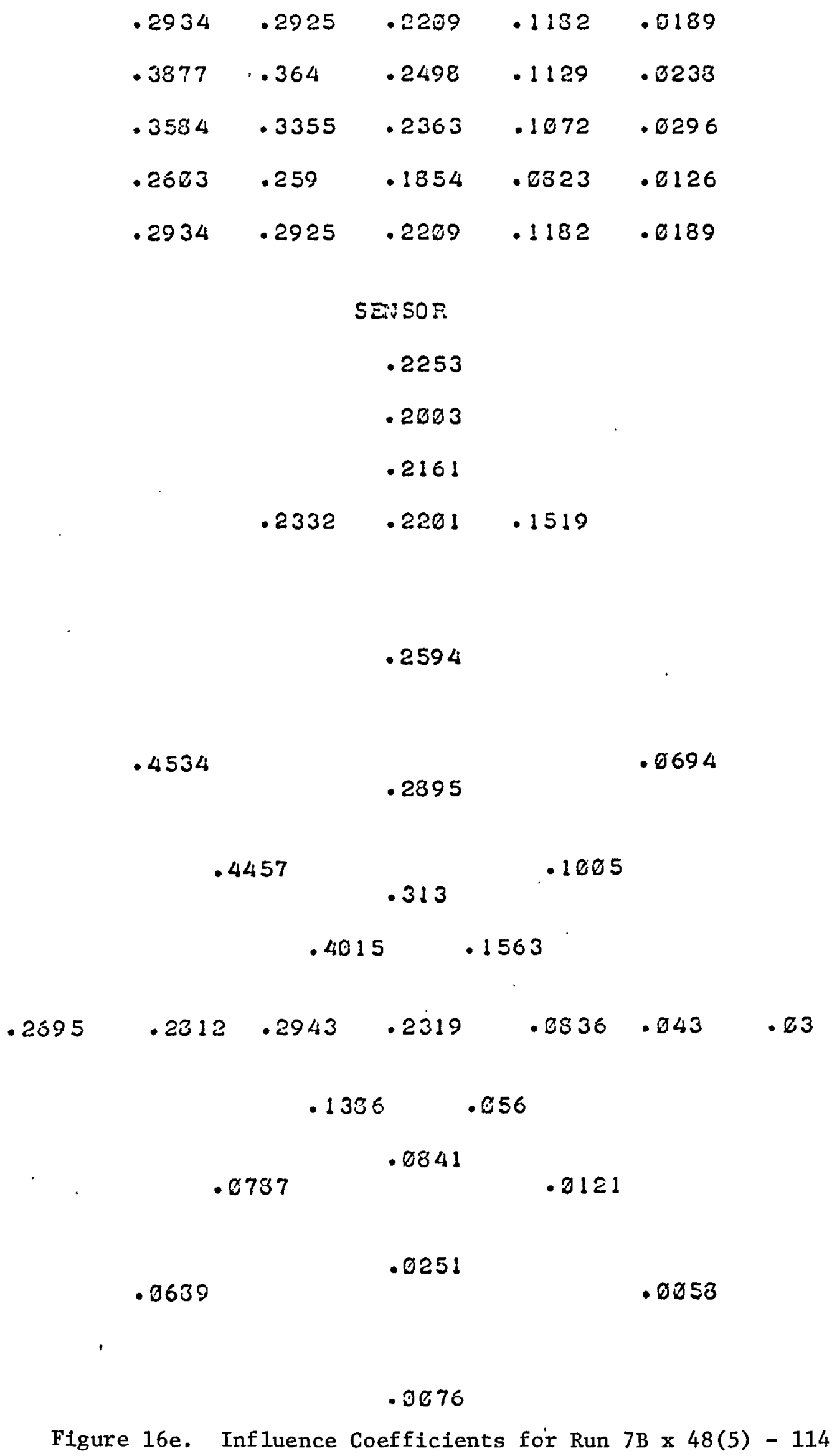


TEST NO.:

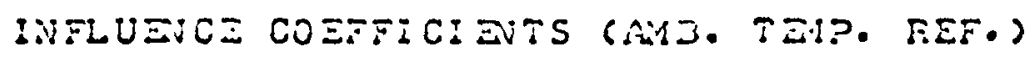

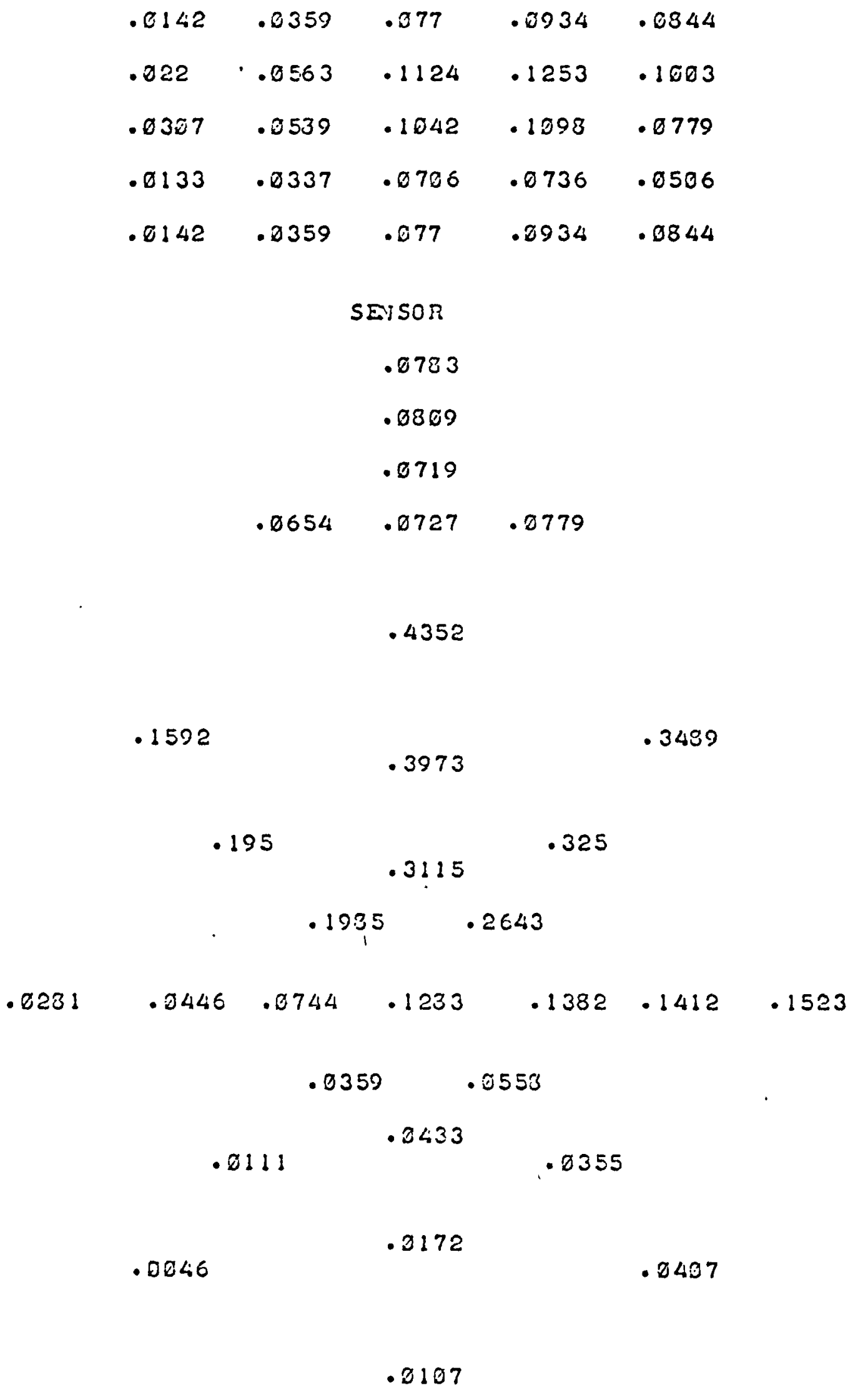

Figure 16f. $\theta^{\prime}$ Influence Coefficients for Run 7B x 48(6) -115 


$\begin{array}{lllll}\text { INILUENCE COEFFICIEITS (ANID. TEAP. RET.) } \\ . .0015 & .0346 & .1432 & .2895 & .4386 \\ .0024 & .0377 & .1614 & .342 & .4852 \\ .0179 & .0527 & .1766 & .3628 & .497 \\ .3233 & .0364 & .1631 & .3194 & .4436 \\ . .0215 & .0346 & .1432 & .2895 & .4386\end{array}$

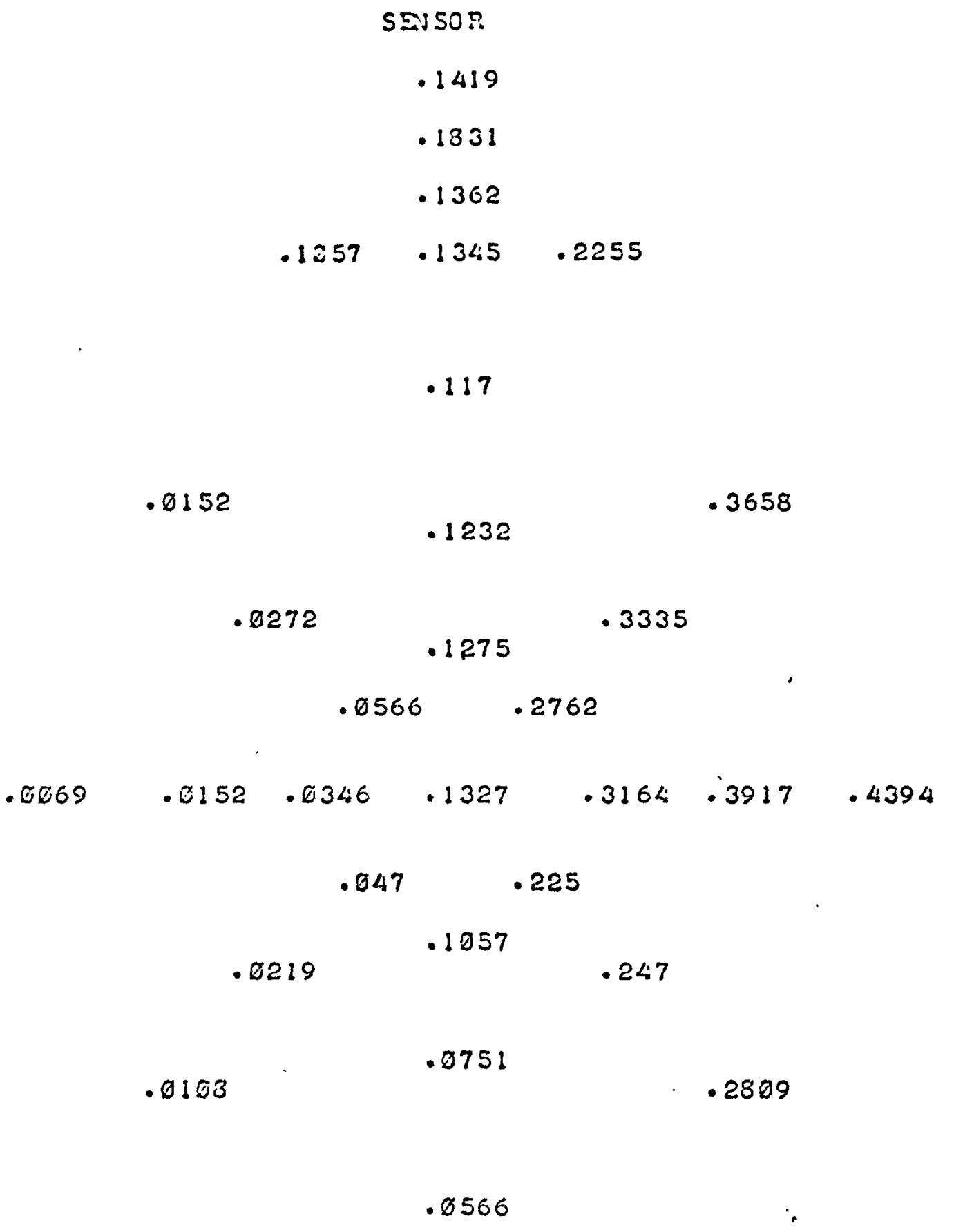

Figure 16g. $\theta^{\prime}$ Influence Coefficients for Run 7B x 48(7) - 119 


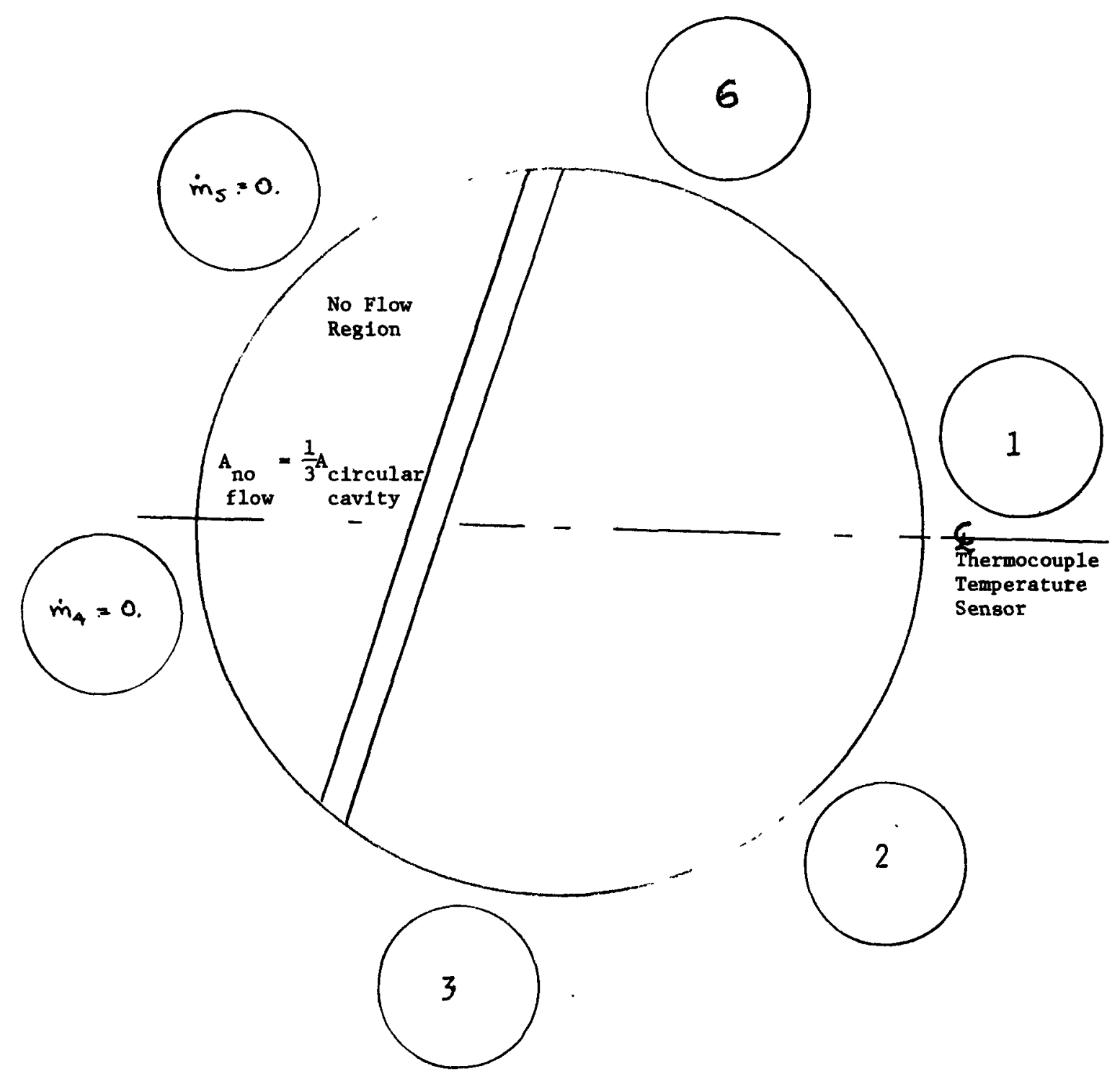

Note: The blocked-off section of the cavity may also be in other positions relative to the temperature sensor, e.g., columns 3 and 4 may be blocked in one section of the reactor core.

Figure 17. 5 Column Region CSB Mixing Cavity 


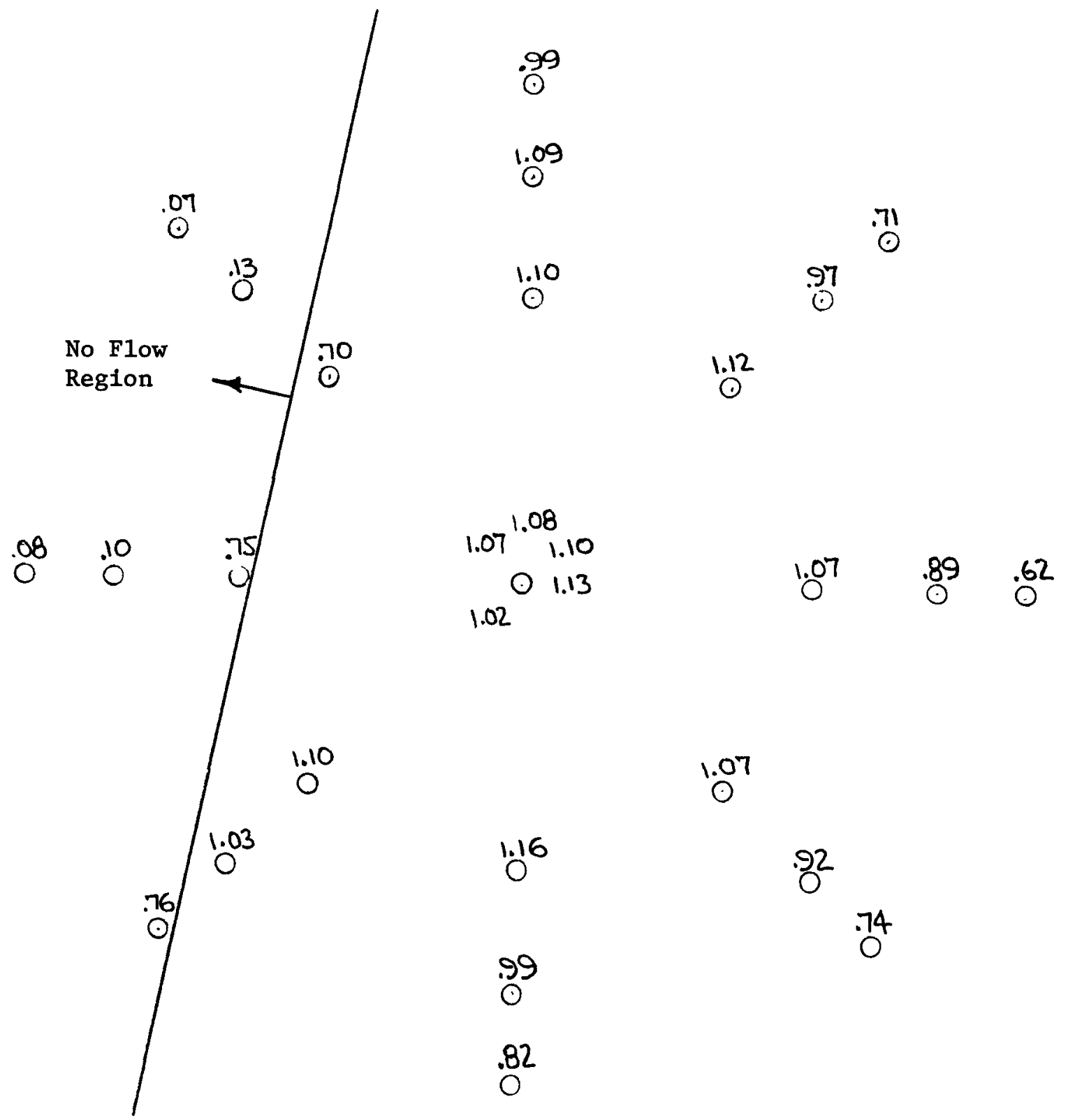

Figure 18. Normalized Velocity Traverse at 5-Column Region CSB Exit Plane with Modified Flow Area 
$7 B \times 48(3,2,4)-110$

INFLUENCE COEFFICIENTS (GUE. TEIP. REF.)

$\begin{array}{rrrrr}(.330) & (.331) & (.308) & (.237) & (.147) \\ .3255 & .3305 & .3021 & .2377 & .1492 \\ (.282) & (.291) & (.279) & (.205) & (.125) \\ .2803 & .2914 & .2741 & .2011 & .1254 \\ (.348) & (.371) & (.361) & (.279) & (.193) \\ .3377 & .3567 & .3361 & .2556 & .1797 \\ (.364) & (.392) & (.368) & (.286) & (.194) \\ .3639 & .385 & .3483 & .2724 & .191 \\ (.330) & (.331) & (.308) & (.237) & (.147) \\ .3255 & .3305 & .3021 & .2377 & .1492\end{array}$

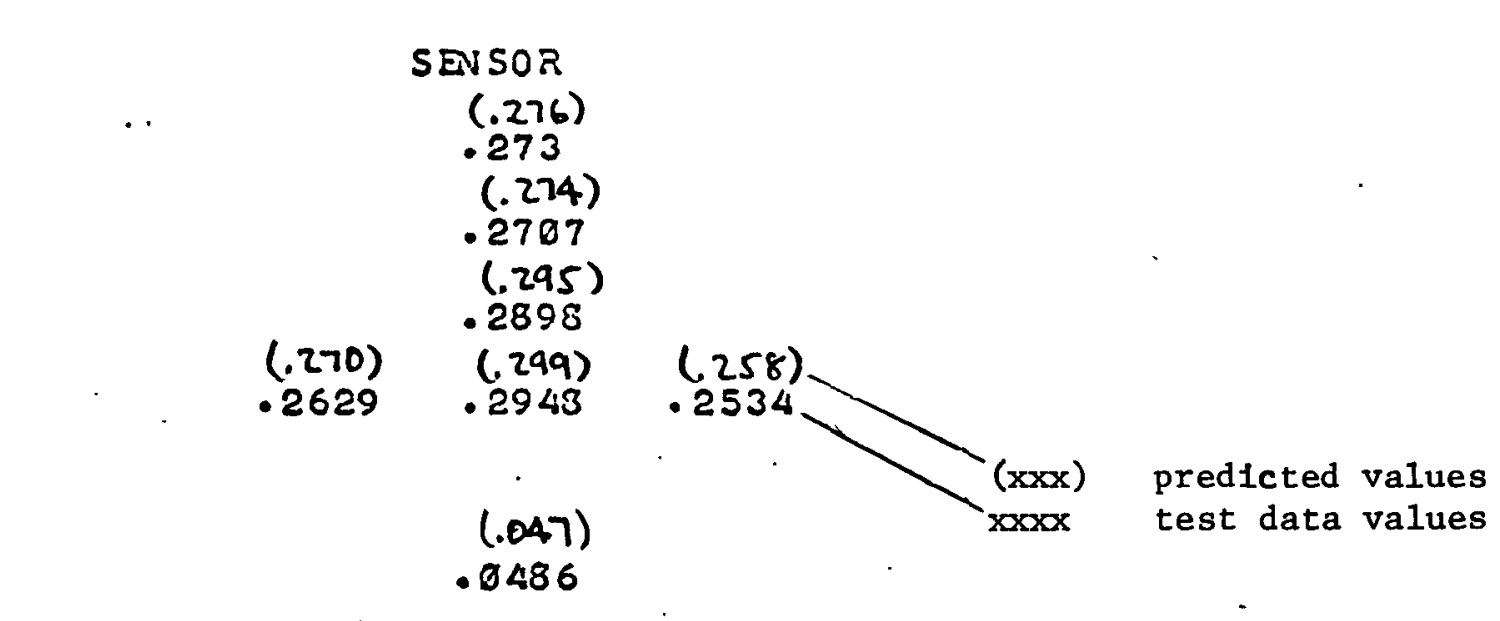
$(.163)$
.1565
(.076)
$(.071)$
.0754
.0726

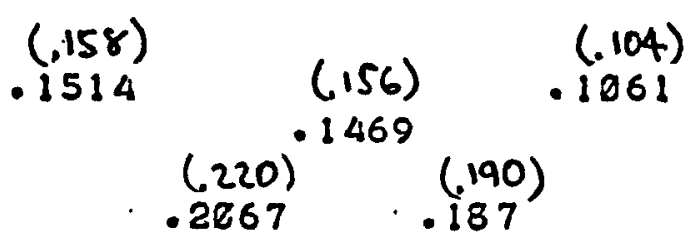

$\left.\begin{array}{lllllll}(.406) & (.409) & (406) & (.388) & (.283) & (.218) & (.176\end{array}\right)$

$\begin{array}{lllllll}.4082 & .4077 & .3966 & .3678 & .2763 & .2191 & .1786\end{array}$

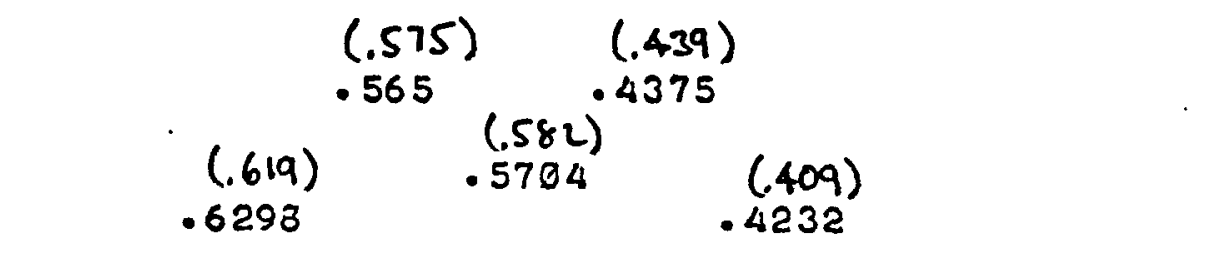

$(.591)$

.6195
$(.624)$
.6439

(360)

. 3778

$(.635)$

.6721

Figure 19. Multiple Heated Column Test Results and Predictions / 7B x 48(3,2,4) - 110 
INFLUENCE COEFFICIENTS (ANB. TEUP. P.EF.)

$\begin{array}{ccccc}(.010) & (.079) & (.269) & (.470) & (.626) \\ .0182 & .1049 & .3039 & .5162 & .6674 \\ (.019) & (.097) & (.311) & (.534) & (.658) \\ .023 & .1697 & .3364 & .5607 & .6917 \\ (.051) & (.127) & (.351) & (.591) & (.704) \\ .0396 & .1191 & .348 & .5858 & .7131 \\ (.015) & (.089) & (.317) & (.536) & (.653) \\ .0206 & .099 & .3242 & .5402 & .6714 \\ (.010) & (.079) & (.269) & (.470) & (.626) \\ .0182 & .1049 & .3039 & .5162 & .06674\end{array}$

SEN SOR

$(.244)$

. 2455

$(.296)$

. 2835

$(.241)$

.2496

$(.185) \quad(.235)$

.181

.2426

$(.356)$

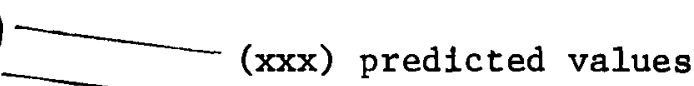

3637
$\mathrm{xxxx})$ predicted values
test data values

$(.412)$

. 3868

.$(.125)$

(.402)

$(.638)$

.1262

.3903

i 6623

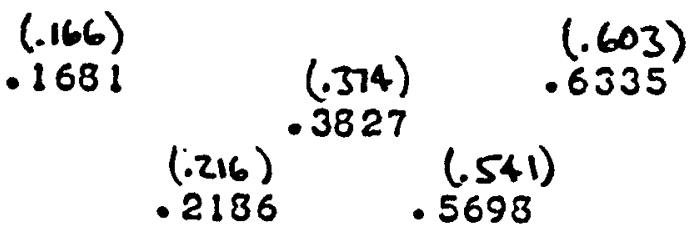

$(.038)$

$(.064)$

(.118) .0658 .1197

(.328)

$\begin{array}{ll}(.581) \quad(649) \quad(.684) & 0\end{array}$

.0444

$$
0658
$$

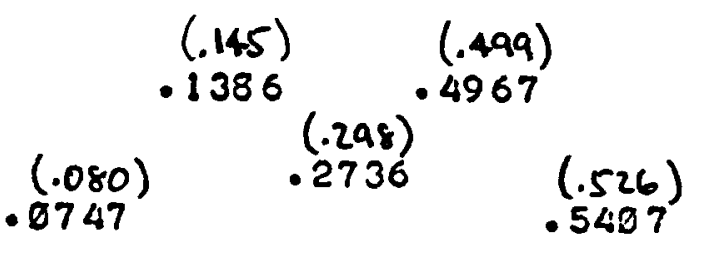

$\begin{array}{ccc}(.046) & (.263) & \\ .0474 & .2461 & (.567) \\ & & .5806\end{array}$

\section{$(.241)$ \\ .2356}

Figure 20. Multiple Heated Column Test Results and Predictions/ZB x 48(7,2,6) - 109 
TES: ivo.: $5 B \times 48(2,3,7)-129$

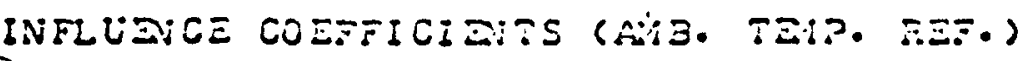
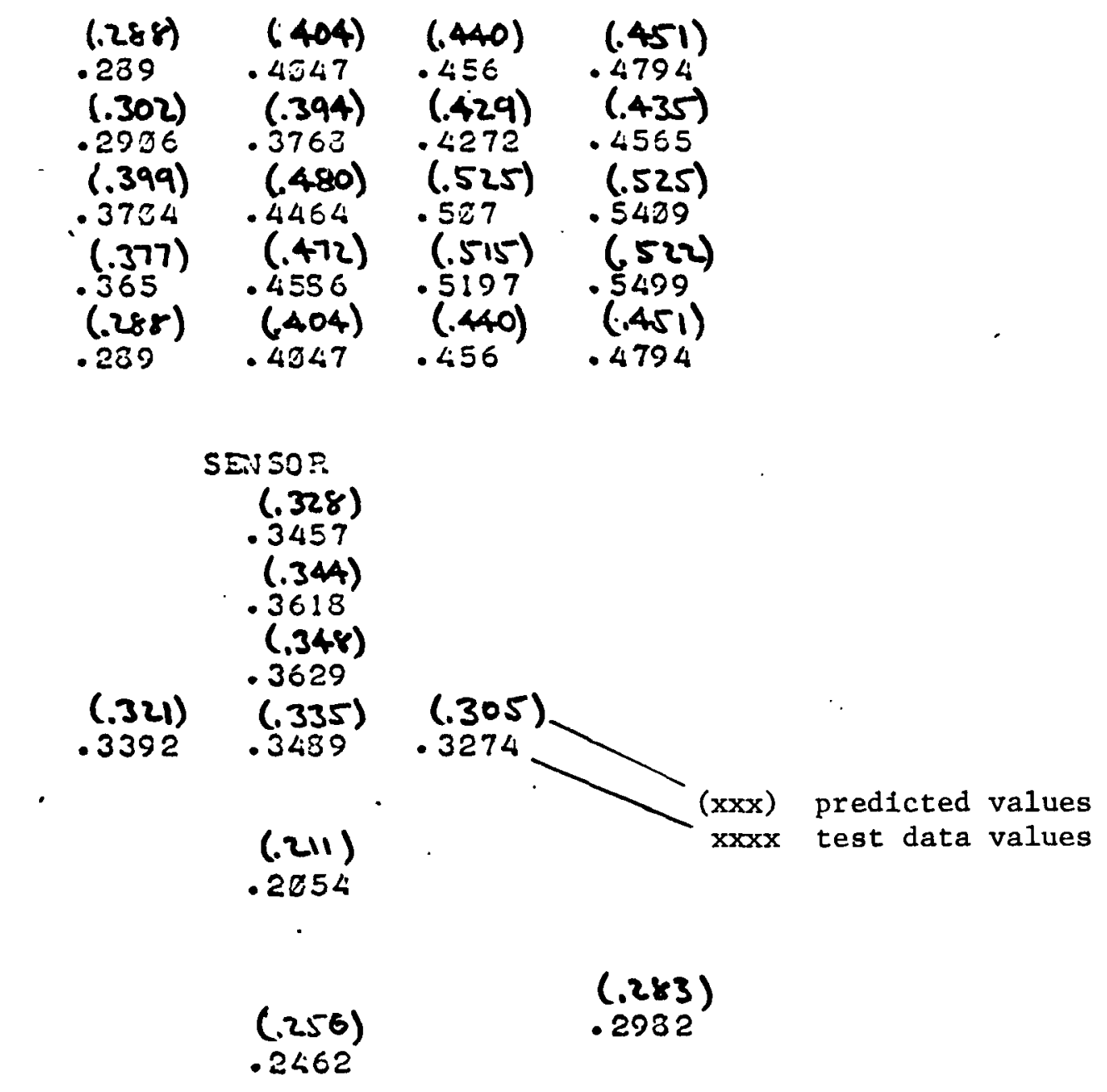

\section{$(.583)$}

.6105

gure 21. Multiple Heated Column Test Results and Predictions/5B x 48(2,3,7) - 129 


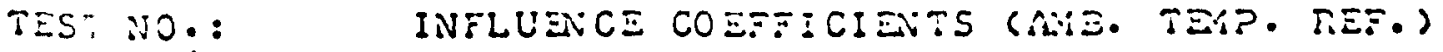

$58 \times 48(7,2,6)-127$

$\begin{array}{cccc}(.301) & (.445) & (597) & (.635) \\ .3115 & .506 & .631 ! & .6316 \\ (.324) & (.515) & (634) & (676) \\ .3292 & .513 & .6531 & .7178 \\ (.344) & (543) & (675) & (702) \\ .3524 & .5355 & .6737 & .7492 \\ (.282) & (482) & (.605) & (641) \\ .2999 & .4946 & .6275 & .6875 \\ (.301) & (485) & (597) & (635) \\ .3115 & .506 & .6311 & .6316\end{array}$

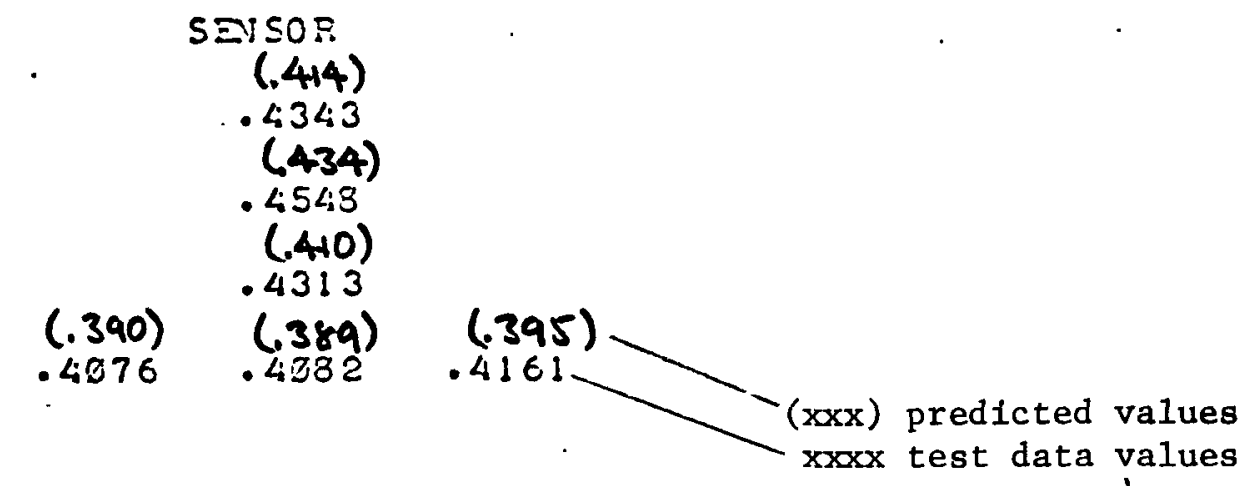

$(.585)$

.6055

(.578)

(637)

.5923

.6911

\section{$\begin{array}{ll}(.566) & (664) \\ .6875\end{array}$}

$(.490)^{.5774}(.643)$

$.4934 \quad .6614$

$\begin{array}{llll}(.520) & (650) & (673) & (690) \\ .5230 & .6753 & .7112 & .7331\end{array}$

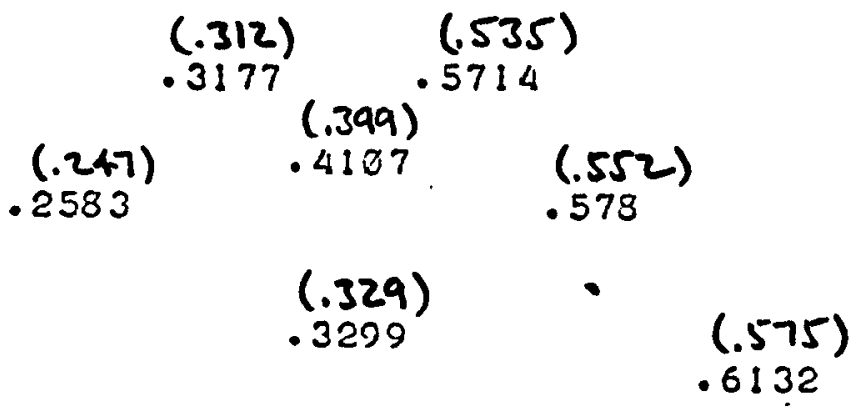

(.289)

.2816

F1gure 22. Multiple Heated Column Test Results and Predictions/5B x 48(7,2,6) - 127 
TABLE 1

SUMMARY OF SELECTED INFLUENCE COEFFICIENT SUMMATION, $\sum_{i}$

\begin{tabular}{|c|c|c|c|c|c|c|c|c|}
\hline CSB Config & $\begin{array}{c}\text { Flow } \\
\text { Rate } \\
\text { (1b/sec) }\end{array}$ & $\begin{array}{l}\text { Press. } \\
\text { Loss } \\
\text { Coeff. } \\
\text { Koverall }\end{array}$ & $\begin{array}{l}\theta_{\text {sens }}^{\prime} \\
\max / \min \\
\left(c_{i j}\right)\end{array}$ & $\begin{array}{l}{ }^{\theta} \text { ĆsBexit } \\
\max / \min \\
\left(C_{i j}\right)\end{array}$ & $\begin{array}{c}{ }^{\theta} \hat{E} \text { sleeve } \\
\max _{\left(A_{i j}\right)}\end{array}$ & $\begin{array}{c}\theta \hat{E} \underset{\min }{\min } \\
\left(A_{i j}\right)\end{array}$ & $\begin{array}{c}\theta_{\mathcal{E}} \dot{E} \text { spacer } \\
\left(A_{i j}\right)\end{array}$ & $\begin{array}{c}\theta^{\prime} \operatorname{spacer}_{B *} \\
\left(A_{i j}\right)\end{array}$ \\
\hline $7 \mathrm{AX} 53$ & 5. & $2.34 \pm 0.05$ & $1.141 / 0.920$ & $1.093 / 0.917$ & 1.141 & 1.037 & 1.073 & 1.074 \\
\hline $7 \mathrm{~B} \times 53$ & 5. & $3.56 \pm 0.09$ & $1.130 / 0.869$ & $1.076 / 0.884$ & 1.130 & 1.011 & 0.953 & 0.970 \\
\hline 7AZ41 & 5. & $2.29 \pm 0.06$ & $1.129 / 0.857$ & $1.158 / 0.908$ & 1.129 & 0.997 & 1.045 & 1.080 \\
\hline $7 \mathrm{BZ} 41$ & 5. & $3.69 \pm 0.09$ & $1.028 / 0.777$ & $1.070 / 0.882$ & 1.028 & 0.871 & 0.871 & 0.888 \\
\hline $7 \mathrm{AX} 48$ & 5. & $2.13 \pm 0.12$ & $1.119 / 0.834$ & $1.101 / 0.941$ & 1.119 & 1.012 & 1.003 & 1.009 \\
\hline $7 \mathrm{BX} 48$ & 5. & $3.57 \pm 0.08$ & $1.179 / 0.843$ & $1.140 / 0.923$ & 1.179 & 0.996 & 0.959 & 0.971 \\
\hline $5 A \times 53$ & 3.5 & $2.89 \pm 0.03$ & $0.989 / 0.874$ & $1.033 / 0.954$ & 0.988 & 0.905 & 0.840 & 0.838 \\
\hline $5 \mathrm{BX} 53$ & 3.5 & $4.39 \pm 0.07$ & $1.046 / 0.882$ & $1.031 / 0.888$ & 1.046 & 0.920 & 0.825 & 0.819 \\
\hline $5 B Z 41$ & 3.5 & $4.81 \pm 0.17$ & $1.095 / 0.831$ & $1.097 / 0.935$ & 1.043 & 0.907 & 0.840 & 0.847 \\
\hline $5 A X 48$ & 3.5 & $2.76 \pm 0.06$ & $1.023 / 0.867$ & $1.052 / 0.928$ & 1.023 & 0.897 & 0.766 & 0.759 \\
\hline $5 B \times 48$ & 3.5 & $4.35 \pm 0.11$ & $1.082 / 0.742$ & $1.072 / 0.934$ & 1.082 & 0.882 & 0.740 & 0.720 \\
\hline
\end{tabular}

* Refer to Figure 5 for locations $A$ and $B$. 
TABLE 2

SUMMARY OF SELECTED INFLUENCE COEFFICIENTS/52 ${ }^{\circ}$ MITER ANGLE

\begin{tabular}{|c|c|c|c|c|c|c|c|c|}
\hline $\begin{array}{l}\text { CSB Config/ } \\
\text { Test No. }\end{array}$ & $\begin{array}{c}\text { Flow } \\
\text { Rate } \\
\text { (1b/sec) }\end{array}$ & $\begin{array}{l}\text { Press. } \\
\text { Loss } \\
\text { Coeff. } \\
\text { Koverall }\end{array}$ & $\begin{array}{l}\theta_{\text {Sens }}^{\prime} \\
\max \\
(\mathrm{Cij})\end{array}$ & $\begin{array}{c}{ }^{\theta} \text { ĆsBexit } \\
\max \\
(\mathrm{C} i j)\end{array}$ & $\begin{array}{c}{ }^{\theta} E \text { sleeve } \\
\text { max } \\
(A 1 j)\end{array}$ & $\begin{array}{c}{ }^{\theta} \mathrm{E} \\
\text { min leeve } \\
(\mathrm{Aij})\end{array}$ & $\begin{array}{c}{ }^{\theta} \in \text { spacer } \\
(A i j)\end{array}$ & $\begin{array}{c}{ }^{\theta} \in \text { spacer }_{B} \\
(A i j)\end{array}$ \\
\hline $7 \mathrm{AX} 53(1)-20$ & 5.11 & 2.39 & 0.162 & 0.133 & 0.082 & 0.042 & 0.046 & 0.045 \\
\hline $7 \mathrm{AX} 53(2)-24$ & 5.09 & 2.41 & 0.276 & 0.577 & -0.026 & -0.074 & -0.042 & -0.045 \\
\hline $7 \mathrm{AX} 53(3)-18$ & 5.15 & 2.27 & 0.163 & 0.570 & -0.021 & -0.072 & -0.069 & -0.067 \\
\hline $7 \mathrm{AX} 53(4)-12$ & 5.15 & 2.39 & 0.548 & 0.513 & -0.041 & -0.064 & -0.031 & -0.005 \\
\hline $7 \mathrm{AX} 53(5)-13$ & 5.12 & 2.27 & 0.218 & 0.518 & -0.050 & -0.079 & -0.052 & -0.046 \\
\hline $7 \mathrm{AX} 53(6)-10$ & 5.11 & 2.34 & 0.117 & 0.502 & -0.037 & -0.073 & -0.078 & -0.081 \\
\hline $7 \mathrm{AX} 53(7)-15$ & 5.12 & 2.33 & 0.656 & 0.501 & 0.266 & 0.225 & 0.226 & 0.204 \\
\hline $7 \mathrm{AX} 48(1)-86$ & 4.86 & 2.22 & 0.163 & 0.131 & 0.084 & 0.047 & 0.037 & 0.037 \\
\hline $7 \mathrm{AX} 48(2)-87$ & 4.84 & 2.32 & 0.205 & 0.551 & -0.008 & -0.054 & -0.059 & -0.067 \\
\hline $7 \mathrm{AX} 48(3)-88$ & 4.81 & 2.18 & 0.129 & 0.544 & -0.025 & -0.077 & -0.072 & -0.077 \\
\hline $7 \mathrm{AX} 48(4)-91$ & 4.98 & 2.01 & 0.624 & 0.549 & 0.103 & 0.048 & 0.135 & 0.165 \\
\hline $7 \mathrm{AX} 48(5)-92$ & 5.00 & 2.00 & 0.258 & 0.552 & 0.027 & -0.031 & -0.021 & -0.021 \\
\hline $7 \mathrm{AX} 48(6)-93$ & 4.94 & 1.97 & 0.120 & 0.560 & -0.033 & -0.083 & -0.096 & -0.101 \\
\hline $7 \mathrm{AX} 48(7)-90$ & 4.97 & 2.18 & 0.627 & 0.526 & 0.079 & 0.055 & 0.092 & 0.087 \\
\hline $7 \mathrm{AZ} 41(1)-121$ & 4.99 & 2.40 & 0.163 & 0.150 & 0.085 & 0.044 & 0.005 & 0.007 \\
\hline $7 A Z 41(2)-122$ & 4.90 & 2.28 & 0.173 & 0.522 & -0.057 & -0.115 & -0.121 & -0.127 \\
\hline $7 \mathrm{AZ} 41(3)-123$ & 4.91 & 2.26 & 0.146 & 0.504 & -0.008 & -0.102 & -0.103 & -0.114 \\
\hline $7 A Z 41(4)-124$ & 4.92 & 2.23 & 0.771 & 0.663 & 0.162 & 0.069 & 0.262 & 0.292 \\
\hline
\end{tabular}


TABLE 3

SUMMARY OF SELECTED INFLUENCE COEFFICIENTS/70 MITER ANGLE

\begin{tabular}{|c|c|c|c|c|c|c|c|c|}
\hline $\begin{array}{l}\text { CSB Config/ } \\
\text { Test No. }\end{array}$ & $\begin{array}{c}\text { Flow } \\
\text { Rate } \\
\text { (1b/sec) }\end{array}$ & $\begin{array}{l}\text { Press. } \\
\text { Loss } \\
\text { Coeff. } \\
\text { Koverall }\end{array}$ & $\begin{array}{c}\theta_{\text {Sens }}^{\prime} \\
\max \\
(\mathrm{C} i j)\end{array}$ & $\begin{array}{c}{ }^{\theta} \max _{\max } \\
(\mathrm{C} i j)\end{array}$ & $\begin{array}{c}{ }^{\theta} \mathrm{E} \text { sleeve } \\
\max \\
(A 1 j)\end{array}$ & $\begin{array}{c}{ }^{\theta} \\
\text { min } \\
(\mathrm{A} \mathbf{i} j)\end{array}$ & $\begin{array}{c}\theta_{\mathcal{E}} \text { spacer } \\
(\mathrm{Aij})\end{array}$ & $\begin{array}{c}{ }^{\theta} E \text { spacer } \\
\text { (Aij) }\end{array}$ \\
\hline $7 \mathrm{BX} 53(1)-26$ & 5.03 & 3.76 & 0.150 & 0.123 & 0.069 & 0.029 & 0.019 & 0.022 \\
\hline $7 \mathrm{BX} 53(2)-27$ & 4.99 & 3.45 & 0.308 & 0.396 & 0.073 & 0.011 & -0.019 & -0.029 \\
\hline $7 \mathrm{BX} 53(3)-28$ & 4.96 & 3.49 & 0.112 & 0.414 & -0.062 & -0.105 & -0.095 & -0.091 \\
\hline $7 \mathrm{BX} 53(4)-29$ & 4.99 & 3.54 & 0.449 & 0.417 & 0.019 & -0.021 & 0.055 & 0.075 \\
\hline $7 \mathrm{BX} 53(5)-30$ & 5.02 & 3.57 & 0.311 & 0.413 & 0.023 & -0.026 & 0.021 & 0.031 \\
\hline $7 \mathrm{BX} 53(6)-31$ & 4.96 & 3.60 & 0.154 & 0.391 & -0.001 & -0.063 & -0.068 & -0.067 \\
\hline $7 \mathrm{BX} 53(7)-32$ & 4.94 & $\begin{array}{c}3.52 \\
3.56 \pm 0.09\end{array}$ & 0.454 & 0.384 & 0.090 & 0.069 & 0.023 & 0.015 \\
\hline $7 \mathrm{BX} 48(1)-106$ & 4.96 & 3.48 & 0.145 & 0.113 & 0.064 & 0.021 & 0.016 & 0.018 \\
\hline $7 \mathrm{BX} 48(2)-111$ & 5.06 & 3.53 & 0.270 & 0.405 & 0.016 & -0.048 & -0.080 & -0.088 \\
\hline $7 \mathrm{BX} 48(3)-112$ & 4.95 & 3.53 & 0.146 & 0.417 & -0.006 & -0.061 & -0.063 & -.064 \\
\hline $7 \mathrm{BX} 48(4)-113$ & 4.92 & 3.60 & 0.469 & 0.416 & 0.091 & 0.045 & 0.114 & 0.132 \\
\hline $7 B \times 48(5)-114$ & 4.92 & 3.56 & 0.388 & 0.453 & 0.113 & 0.036 & 0.073 & 0.077 \\
\hline $7 B \times 48(6)-115$ & 4.92 & 3.74 & 0.125 & 0.435 & -0.043 & -0.092 & -0.090 & -0.089 \\
\hline $7 \mathrm{BX} 48(7)-119$ & 4.81 & $\begin{array}{c}3.58 \\
3.57 \pm 0.08\end{array}$ & 0.497 & 0.439 & 0.029 & -0.011 & -0.019 & -0.021 \\
\hline $7 \mathrm{BZ} 41(1)-36$ & 5.15 & 3.86 & 0.149 & 0.112 & 0.067 & 0.024 & 0.022 & 0.025 \\
\hline $7 \mathrm{BZ} 41(2)-37$ & 5.05 & 3.56 & 0.276 & 0.440 & 0.082 & -0.038 & -0.017 & -0.032 \\
\hline $7 \mathrm{BZ} 41(3)-38$ & 5.05 & 3.68 & 0.120 & 0.514 & -0.042 & -0.123 & -0.111 & -0.113 \\
\hline $7 \mathrm{BZ} 41(4)-39$ & 5.06 & 3.64 & 0.629 & 0.479 & -0.014 & -0.062 & 0.075 & 0.110 \\
\hline $7 \mathrm{BZ} 41(5)-40$ & 5.06 & 3.76 & 0.276 & 0.454 & -0.025 & -0.086 & -0.044 & -0.037 \\
\hline $7 B Z 41(6)-41$ & 5.07 & 3.69 & 0.147 & 0.425 & -0.003 & -0.102 & -0.093 & -0.094 \\
\hline $7 B Z 41(7)-42$ & 5.03 & $\begin{array}{c}3.62 \\
3.69 \pm 0.09\end{array}$ & 0.653 & 0.501 & 0.103 & 0.042 & 0.023 & 0.016 \\
\hline
\end{tabular}


TABLE 4

SUMMARY OF MISCELLANEOUS SELECTED INFLUENCE COEFFICIENTS

\begin{tabular}{|c|c|c|c|c|c|c|c|c|c|}
\hline $\begin{array}{l}\text { CSB Config/ } \\
\text { Test No. }\end{array}$ & $\begin{array}{l}\text { Heated } \\
\text { Column } \\
\text { Flow Ratio } \\
\dot{\mathrm{m}}_{\mathrm{i}} / \dot{\mathrm{m}}_{\text {total }}\end{array}$ & $\begin{array}{c}\text { Flow } \\
\text { Rate } \\
\text { (lb/sec) }\end{array}$ & $\begin{array}{l}\text { Press. } \\
\text { Loss } \\
\text { Coeff. } \\
\text { Koverali }\end{array}$ & $\begin{array}{l}\theta_{\text {sens }}^{\prime} \\
\max \\
(C i j)\end{array}$ & 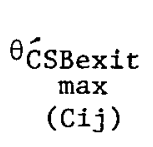 & $\begin{array}{c}\theta_{E} \max _{(\mathrm{A}} \text { sleeve } \\
(\mathrm{A})\end{array}$ & $\underset{\substack{{ }^{\theta} i n \\
(A i j)}}{\text { sleeve }}$ & ${ }^{{ }^{\theta}} \underset{\mathrm{A}}{\operatorname{Aij})}$ & $\begin{array}{c}{ }_{E}^{\theta} \underset{B}{\text { spacer }} \\
(A i j)\end{array}$ \\
\hline $7 A X 53(1)-6$ & 0.085 & 6.28 & 2.35 & 0.150 & 0.129 & 0.072 & 0.023 & 0.011 & 0.010 \\
\hline $7 \mathrm{AX} 53(2)-7$ & 0.155 & 6.23 & 2.23 & 0.324 & 0.564 & -0.047 & -0.090 & -0.059 & -0.066 \\
\hline $7 \mathrm{AX} 53(3)-9$ & 0.150 & 6.46 & 2.24 & 0.103 & 0.543 & -0.080 & -0.118 & -0.114 & -0.112 \\
\hline $7 \mathrm{AX} 53(2)-16$ & 0.155 & 5.13 & 2.38 & 0.283 & 0.566 & 0.019 & -0.031 & 0.054 & 0.046 \\
\hline $7 \mathrm{AX} 53(2)-25$ & 0.152 & 5.07 & 2.40 & 0.281 & 0.518 & -0.004 & -0.053 & -0.002 & -0.007 \\
\hline $7 \operatorname{Ax} 53(4)-11$ & 0.154 & 5.18 & 2.42 & 0.571 & 0.568 & -0.050 & -0.081 & -0.082 & -0.050 \\
\hline $7 \mathrm{AX53}(7)-14$ & 0.154 & 5.11 & 2.29 & 0.653 & 0.521 & 0.220 & 0.191 & 0.090 & 0.067 \\
\hline $7 A X 48(7)-89$ & 0.164 & 5.15 & 2.08 & 0.659 & 0.514 & 0.195 & 0.156 & 0.151 & 0.134 \\
\hline $7 \mathrm{AX} 48(1)-99$ & 0.086 & 1.75 & 2.20 & 0.162 & 0.144 & 0.082 & 0.061 & 0.054 & 0.055 \\
\hline $7 \mathrm{AX} 48(2)-100$ & 0.152 & 1.74 & 2.21 & 0.187 & 0.525 & -0.018 & -0.060 & -0.060 & -0.067 \\
\hline $7 \mathrm{AX} 48(3)-102$ & 0.149 & 1.74 & 2.14 & 0.128 & 0.545 & -0.024 & -0.066 & -0.045 & -0.049 \\
\hline $7 \mathrm{AX} 48(4)-101$ & 0.153 & 1.74 & 2.19 & 0.609 & 0.526 & 0.138 & 0.089 & 0.161 & 0.188 \\
\hline $7 \mathrm{BZ} 41(1)-48$ & 0.086 & 1.71 & 3.75 & 0.148 & 0.130 & 0.068 & 0.046 & 0.032 & 0.034 \\
\hline $7 \mathrm{BZ} 41(2)-49$ & 0.151 & 1.70 & 3.52 & 0.301 & 0.429 & 0.078 & -0.008 & 0.001 & -0.014 \\
\hline $7 \mathrm{BZ} 41(3)-50$ & 0.154 & 1.75 & 3.64 & 0.134 & 0.478 & -0.023 & -0.101 & -0.071 & -0.073 \\
\hline $7 B Z 41(4)-51$ & 0.155 & 1.75 & 3.77 & 0.630 & 0.495 & 0.021 & -0.023 & 0.061 & 0.095 \\
\hline $7 \mathrm{BZ} 41(4)-52$ & 0.172 & 1.76 & 3.76 & 0.676 & 0.514 & 0.073 & 0.013 & 0.094 & 0.129 \\
\hline $7 B Z 41(4)-53$ & 0.142 & 1.77 & 3.53 & 0.575 & 0.462 & -0.025 & -0.060 & 0.026 & 0.057 \\
\hline $7 \mathrm{BZ} 41(1)-143$ & 0.076 & 4.81 & 4.05 & 0.119 & 0.098 & 0.047 & 0.005 & -0.003 & -0.004 \\
\hline $7 \mathrm{BZ} 41(1)-144$ & 0.094 & 4.86 & 4.09 & 0.147 & 0.129 & 0.058 & 0.014 & 0.003 & 0.002 \\
\hline $7 \mathrm{BZ} 41(2)-147$ & 0.133 & 5.03 & 3.64 & 0.190 & 0.429 & -0.032 & -0.087 & -0.075 & -0.080 \\
\hline $7 \mathrm{BZ} 41(2)-148$ & 0.175 & 5.12 & 3.66 & 0.372 & 0.452 & 0.140 & 0.007 & -0.044 & -0.066 \\
\hline $7 \mathrm{BZ} 41(3)-149$ & 0.174 & 5.07 & 3.60 & 0.197 & 0.505 & 0.029 & -0.093 & -0.059 & -0.071 \\
\hline
\end{tabular}


TABLE 5

SUMMARY OF SELECTED INFLUENCE COEFFICIENTS/5-COLUMN REGIONS

\begin{tabular}{|c|c|c|c|c|c|c|c|c|}
\hline $\begin{array}{l}\text { CSB Config/ } \\
\text { Test No. }\end{array}$ & $\begin{array}{c}\text { Flow } \\
\text { Rate } \\
\text { (1b/sec) }\end{array}$ & $\begin{array}{l}\text { Press. } \\
\text { Loss } \\
\text { Coeff. } \\
\text { Koverall } \\
\end{array}$ & $\begin{array}{c}\theta_{\text {sens }}^{\prime} \\
\max \\
(\mathrm{Cij})\end{array}$ & $\begin{array}{c}{ }^{\theta}{ }_{\max }^{\mathrm{CSBexit}} \\
(\mathrm{C} i \mathrm{j}) \\
\end{array}$ & $\begin{array}{c}{ }^{\theta_{\mathrm{E}}} \begin{array}{l}\text { sleeve } \\
\max \\
(\mathrm{A} i \mathrm{j})\end{array} \\
\end{array}$ & $\begin{array}{c}\theta_{\mathrm{E}} \mathrm{c}_{\mathrm{min}} \\
(\mathrm{A} i \mathrm{j}) \\
\end{array}$ & $\begin{array}{c}\theta_{\mathrm{E}} \text { spacer } \\
\mathrm{A} \\
(\mathrm{A} i \mathrm{j})\end{array}$ & $\begin{array}{c}{ }^{\theta} \mathrm{E} \text { spacer } \\
\mathrm{B} \\
(\mathrm{Aij})\end{array}$ \\
\hline $5 A \times 53(1)-65$ & 3.42 & 2.92 & 0.184 & 0.170 & 0.058 & 0.012 & -0.013 & -0.012 \\
\hline $5 A \times 53(2)-66$ & 3.44 & 2.87 & 0.266 & 0.516 & -0.021 & -0.094 & -0.037 & -0.042 \\
\hline $5 \mathrm{AX} 53(3)-67$ & 3.39 & 2.92 & 0.234 & 0.630 & -0.109 & -0.169 & -0.176 & -0.166 \\
\hline $5 \operatorname{Ax} 53(6)-68$ & 3.39 & 2.90 & 0.217 & 0.523 & 0.0 & -0.098 & -0.134 & -0.131 \\
\hline $5 A \times 53(7)-69$ & 3.42 & $\begin{array}{c}2.83 \\
2.89 \pm 0.03\end{array}$ & 0.576 & 0.431 & 0.169 & 0.110 & 0.165 & 0.153 \\
\hline $5 A \times 48(1)-135$ & 3.51 & 2.88 & 0.194 & 0.195 & 0.079 & 0.027 & -0.001 & -0.004 \\
\hline $5 A \times 48(2)-136$ & 3.51 & 2.77 & 0.181 & 0.493 & -0.057 & -0.151 & -0.118 & -0.127 \\
\hline $5 \mathrm{AX} 48(3)-137$ & 3.46 & 2.72 & 0.301 & 0.601 & -0.010 & -0.121 & -0.143 & -0.140 \\
\hline $5 \mathrm{AX} 48(6)-139$ & 3.51 & 2.71 & 0.196 & 0.504 & -0.027 & -0.141 & -0.163 & -0.164 \\
\hline $5 \mathrm{AX} 48(7)-138$ & 3.53 & $\begin{array}{c}2.74 \\
2.76 \pm 0.06 \\
\end{array}$ & 0.642 & 0.498 & 0.175 & 0.110 & 0.149 & 0.136 \\
\hline $5 B \times 53(1)-57$ & 3.46 & 4.53 & 0.177 & 0.154 & 0.062 & 0.016 & -0.006 & -0.005 \\
\hline $5 B \times 53(2)-58$ & 3.46 & 4.37 & 0.336 & 0.389 & 0.061 & -0.003 & 0.014 & -0.001 \\
\hline $5 B \times 53(3)-60$ & 3.46 & 4.33 & 0.286 & 0.461 & -0.039 & -0.115 & -0.156 & -0.146 \\
\hline $5 \mathrm{~B} \times 53(6)-61$ & 3.48 & 4.36 & 0.281 & 0.549 & 0.012 & -0.084 & -0.118 & -0.112 \\
\hline $5 B \times 53(7)-62$ & 3.50 & $\begin{array}{c}4.37 \\
4.39 \pm 0.07\end{array}$ & 0.424 & 0.370 & 0.033 & -0.023 & 0.038 & 0.029 \\
\hline $5 B \times 48(1)-130$ & 3.60 & 4.50 & 0.181 & 0.155 & 0.064 & 0.013 & -0.004 & -0.007 \\
\hline $5 \mathrm{BX} 48(2)-131$ & 3.58 & 4.27 & 0.259 & 0.386 & -0.027 & -0.101 & -0.102 & -0.114 \\
\hline $5 B \times 48(3)-132$ & 3.56 & 4.26 & 0.363 & 0.554 & 0.004 & -0.091 & -0.129 & -0.118 \\
\hline $5 B \times 48(6)-133$ & 3.49 & 4.26 & 0.234 & 0.552 & 0.021 & -0.100 & -0.132 & -0.136 \\
\hline $5 B \times 48(7)-134$ & 3.49 & $\begin{array}{c}4.46 \\
4.35 \pm 0.11 \\
\end{array}$ & 0.493 & 0.421 & 0.088 & 0.063 & 0.029 & 0.013 \\
\hline $5 B Z 41(1)-72$ & 3.50 & 4.99 & 0.168 & 0.149 & 0.044 & -0.011 & -0.036 & -0.035 \\
\hline $5 B Z 41(2)-73$ & 3.49 & 4.91 & 0.265 & 0.467 & 0.015 & -0.037 & -0.036 & -0.053 \\
\hline $5 B Z 41(3)-74$ & 3.42 & 4.84 & 0.374 & 0.476 & -0.124 & -0.197 & -0.188 & -0.149 \\
\hline $5 B Z 41(6)-75$ & 3.45 & 4.81 & 0.292 & 0.645 & 0.022 & -0.158 & -0.166 & -0.159 \\
\hline $5 B Z 41(7)-77$ & 3.47 & $\begin{array}{c}4.48 \\
4.81 \pm 0.17\end{array}$ & 0.667 & 0.441 & 0.202 & 0.122 & 0.215 & 0.200 \\
\hline
\end{tabular}


TABLE 6

SUMMARY OF MULTIPLE-HEATED COL. INFLUENCE COEFFICIENTS/7-COLUMN REGIONS

\begin{tabular}{|c|c|c|c|c|c|c|c|c|c|c|}
\hline $\begin{array}{l}\text { CSB Config./ } \\
\text { Test No. }\end{array}$ & $\begin{array}{c}\text { Flow } \\
\text { Rate } \\
\text { (1b/sec) }\end{array}$ & $\begin{array}{l}\text { Press. } \\
\text { Loss } \\
\text { Coeff. } \\
\text { Koverall }\end{array}$ & $\begin{array}{l}\theta_{\text {sens }}^{\prime} \\
\max \\
(\mathrm{C} i j)\end{array}$ & $\begin{array}{c}\theta_{\max }^{\theta^{-}} \\
(\mathrm{C} i j)\end{array}$ & $\begin{array}{c}\theta_{\hat{E}}^{-} \underset{A}{\text { spacer }} \\
(C i j)\end{array}$ & $\begin{array}{c}\theta^{\theta} \dot{E} \\
\text { spacer } \\
(\mathrm{C} i j)\end{array}$ & ${ }^{\theta} \in \underset{\max }{\underset{\max }{\text { sleeve }}}$ & 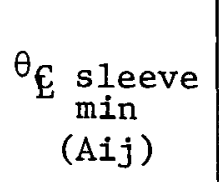 & 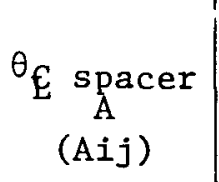 & $\begin{array}{c}{ }_{E}^{\theta} \underset{B}{\text { spacer }} \\
(A i j)\end{array}$ \\
\hline \multirow{2}{*}{$7 \mathrm{AX5} 3(2,7,6)-23$} & 4.74 & 2.33 & 0.819 & 0.784 & 0.492 & 0.466 & 0.283 & 0.235 & 0.195 & 0.152 \\
\hline & \multicolumn{2}{|c|}{ Prediction } & $(0.852)$ & $(0.773)$ & $(0.540)$ & $(0.515)$ & & & & \\
\hline \multirow{2}{*}{$7 \mathrm{BX} 53(7,2,6)-33$} & 4.77 & 3.52 & 0.776 & 0.733 & 0.399 & 0.382 & 0.226 & 0.191 & 0.068 & 0.042 \\
\hline & \multicolumn{2}{|c|}{ Prediction } & $(0.704)$ & $(0.655)$ & $(0.325)$ & $(0.313)$ & & & & \\
\hline \multirow[t]{2}{*}{$7 \mathrm{BX} 53(3,2,4)-34$} & 4.79 & 3.49 & 0.369 & 0.666 & 0.251 & 0.261 & -0.068 & -0.166 & -0.121 & -0.107 \\
\hline & \multicolumn{2}{|c|}{ Prediction } & $(0.369)$ & $(0.614)$ & $(0.272)$ & $(0.280)$ & & & & \\
\hline $7 \mathrm{BX} 53(3,2,4)-35$ & 4.82 & 3.51 & 0.370 & 0.664 & 0.230 & 0.239 & -0.103 & -0.200 & -0.144 & -0.131 \\
\hline \multirow[t]{2}{*}{$7 \mathrm{AX} 48(7,2,6)-95$} & 5.01 & 2.06 & 0.787 & 0.781 & 0.351 & 0.340 & 0.057 & 0.006 & 0.011 & -0.005 \\
\hline & \multicolumn{2}{|c|}{ Prediction } & $(0.750)$ & $(0.728)$ & $(0.336)$ & $(0.325)$ & & & & \\
\hline \multirow[t]{2}{*}{$7 \mathrm{AX} 48(7,2,6)-103$} & 1.52 & 2.18 & 0.713 & 0.707 & 0.265 & 0.256 & 0.048 & -0.015 & -0.052 & -0.065 \\
\hline & \multicolumn{2}{|c|}{ Prediction } & $(0.719)$ & $(0.678)$ & $(0.312)$ & $(0.302)$ & & & & \\
\hline \multirow[t]{2}{*}{$7 \mathrm{AX} 48(3,2,4)-98$} & 4.94 & 2.08 & 0.424 & 0.749 & 0.271 & 0.276 & -0.044 & -0.161 & -0.101 & -0.094 \\
\hline & \multicolumn{2}{|c|}{ Prediction } & $(0.433)$ & $(0.762)$ & $(0.319)$ & $(0.327)$ & & & & \\
\hline \multirow[t]{2}{*}{$7 \mathrm{BX} 48(7,2,6)-109$} & 4.87 & 3.49 & 0.713 & 0.719 & 0.250 & 0.243 & -0.006 & -0.074 & -0.158 & -0.169 \\
\hline & \multicolumn{2}{|c|}{ Prediction } & $(0.704)$ & $(0.684)$ & $(0.241)$ & $(0.235)$ & & & & \\
\hline \multirow[t]{2}{*}{$7 \mathrm{BX} 48(3,2,4)-110$} & 4.89 & 3.52 & 0.385 & 0.672 & 0.290 & 0.295 & 0.032 & -0.078 & -0.055 & -0.047 \\
\hline & \multicolumn{2}{|c|}{ Prediction } & $(0.392)$ & $(0.635)$ & $(0.295)$ & $(0.299)$ & & & & \\
\hline \multirow[t]{2}{*}{$7 \mathrm{BX} 48(6,2,7)-107$} & 4.87 & 3.51 & 0.522 & 0.654 & 0.216 & 0.212 & -0.051 & -0.111 & -0.176 & -0.184 \\
\hline & \multicolumn{2}{|c|}{ Prediction } & $(0.558)$ & $(0.614)$ & $(0.208)$ & $(0.204)$ & & & & \\
\hline
\end{tabular}


TABLE 6 (Continued)

\begin{tabular}{|c|c|c|c|c|c|c|c|c|c|c|}
\hline $\begin{array}{l}\text { CSB Config./ } \\
\text { Test No. }\end{array}$ & $\begin{array}{c}\text { F1ow } \\
\text { Rate } \\
(1 \mathrm{~b} / \mathrm{sec})\end{array}$ & $\begin{array}{l}\text { Press. } \\
\text { Loss } \\
\text { Coeff. } \\
\text { Kovera11 }\end{array}$ & $\begin{array}{c}\theta_{\text {sens }}^{\prime} \\
\max \\
(\mathrm{Cij})\end{array}$ & $\begin{array}{c}\theta_{\text {max }}^{\text {CSBexit }} \\
(\mathrm{Cij})\end{array}$ & 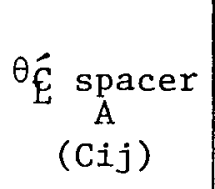 & $\begin{array}{c}{ }^{\theta} \hat{E} \underset{B}{\text { spacer }} \\
(A i j)\end{array}$ & 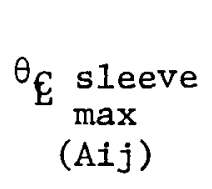 & 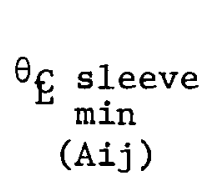 & ${ }^{\theta}{ }_{E} \operatorname{spacer}_{(A i j)}$ & $\begin{array}{c}\theta_{\mathrm{E}} \text { spacer } \\
(\mathrm{Aij})\end{array}$ \\
\hline $7 \mathrm{AZ} 41(7,2,6)-125$ & $\begin{array}{l}5.02 \\
\text { Predi } \\
\text { (Modi }\end{array}$ & $\begin{array}{l}2.37 \\
\text { ction } \\
\text { fied) }\end{array}$ & $\begin{array}{c}0.817 \\
(0.822)\end{array}$ & $\begin{array}{c}0.801 \\
(0.809)\end{array}$ & $\begin{array}{c}0.255 \\
(0.447)\end{array}$ & $\begin{array}{c}0.251 \\
(0.460)\end{array}$ & -0.079 & -0.151 & -0.146 & -0.151 \\
\hline $7 B Z 41(3,2,4)-43$ & $\begin{array}{l}4.85 \\
\text { Predi }\end{array}$ & $\begin{array}{l}3.76 \\
\text { ction }\end{array}$ & $\begin{array}{c}0.445 \\
(0.440)\end{array}$ & $\begin{array}{c}0.717 \\
(0.694)\end{array}$ & $\begin{array}{c}0.263 \\
(0.273)\end{array}$ & $\begin{array}{c}0.273 \\
(0.283)\end{array}$ & -0.034 & -0.223 & -0.100 & -0.086 \\
\hline $7 B Z 41(7,2,6)-44$ & $\begin{array}{l}4.85 \\
\text { Predi }\end{array}$ & $\begin{array}{l}3.56 \\
\text { tion }\end{array}$ & $\begin{array}{c}0.821 \\
(0.731)\end{array}$ & $\begin{array}{c}0.753 \\
(0.702)\end{array}$ & $\begin{array}{c}0.403 \\
(0.292)\end{array}$ & $\begin{array}{c}0.383 \\
(0.278)\end{array}$ & 0.223 & 0.149 & 0.106 & 0.076 \\
\hline $7 B Z 41(7,2,6)-46$ & 1.55 & 3.47 & 0.820 & 0.767 & 0.406 & 0.387 & 0.212 & 0.149 & 0.100 & 0.072 \\
\hline
\end{tabular}


TABLE 7

SUMMARY OF MULTIPLE-HEATED COL. INFLUENCE COEFFICIENTS/5-COLUMN REGIONS

\begin{tabular}{|c|c|c|c|c|c|c|c|c|c|c|}
\hline $\begin{array}{l}\text { CSB Config./ } \\
\text { Test No. }\end{array}$ & $\begin{array}{c}\text { F1ow } \\
\text { Rate } \\
\text { (1b/sec) }\end{array}$ & $\begin{array}{l}\text { Press. } \\
\text { Loss } \\
\text { Coeff. } \\
\text { Koverall }\end{array}$ & $\begin{array}{l}\theta_{\text {sens }}^{-} \\
\max \\
(C i j)\end{array}$ & $\begin{array}{c}{ }^{\theta}{ }_{\max }^{\operatorname{CSBexit}} \\
(\text { Cij) }\end{array}$ & $\begin{array}{c}\theta^{\theta} \bar{E} \text { spacer } \\
(C i j)\end{array}$ & $\begin{array}{c}\theta^{\theta} \underset{\mathrm{E}}{\operatorname{E}} \text { spacer } \\
(\mathrm{C} i j)\end{array}$ & $\begin{array}{c}{ }^{\theta} \in \operatorname{sleeve}_{\max } \\
(A i j)\end{array}$ & ${ }^{\theta} \mathrm{E} \underset{\text { min }}{\text { sleeve }}$ & ${ }_{\mathrm{E}}^{\theta_{\mathrm{E}} \underset{\mathrm{A} i j)}{\text { spacer }}}$ & $\begin{array}{c}{ }^{\theta} \mathcal{E}_{B} \text { spacer } \\
(A i j)\end{array}$ \\
\hline \multirow[t]{2}{*}{$5 \operatorname{AX} 53(7,2,6)-71$} & 3.43 & 2.86 & 0.771 & 0.415 & 0.571 & 0.562 & 0.159 & 0.063 & 0.145 & 0.126 \\
\hline & \multicolumn{2}{|c|}{ Prediction } & $(0.744)$ & $(0.428)$ & $(0.545)$ & $(0.536)$ & & & & \\
\hline \multirow[t]{2}{*}{$5 \operatorname{AX} 53(2,3,7)-70$} & 3.43 & 2.81 & 0.714 & 0.844 & 0.576 & 0.569 & 0.081 & -0.101 & 0.047 & 0.031 \\
\hline & \multicolumn{2}{|c|}{ Prediction } & $(0.682)$ & $(0.795)$ & $(0.528)$ & $(0.523)$ & & & & \\
\hline \multirow[t]{2}{*}{$5 B \times 53(7,2,6)-64$} & 3.48 & 4.37 & 0.725 & 0.722 & 0.534 & 0.523 & 0.081 & 0.003 & 0.040 & 0.016 \\
\hline & \multicolumn{2}{|c|}{ Prediction } & $(0.696)$ & $(0.677)$ & $(0.496)$ & $(0.484)$ & & & & \\
\hline \multirow[t]{2}{*}{$5 \operatorname{BX} 53(2,3,7)-63$} & 3.48 & 4.39 & 0.696 & 0.767 & 0.550 & 0.539 & 0.072 & -0.081 & -0.014 & -0.040 \\
\hline & \multicolumn{2}{|c|}{ Prediction } & $(0.664)$ & $(0.669)$ & $(0.503)$ & $(0.490)$ & & & & \\
\hline \multirow[t]{2}{*}{$5 \mathrm{AX} 48(7,2,6)-142$} & 3.55 & 2.76 & 0.803 & 0.783 & 0.492 & 0.477 & 0.124 & 0.001 & -0.003 & -0.032 \\
\hline & \multicolumn{2}{|c|}{ Prediction } & $(0.756)$ & $(0.732)$ & $(0.472)$ & $(0.457)$ & & & & \\
\hline \multirow[t]{2}{*}{$5 \operatorname{AX} 48(2,3,7)-141$} & 3.43 & 2.76 & 0.514 & 0.701 & 0.362 & 0.346 & 0.015 & -0.105 & -0.179 & -0.208 \\
\hline & \multicolumn{2}{|c|}{ Prediction } & $(0.503)$ & $(0.682)$ & $(0.369)$ & $(0.358)$ & & & & \\
\hline \multirow[t]{2}{*}{$5 \mathrm{BX} 48(7,2,6)-127$} & 3.42 & 4.23 & 0.740 & 0.733 & 0.431 & 0.408 & 0.063 & -0.020 & -0.148 & -0.194 \\
\hline & \multicolumn{2}{|c|}{ Prediction } & $(0.702)$ & $(0.690)$ & $(0.410)$ & $(0.389)$ & & & & \\
\hline \multirow[t]{2}{*}{$5 \mathrm{BX} 48(2,3,7)-129$} & 3.53 & 4.21 & 0.550 & 0.645 & 0.363 & 0.349 & -0.007 & -0.159 & -0.185 & -0.211 \\
\hline & \multicolumn{2}{|c|}{ Prediction } & $(0.525)$ & $(0.618)$ & $(0.348)$ & $(0.335)$ & & & & \\
\hline \multirow[t]{2}{*}{$5 \mathrm{BZ} 41(7,2,6)-81$} & 3.47 & 4.39 & 0.827 & 0.772 & 0.610 & 0.588 & 0.227 & 0.094 & 0.179 & 0.133 \\
\hline & \multicolumn{2}{|c|}{ Prediction } & $(0.771)$ & $(0.730)$ & $(0.588)$ & $(0.572)$ & & & & \\
\hline \multirow[t]{2}{*}{$5 \operatorname{Bz} 41(2,3,7)-79$} & 3.45 & 4.32 & 0.625 & 0.725 & 0.500 & 0.491 & 0.087 & -0.168 & -0.002 & -0.021 \\
\hline & \multicolumn{2}{|c|}{ Prediction } & $(0.602)$ & $(0.769)$ & $(0.498)$ & $(0.496)$ & & & & \\
\hline
\end{tabular}


APPENDIX A

PRELIMINARY SCREENING TEST DATA

(Not QAL-I leve1)

This data not to be used directly for design purposes. 
TABLE A-1

PRELIMINARY PRESSURE LOSS COEFFICIENTS FROM HIGH FLOW TESTS USING LARGE VENTURI METER

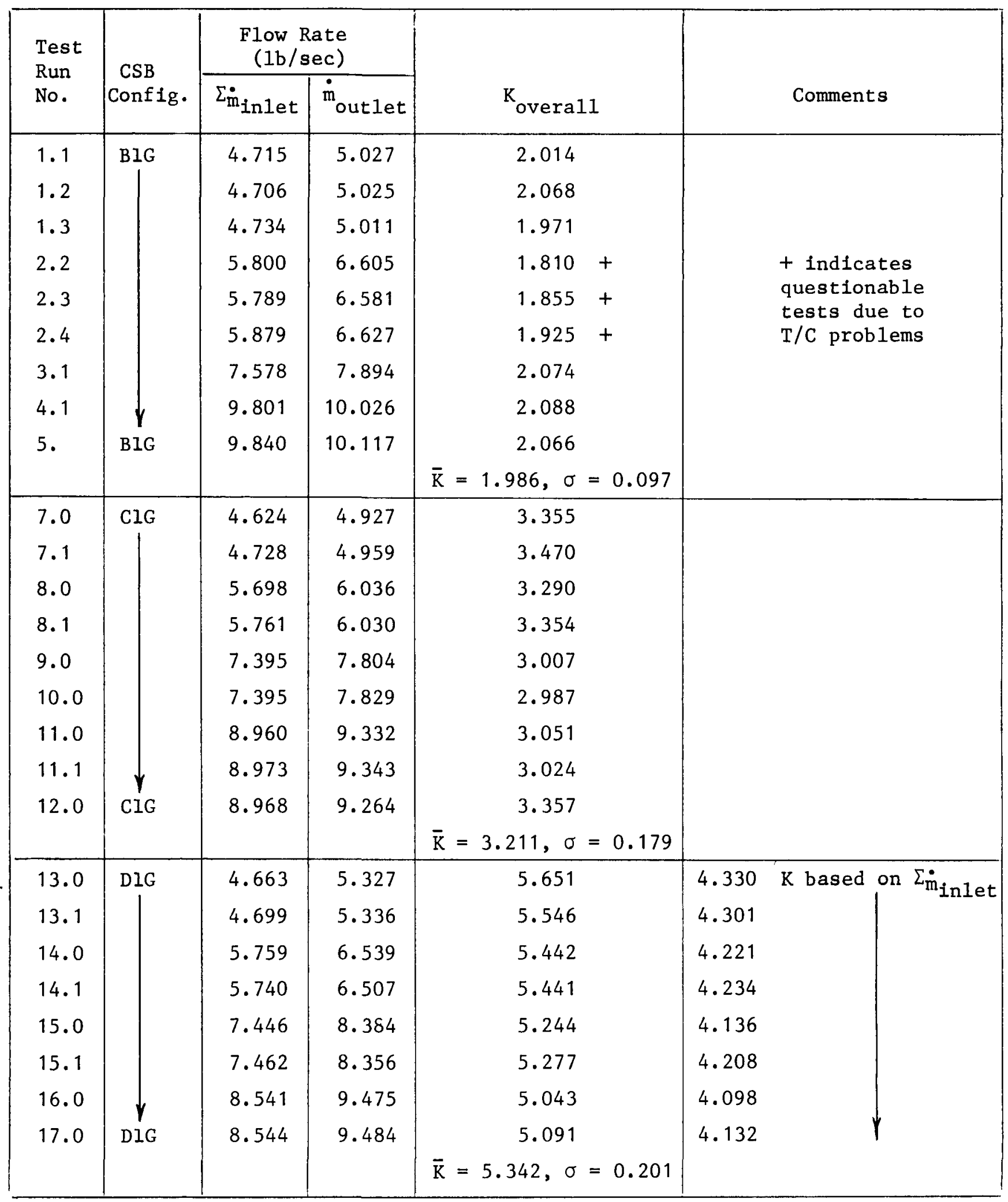


TABLE A-1 (Continued)

\begin{tabular}{|c|c|c|c|c|c|c|}
\hline \multirow{2}{*}{$\begin{array}{l}\text { Test } \\
\text { Run } \\
\text { No. }\end{array}$} & \multirow{2}{*}{$\begin{array}{l}\text { CSB } \\
\text { Config. }\end{array}$} & \multicolumn{2}{|c|}{$\begin{array}{c}\text { F1ow Rate } \\
(1 \mathrm{~b} / \mathrm{sec})\end{array}$} & \multirow[b]{2}{*}{ K overa11 } & \multirow{2}{*}{\multicolumn{2}{|c|}{ Comments }} \\
\hline & & $\dot{\Sigma}_{\mathrm{m}_{\text {In } 1 \mathrm{et}}}$ & $\dot{\mathrm{m}}_{\text {outlet }}$ & & & \\
\hline 19.0 & $\mathrm{~A} 2 \mathrm{G}$ & 4.847 & 5.098 & 1.416 & 1.280 & $\mathrm{~K}$ based on $\Sigma_{\dot{m}_{\text {inlet }}}$ \\
\hline 20.0 & & 5.880 & 6.158 & 1.392 & 1.269 & \\
\hline 21.0 & & 7.602 & 7.910 & 1.394 & 1.288 & \\
\hline 22.0 & & 9.842 & 10.014 & 1.433 & 1.384 & \\
\hline 23.0 & $\downarrow$ & 9.830 & 9.972 & 1.416 & 1.376 & \\
\hline 24.0 & $\mathrm{~A} 2 \mathrm{G}$ & 10.297 & 10.376 & $\begin{array}{c}1.381 \\
\overline{\mathrm{K}}=1.405, \sigma=0.018\end{array}$ & 1.360 & $\gamma$ \\
\hline
\end{tabular}


TABLE A-2

PRELIMINARY PRESSURE LOSS COEFFICIENTS FOR LOW FLOW TESTS USING SMALI VENTURI METER

\begin{tabular}{|c|c|c|c|c|c|c|c|c|}
\hline \multirow{2}{*}{$\begin{array}{l}\text { Test } \\
\text { Run } \\
\text { No. }\end{array}$} & \multirow{2}{*}{$\begin{array}{l}\text { CSB } \\
\text { Config. }\end{array}$} & \multicolumn{2}{|c|}{$\begin{array}{l}\text { Flow Rate } \\
(1 \mathrm{~b} / \mathrm{sec})\end{array}$} & \multirow{2}{*}{$\begin{array}{c}\text { Heated Col. } \\
\text { Temp. } \\
\left({ }^{\circ} \mathrm{F}\right)\end{array}$} & \multirow{2}{*}{$\begin{array}{c}\mathrm{T}_{\text {avg. }} \\
\text { in } \\
\left({ }^{\circ} \mathrm{F}\right)\end{array}$} & \multirow{2}{*}{$\begin{array}{c}\text { Tavg. } \\
\text { out } \\
\left({ }^{\circ} \mathrm{F}\right)\end{array}$} & \multirow{2}{*}{$\begin{array}{l}\text { Tavg. } \\
\text { Rake } \\
\left({ }^{\circ} \mathrm{F}\right)\end{array}$} & \multirow{2}{*}{$\begin{array}{c}\mathrm{K}_{\text {overall }} \\
\text { arith. avg. }\end{array}$} \\
\hline & & $\Sigma_{\dot{m}_{\text {inlet }}}$ & $\dot{\mathrm{m}}_{\text {outlet }}$ & & & & & \\
\hline 25 & \multirow{16}{*}{$B I G$} & 6.272 & 6.346 & & & & & 2.083 \\
\hline 26 & & 5.520 & 5.545 & & & & & 2.117 \\
\hline 27 & & 4.451 & 4.494 & & & & & 2.086 \\
\hline 28 & & 2.406 & 2.420 & & & & & 2.109 \\
\hline 29 & & 1.709 & 1.699 & & & & & 2.061 \\
\hline 29.1 & & 1.73 & 1.73 & & & & & 2.117 \\
\hline 30 & & 3.145 & 3.200 & & & & & 2.037 \\
\hline 31. & & 3.217 & 3.225 & & & & & 2.113 \\
\hline 31.1 & & 3.220 & 3.238 & & & & & 2.068 \\
\hline 31.2 & & 3.177 & 3.248 & $\mathrm{~T}_{1}=200.3$ & 84.5 & 83.5 & 84.5 & 2.164 \\
\hline 32.0 & & 3.165 & 3.163 & $\mathrm{~T}_{2}=184.3$ & 89.3 & 89.9 & 90.8 & 2.135 \\
\hline 33. & & 3.165 & 3.173 & $\mathrm{~T}_{3}=159.3$ & 85.3 & 85.3 & 86.7 & 2.100 \\
\hline 33.1 & & 3.125 & 3.216 & & & & & 2.115 \\
\hline 33.2 & & 3.178 & 3.162 & $\mathrm{~T}_{3}=180.8$ & 89.2 & 89.3 & 90.9 & 2.024 \\
\hline 34. & & 3.126 & 3.105 & $\mathrm{~T}_{4}=164.1$ & 90.1 & 90.4 & 90.8 & 2.041 \\
\hline 34.1 & & 3.142 & 3.146 & $\mathrm{~T}_{4}=182.6$ & 89.5 & 89.3 & 91.2 & 2.097 \\
\hline 35 & \multirow[t]{11}{*}{ BG } & 5.467 & 5.581 & & & & & 2.451 \\
\hline 36 & & 4.231 & 4.362 & & & & & 2.506 \\
\hline 37 & & 3.209 & 3.254 & & & & & 2.444 \\
\hline 37.1 & & 3.070 & 3.173 & & & & & 2.428 \\
\hline 38 & & 2.370 & 2.388 & & & & & 2.441 \\
\hline 39 & & 1.668 & 1.686 & & & & & 2.397 \\
\hline 40 & & 3.153 & 3.206 & $\mathrm{~T}_{3}=181.1$ & 90.4 & 91.8 & 90.1 & 2.460 \\
\hline 40.1 & & 2.768 & 2.802 & $\mathrm{~T}_{4}=189.7$ & 93.7 & 93.3 & 97.1 & 2.377 \\
\hline 41 & & 3.174 & 3.272 & $\mathrm{~T}_{1}=170.4$ & 79.7 & 78.0 & 78.2 & 2.505 \\
\hline 42 & & 3.173 & 3.247 & $\mathrm{~T}_{4}=177.1$ & 87.3 & 86.8 & 90.9 & 2.380 \\
\hline 43 & & 3.187 & 3.237 & $\mathrm{~T}_{2}=176.9$ & 88.3 & 90.1 & 93.1 & 2.319 \\
\hline
\end{tabular}


TABLE A-2 (Continued)

\begin{tabular}{|c|c|c|c|c|c|c|c|c|}
\hline \multirow{2}{*}{$\begin{array}{l}\text { Test } \\
\text { Run } \\
\text { No. }\end{array}$} & \multirow{2}{*}{$\begin{array}{l}\text { CSB } \\
\text { Config. }\end{array}$} & \multicolumn{2}{|c|}{$\begin{array}{l}\text { F1ow Rate } \\
(1 \mathrm{~b} / \mathrm{sec})\end{array}$} & \multirow{2}{*}{$\begin{array}{c}\text { Heated Col. } \\
\text { Temp. } \\
\left({ }^{\circ} \mathrm{F}\right)\end{array}$} & \multirow{2}{*}{$\begin{array}{c}\mathrm{T}_{\text {avg. }} . \\
\text { in } \\
\left({ }^{\circ} \mathrm{F}\right)\end{array}$} & \multirow{2}{*}{$\begin{array}{l}\mathrm{T}_{\text {avg }} \\
\text { out } \\
\left({ }^{\circ} \mathrm{F}\right)\end{array}$} & \multirow{2}{*}{$\begin{array}{l}\mathrm{T}_{\text {avg. }} \\
\text { Rake } \\
\left({ }^{\circ} \mathrm{F}\right)\end{array}$} & \multirow{2}{*}{$\begin{array}{c}\mathrm{K} \text { overal1 } \\
\text { arith. avg. }\end{array}$} \\
\hline & & $\sum_{\dot{m}_{\text {in } 1 e t}}$ & $\dot{\mathrm{m}}_{\text {outlet }}$ & & & & & \\
\hline 44 & \multirow[t]{9}{*}{ B2G } & 5.512 & 5.648 & \multirow{10}{*}{$\begin{aligned} \mathrm{T}_{3} & =176.3 \\
\mathrm{~T}_{4} & =177.0 \\
\mathrm{~T}_{2} & =183.6 \\
\mathrm{~T}_{1} & =176.0\end{aligned}$} & \multirow{10}{*}{$\begin{array}{l}90.4 \\
90.7 \\
88.9 \\
85.1 \\
\end{array}$} & \multirow{8}{*}{$\begin{array}{l}90.9 \\
90.4\end{array}$} & \multirow[b]{7}{*}{91.4} & 2.008 \\
\hline 45 & & 4.423 & 4.608 & & & & & 2.120 \\
\hline 46 & & 3.195 & 3.298 & & & & & 2.099 \\
\hline 47 & & 2.448 & 2.517 & & & & & 2.078 \\
\hline 48 & & 1.743 & 1.785 & & & & & 2.040 \\
\hline 49 & & 6.955 & 7.132 & & & & & 2.074 \\
\hline 50 & & 3.185 & 3.266 & & & & & 2.091 \\
\hline 51 & & 3.202 & 3.269 & & & & 92.5 & 2.067 \\
\hline 52 & & 3.120 & 3.210 & & & 90.3 & 93.8 & 2.035 \\
\hline 53 & $\mathrm{~B} 2 \mathrm{G}$ & 3.110 & 3.210 & & & 84.2 & 84.4 & 2.104 \\
\hline 54 & \multirow{11}{*}{$\mathrm{ClG}$} & 3.143 & 3.246 & \multirow{8}{*}{$\mathrm{T}_{1}=203.1$} & \multirow[b]{8}{*}{89.6} & \multirow[b]{8}{*}{87.9} & \multirow[b]{8}{*}{88.3} & 3.583 \\
\hline 55 & & 2.421 & 2.503 & & & & & 3.651 \\
\hline 56 & & 1.707 & 1.749 & & & & & 3.580 \\
\hline 57 & & 4.411 & 4.649 & & & & & 3.754 \\
\hline 58 & & 5.552 & 5.783 & & & & & 3.753 \\
\hline 59 & & 6.639 & 6.944 & & & & & 3.693 \\
\hline 60 & & 3.119 & 3.226 & & & & & 3.646 \\
\hline 61 & & 3.155 & 3.313 & & & & & 3.651 \\
\hline 62 & & 3.173 & 3.282 & \multirow{2}{*}{$\begin{array}{l}\mathrm{T}_{2}=191.7 \\
\mathrm{~T}_{3}=197.9\end{array}$} & \multirow{3}{*}{$\begin{array}{r}97.5 \\
104.1 \\
107.6\end{array}$} & \multirow{3}{*}{$\begin{array}{r}98.8 \\
105.2 \\
107.5 \\
\end{array}$} & \multirow{3}{*}{$\begin{array}{l}101.2 \\
107.3 \\
108.8 \\
\end{array}$} & 3.576 \\
\hline 63 & & 3.146 & 3.246 & & & & & 3.606 \\
\hline 64 & & 3.119 & 3.256 & $\mathrm{~T}_{4}=200.7$ & & & & 3.628 \\
\hline 65 & CG & 6.437 & 6.785 & & & & & 4.273 \\
\hline 66 & & 5.608 & 5.887 & & & & & 4.412 \\
\hline 67 & & 4.342 & 4.571 & & & & & 4.439 \\
\hline 68 & & 3.098 & 3.238 & & & & & 4.318 \\
\hline 69 & & 2.396 & 2.488 & & & & & 4.100 \\
\hline 70 & & 1.719 & 1.769 & & & & & 3.963 \\
\hline 71 & & 3.168 & 3.288 & $\mathrm{~T}_{1}=179.8$ & 87.1 & 86.3 & 85.9 & 4.276 \\
\hline 72 & & 3.151 & 3.258 & $\mathrm{~T}_{2}=189.7$ & 98.4 & 100.3 & 105.6 & 4.068 \\
\hline 73 & 7 & 3.127 & 3.251 & $\mathrm{~T}_{3}=194.9$ & 100.6 & 101.3 & 102.0 & 4.293 \\
\hline 74 & CG & 3.150 & 3.245 & $\mathrm{~T}_{4}=194.0$ & 100.3 & 100.3 & 100.3 & 4.047 \\
\hline
\end{tabular}


TABLE A-2 (Continued)

\begin{tabular}{|c|c|c|c|c|c|c|c|c|}
\hline \multirow{2}{*}{$\begin{array}{l}\text { Test } \\
\text { Run } \\
\text { No. }\end{array}$} & \multirow{2}{*}{$\begin{array}{l}\text { CSB } \\
\text { Config. }\end{array}$} & \multicolumn{2}{|c|}{$\begin{array}{l}\text { Flow Rate } \\
(1 \mathrm{~b} / \mathrm{sec})\end{array}$} & \multirow{2}{*}{$\begin{array}{c}\text { Heated Col. } \\
\text { Temp. } \\
\left({ }^{\circ} \mathrm{F}\right)\end{array}$} & \multirow{2}{*}{$\begin{array}{l}\mathrm{T}_{\text {avg. }} . \\
\text { in } \\
\left({ }^{\circ} \mathrm{F}\right)\end{array}$} & \multirow{2}{*}{$\begin{array}{c}\mathrm{T}_{\text {avg. }} \\
\text { out } \\
\left({ }^{\circ} \mathrm{F}\right)\end{array}$} & \multirow{2}{*}{$\begin{array}{l}\text { Tavg. } \\
\text { Rake } \\
\left({ }^{\circ} \mathrm{F}\right)\end{array}$} & \multirow{2}{*}{$\begin{array}{c}\mathrm{K} \text { overal1 } \\
\text { Arith. Avg. }\end{array}$} \\
\hline & & $\Sigma_{\dot{m}_{\text {inlet }}}$ & $\dot{\mathrm{m}}_{\text {outlet }}$ & & & & & \\
\hline 75 & \multirow{10}{*}{$\begin{array}{c}7 \\
\mathrm{C} 2 \mathrm{G} \\
\end{array}$} & 6.487 & 6.829 & & & & & 3.608 \\
\hline 76 & & 5.322 & 5.651 & & & & & 3.741 \\
\hline 77 & & 4.286 & 4.543 & & & & & 3.690 \\
\hline 78 & & 3.122 & 3.273 & & & & & 3.572 \\
\hline 79 & & 2.412 & 2.488 & & & & & 3.500 \\
\hline 80 & & 1.658 & 1.721 & & & & & 3.559 \\
\hline 81 & & 3.086 & 3.253 & $\mathrm{~T}_{1}=179.1$ & 82.1 & 81.0 & 81.1 & 3.570 \\
\hline 82 & & 3.106 & 3.234 & $\mathrm{~T}_{2}=186.9$ & 91.4 & 92.8 & 97.4 & 3.690 \\
\hline 83 & & 3.102 & 3.218 & $\mathrm{~T}_{3}=202.9$ & 95.5 & 96.6 & 99.2 & 3.606 \\
\hline 84 & & 3.073 & 3.201 & $\mathrm{~T}_{4}=208.4$ & 99.6 & 98.6 & 101.5 & 3.617 \\
\hline 85 & \multirow{11}{*}{$\mathrm{DIG}$} & 3.054 & 3.244 & \multirow{11}{*}{$\begin{aligned} \mathrm{T}_{1} & =197.6 \\
\mathrm{~T}_{2} & =201.7 \\
\mathrm{~T}_{3} & =196.4 \\
\mathrm{~T}_{4} & =200.7\end{aligned}$} & \multirow[b]{8}{*}{85.3} & \multirow[b]{8}{*}{83.7} & \multirow[b]{8}{*}{83.6} & 4.665 \\
\hline 86 & & 6.303 & 6.717 & & & & & 4.729 \\
\hline 87 & & 5.295 & 5.678 & & & & & 4.787 \\
\hline 88 & & 4.189 & 4.510 & & & & & 4.658 \\
\hline 89 & & 3.004 & 3.214 & & & & & 4.617 \\
\hline 90 & & 2.329 & 2.471 & & & & & 4.658 \\
\hline 91 & & 1.649 & 1.740 & & & & & 4.563 \\
\hline 92 & & 3.024 & 3.206 & & & & & 4.622 \\
\hline 93 & & 3.082 & 3.232 & & 93.5 & 95.1 & 100.8 & 4.575 \\
\hline 94 & & 3.064 & 3.240 & & 92.9 & 94.6 & 97.8 & 4.620 \\
\hline 95 & & 3.009 & 3.212 & & 85.9 & 84.7 & 86.4 & 4.717 \\
\hline 96 & \multirow[t]{8}{*}{ DG } & 6.143 & 6.579 & \multirow{9}{*}{$\begin{array}{l}\mathrm{T}_{1}=180.4 \\
\mathrm{~T}_{2}=201.8 \\
\mathrm{~T}_{3}=200.0\end{array}$} & \multirow{8}{*}{$\begin{array}{l}78.7 \\
99.8\end{array}$} & \multirow[b]{7}{*}{76.3} & \multirow[b]{7}{*}{77.9} & 5.506 \\
\hline 97 & & 5.220 & 5.606 & & & & & 5.562 \\
\hline 98 & & 4.248 & 4.583 & & & & & 5.340 \\
\hline 99 & & 3.076 & 3.259 & & & & & 5.437 \\
\hline 100 & & 2.401 & 2.492 & & & & & 5.251 \\
\hline 101 & & 1.678 & 1.748 & & & & & 5.422 \\
\hline 102 & & 3.080 & 3.278 & & & & & 5.446 \\
\hline 103 & & 3.046 & 3.186 & & & 101.3 & 108.1 & 5.450 \\
\hline 104 & DG & 3.046 & 3.233 & & 103.3 & 103.5 & 104.3 & 5.444 \\
\hline
\end{tabular}


TABLE A-2 (Continued)

\begin{tabular}{|c|c|c|c|c|c|c|c|c|}
\hline \multirow{2}{*}{$\begin{array}{l}\text { Test } \\
\text { Run } \\
\text { No. }\end{array}$} & \multirow{2}{*}{$\begin{array}{c}\text { CSB } \\
\text { Config. }\end{array}$} & \multicolumn{2}{|c|}{$\begin{array}{l}\text { Flow Rate } \\
(1 \mathrm{~b} / \mathrm{sec})\end{array}$} & \multirow{2}{*}{$\begin{array}{c}\text { Heated Col. } \\
\text { Temp. } \\
\left({ }^{\circ} \mathrm{F}\right)\end{array}$} & \multirow{2}{*}{$\begin{array}{l}\mathrm{T}_{\text {avg. }} . \\
\text { in } \\
\left({ }^{\circ} \mathrm{F}\right)\end{array}$} & \multirow{2}{*}{$\begin{array}{l}\mathrm{T}_{\text {avg. }} \\
\text { out } \\
\left({ }^{\circ} \mathrm{F}\right)\end{array}$} & \multirow{2}{*}{$\begin{array}{l}\mathrm{T}_{\text {avg. }} \\
\text { Rake } \\
\left({ }^{\circ} \mathrm{F}\right)\end{array}$} & \multirow{2}{*}{$\begin{array}{c}\text { Kovera11 } \\
\text { Arith. Avg. }\end{array}$} \\
\hline & & $\Sigma_{\mathbf{m}_{\text {inlet }}}$ & $\dot{\mathrm{m}}_{\text {outlet }}$ & & & & & \\
\hline 105 & DG & 3.063 & 3.211 & $\mathrm{~T}_{4}=201.1$ & 104.8 & 104.4 & 104.5 & 5.325 \\
\hline 106 & $\mathrm{~A} 2 \mathrm{G}$ & 3.060 & 3.290 & & & & & 1.295 \\
\hline 107 & & 6.688 & 7.079 & & & & & 1.386 \\
\hline 108 & & 5.284 & 5.655 & & & & & 1.361 \\
\hline 109 & & 4.252 & 4.544 & & & & & 1.356 \\
\hline 110 & & 3.060 & 3.239 & & & & & 1.329 \\
\hline 111 & & 2.358 & 2.503 & & & & & 1.285 \\
\hline 112 & & 1.670 & 1.752 & & & & & 1.332 \\
\hline 113 & & 3.079 & 3.255 & $\mathrm{~T}_{1}=181.4$ & 85.2 & 83.6 & 85.1 & 1.359 \\
\hline 114 & & 3.081 & 3.237 & $\mathrm{~T}_{2}=189.6$ & 92.7 & 94.2 & 98.0 & 1.206 \\
\hline 115 & $\phi$ & 3.071 & 3.237 & $\mathrm{~T}_{3}=200.5$ & 93.5 & 94.9 & 94.1 & 1.300 \\
\hline 116 & $\mathrm{~A} 2 \mathrm{G}$ & 3.118 & 3.282 & $\mathrm{~T}_{4}=203.1$ & 88.7 & 87.3 & 92.2 & 1.250 \\
\hline 117 & $\mathrm{AIG}$ & 6.664 & 7.083 & & & & & 1.413 \\
\hline 118 & & 5.269 & 5.633 & & & & & 1.388 \\
\hline 119 & & 4.187 & 4.518 & & & & & 1.329 \\
\hline 120 & & 3.087 & 3.283 & & & & & 1.305 \\
\hline 121 & & 2.331 & 2.471 & & & & & 1.178 \\
\hline 122 & & 1.728 & 1.793 & & & & & 1.242 \\
\hline 123 & & 3.059 & 3.232 & $\mathrm{~T}_{1}=186.0$ & 86.7 & 84.8 & 85.4 & 1.396 \\
\hline 124 & & 3.067 & 3.213 & $\mathrm{~T}_{2}=191.7$ & 93.0 & 95.1 & 97.9 & 1.321 \\
\hline 125 & $\gamma$ & 3.021 & 3.201 & $\mathrm{~T}_{3}=205.1$ & 95.3 & 96.2 & 95.1 & 1.302 \\
\hline 126 & $\mathrm{~A} I \mathrm{G}$ & 3.072 & 3.246 & $\mathrm{~T}_{4}=202.2$ & 94.2 & 94.2 & 95.9 & 1.292 \\
\hline
\end{tabular}


TABLE A-3

PRELIMINARY PRESSURE LOSS COEFFICIENTS

(With Increased Reflector Block Height)

\begin{tabular}{|c|c|c|c|c|c|c|c|c|}
\hline \multirow{2}{*}{$\begin{array}{l}\text { Test } \\
\text { Run } \\
\text { No. }\end{array}$} & \multirow{2}{*}{$\begin{array}{l}\text { CSB } \\
\text { Config. }\end{array}$} & \multicolumn{2}{|c|}{$\begin{array}{l}\text { F1ow Rate } \\
(1 \mathrm{~b} / \mathrm{sec})\end{array}$} & \multirow{2}{*}{$\begin{array}{c}\text { Heated Col. } \\
\text { Temp. } \\
\left({ }^{\circ} \mathrm{F}\right)\end{array}$} & \multirow{2}{*}{$\begin{array}{l}\mathrm{T}_{\text {avg. }} . \\
\text { in } \\
\left({ }^{\circ} \mathrm{F}\right)\end{array}$} & \multirow{2}{*}{$\begin{array}{c}\mathrm{T}_{\text {avg. }} \\
\text { out } \\
\left({ }^{\circ} \mathrm{F}\right)\end{array}$} & \multirow{2}{*}{$\begin{array}{l}\mathrm{T}_{\text {avg. }} \\
\text { Rake } \\
\left({ }^{\circ} \mathrm{F}\right)\end{array}$} & \multirow{2}{*}{$\begin{array}{c}\text { Koverall } \\
\text { Arith. Avg. }\end{array}$} \\
\hline & & $\Sigma_{\dot{m}_{\text {inlet }}}$ & $\dot{\mathrm{m}}_{\text {outlet }}$ & & & & & \\
\hline F1 & $3 B I G$ & 2.934 & 3.168 & $\mathrm{~T}_{1}=167.2$ & 75.1 & 74.1 & 76.5 & 2.799 \\
\hline $\mathrm{F} 2$ & $3 B 1 G$ & 2.973 & 3.104 & $\mathrm{~T}_{2}=193.9$ & 86.6 & 87.2 & 90.1 & 2.494 \\
\hline F3 & $3 B I G$ & 2.927 & 3.135 & $\mathrm{~T}_{3}=183.2$ & 89.3 & 88.8 & 88.9 & 2.623 \\
\hline F4 & $3 B I G$ & 2.987 & 3.202 & $\mathrm{~T}_{4}=174.8$ & 85.8 & 84.2 & 86.2 & 2.671 \\
\hline F5 & $4 \mathrm{BIG}$ & 3.019 & 3.204 & $\mathrm{~T}_{1}=184.8$ & 73.7 & 73.3 & 73.7 & 2.677 \\
\hline F6 & $4 \mathrm{BIG}$ & 3.034 & 3.133 & $\mathrm{~T}_{2}=178.8$ & 86.8 & 85.9 & 88.0 & 2.665 \\
\hline F7 & $4 B I G$ & 3.045 & 3.197 & $\mathrm{~T}_{3}=177.5$ & 90.4 & 88.7 & 89.6 & 2.299 \\
\hline F8 & $4 \mathrm{BIG}$ & 3.132 & 3.189 & $\mathrm{~T}_{4}=177.8$ & 90.3 & 89.9 & 90.0 & 2.236 \\
\hline F9 & $3 \mathrm{CIG}$ & 3.009 & 3.185 & $\mathrm{~T}_{1}=178.0$ & 81.7 & 82.0 & 81.8 & 3.884 \\
\hline F10 & $3 \mathrm{CIG}$ & 3.126 & 3.174 & $\mathrm{~T}_{2}=190.0$ & 91.7 & 89.9 & 93.1 & 3.464 \\
\hline $\mathrm{F} 11$ & $3 \mathrm{CIG}$ & 3.102 & 3.205 & $\mathrm{~T}_{3}=180.2$ & 89.1 & 87.2 & 87.3 & 3.588 \\
\hline F12 & $3 \mathrm{CIG}$ & 3.059 & 3.202 & $\mathrm{~T}_{4}=175.6$ & 79.8 & 79.5 & 81.1 & 3.485 \\
\hline F13 & $4 \mathrm{ClG}$ & 3.043 & 3.168 & $\mathrm{~T}_{1}=171.7$ & 79.5 & 79.3 & 79.2 & 3.712 \\
\hline F14 & $4 \mathrm{ClG}$ & 3.077 & 3.168 & $\mathrm{~T}_{2}=193.2$ & 88.8 & 86.9 & 86.9 & 3.557 \\
\hline F15 & $4 \mathrm{CIG}$ & 3.091 & 3.163 & $\mathrm{~T}_{3}=182.4$ & 85.1 & 83.3 & 84.8 & 3.699 \\
\hline F16 & $4 C I G$ & 3.058 & 3.208 & $\mathrm{~T}_{4}=173.8$ & 84.3 & 83.4 & 85.2 & 4.257 \\
\hline
\end{tabular}


TABLE A-4

LOW FLOW PRESSURE LOSS COEFFICIENTS

FOR PRELIMINARY FOUR-COLUMN REGIONS

\begin{tabular}{|c|c|c|c|c|c|c|c|c|}
\hline \multirow{2}{*}{$\begin{array}{l}\text { Test } \\
\text { Run } \\
\text { No. }\end{array}$} & \multirow{2}{*}{$\begin{array}{l}\text { CSB } \\
\text { Config. }\end{array}$} & \multicolumn{2}{|c|}{$\begin{array}{l}\text { F1ov Rate } \\
(1 \mathrm{~b} / \mathrm{sec})\end{array}$} & \multirow{2}{*}{$\begin{array}{c}\text { Heated Col. } \\
\text { Temp. } \\
\left({ }^{\circ} \mathrm{F}\right)\end{array}$} & \multirow{2}{*}{$\begin{array}{l}\text { Tavg. } \\
\text { in } \\
\left({ }^{\circ} \mathrm{F}\right)\end{array}$} & \multirow{2}{*}{$\begin{array}{l}\text { Tavg. } \\
\text { out } \\
\left({ }^{\circ} \mathrm{F}\right)\end{array}$} & \multirow{2}{*}{$\begin{array}{l}\text { Tavg. } \\
\text { Rake } \\
\left({ }^{\circ} \mathrm{F}\right)\end{array}$} & \multirow{2}{*}{$\begin{array}{c}\text { Koverall } \\
\text { Arith. Avg. }\end{array}$} \\
\hline & & $\Sigma_{\dot{\mathrm{m}}_{\text {inlet }}}$ & $\dot{m}_{\text {outlet }}$ & & & & & \\
\hline 127 & $\begin{array}{cc}\text { Col. } \\
\text { BIG } 1,2,3,4\end{array}$ & 4.263 & 4.707 & & & & & $>7.2$ \\
\hline 128 & & 3.993 & 4.487 & $\mathrm{~T}_{1}=198.3$ & 91.6 & 88.0 & 91.1 & 6.46 \\
\hline 129 & & 3.999 & 4.346 & $\mathrm{~T}_{2}=203.1$ & 113.4 & 119.1 & 118.1 & 6.27 \\
\hline 130 & Co1. & 4.010 & 4.425 & $\mathrm{~T}_{3}=199.7$ & 108.6 & 106.8 & 111.0 & 6.21 \\
\hline 131 & BIG $1,2,3,4$ & 4.211 & 4.530 & $\mathrm{~T}_{4}=218.4$ & 115.5 & 112.1 & 112.6 & 6.13 \\
\hline 132 & $\begin{array}{c}\text { Col. } \\
\text { BIG } 1,2,6,7\end{array}$ & 4.530 & 4.708 & $\mathrm{~T}_{1}=195.5$ & 89.4 & 87.3 & 89.8 & 6.23 \\
\hline 133 & & 4.460 & 4.524 & $\mathrm{~T}_{2}=188.8$ & 103.3 & 111.5 & 112.8 & 5.81 \\
\hline 134 & $\begin{array}{l}\text { Col. } \\
\text { Col }\end{array}$ & 4.001 & 4.281 & $\mathrm{~T}_{6}=173.7$ & 105.8 & 105.2 & 105.4 & 5.98 \\
\hline 135 & BIG $1,2,6,7$ & 3.600 & 4.022 & $\mathrm{~T}_{7}=171.9$ & 110.4 & 110.0 & 109.3 & 5.98 \\
\hline 136 & BIG $\begin{array}{c}\text { Col. } \\
1,2,3,7\end{array}$ & 3.717 & 4.170 & $\mathrm{~T}_{7}=178.6$ & 108.9 & 108.7 & 112.7 & 6.43 \\
\hline 137 & & 3.720 & 4.232 & $\mathrm{~T}_{1}=183.0$ & 94.7 & 92.1 & 93.7 & 6.72 \\
\hline 138 & Col. & 3.828 & 4.299 & $\mathrm{~T}_{2}=156.5$ & 88.6 & 93.5 & 90.5 & 6.62 \\
\hline 139 & BIG $1,2,3,7$ & 3.692 & 4.222 & $\mathrm{~T}_{3}=181.1$ & 100.3 & 98.0 & 96.0 & 6.27 \\
\hline
\end{tabular}


TABLE A-5

SUMMARY OF SELECTED INFLUENCE COEFFICIENTS - 7-COLUMN REGIONS

\begin{tabular}{|c|c|c|c|c|c|c|c|c|c|}
\hline \multirow[b]{2}{*}{$\begin{array}{l}\text { Test } \\
\text { No. }\end{array}$} & \multirow[b]{2}{*}{ Config. } & \multirow{2}{*}{$\begin{array}{c}\text { Heated } \\
\text { Col. } \\
\text { No. }\end{array}$} & \multirow{2}{*}{$\begin{array}{c}\text { Flow } \\
\text { Rate } \\
\text { (1b/sec) }\end{array}$} & \multirow[b]{2}{*}{$\begin{array}{c}\mathrm{K}_{\text {overa11 }} \\
\text { Arith. Avg. }\end{array}$} & \multirow{2}{*}{$\begin{array}{c}\theta_{\text {sensor }}^{\prime} \\
\max \\
(\mathrm{Cij})\end{array}$} & \multirow{2}{*}{ 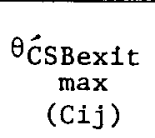 } & \multicolumn{3}{|c|}{$\theta(\mathrm{Aij})$ for Sensor Centerline } \\
\hline & & & & & & & ${ }^{\theta} \in \underset{\max }{\operatorname{sens} .}$ & ${ }^{\theta} E$ sens. & ${ }^{\theta} E \begin{array}{l}\text { sens. } \\
\text { avg. }\end{array}$ \\
\hline 123 & $\mathrm{AlG}$ & 1 & 3.23 & 1.40 & 0.180 & 0.181 & 0.102 & -0.054 & 0.016 \\
\hline 113 & A2G & 1 & 3.26 & 1.36 & 0.160 & 0.171 & 0.080 & -0.054 & 0.006 \\
\hline 41 & BG & 1 & 3.27 & 2.51 & 0.137 & 0.153 & 0.054 & -0.062 & -0.010 \\
\hline 31.2 & $B I G$ & 1 & 3.25 & 2.13 & 0.174 & 0.156 & 0.096 & -0.025 & 0.023 \\
\hline 53 & B2G & 1 & 3.21 & 2.10 & 0.107 & 0.122 & 0.023 & -0.073 & -0.029 \\
\hline 71 & CG & 1 & 3.29 & 4.28 & 0.105 & 0.128 & 0.020 & -0.056 & -0.021 \\
\hline 61 & $\mathrm{ClG}$ & 1 & 3.31 & 3.65 & 0.123 & 0.121 & 0.039 & -0.056 & -0.010 \\
\hline 81 & $\mathrm{C} 2 \mathrm{G}$ & 1 & 3.25 & 3.57 & 0.112 & 0.113 & 0.027 & -0.065 & -0.024 \\
\hline 102 & DG & 1 & 3.28 & 5.45 & 0.079 & 0.127 & -0.003 & -0.107 & -0.057 \\
\hline 92 & $\mathrm{DIG}$ & 1 & 3.21 & 4.62 & 0.103 & 0.103 & 0.017 & -0.064 & -0.026 \\
\hline 124 & $\mathrm{AlG}$ & 2 & 3.21 & 1.32 & 0.328 & 0.884 & 0.033 & -0.134 & -0.059 \\
\hline 114 & $A \approx G$ & 2 & 3.24 & 1.21 & 0.296 & 0.798 & 0.054 & -0.118 & -0.049 \\
\hline 43 & BG & 2 & 3.24 & 2.32 & 0.262 & 0.749 & 0.132 & -0.158 & -0.050 \\
\hline 32.0 & $B I G$ & 2 & 3.16 & 2.13 & 0.220 & 0.590 & 0.050 & -0.134 & -0.056 \\
\hline 52 & $\mathrm{~B} 2 \mathrm{G}$ & 2 & 3.21 & 2.04 & 0.285 & 0.464 & 0.141 & -0.115 & -0.005 \\
\hline 72 & CG & 2 & 3.28 & 4.07 & 0.413 & 0.609 & 0.157 & -0.148 & -0.021 \\
\hline 62 & $\mathrm{ClG}$ & 2 & 3.28 & 3.58 & 0.372 & 0.492 & 0.066 & -0.138 & -0.051 \\
\hline 82 & $\mathrm{C} 2 \mathrm{G}$ & 2 & 3.23 & 3.69 & 0.325 & 0.478 & 0.092 & -0.115 & -0.016 \\
\hline 103 & DG & 2 & 3.19 & 5.45 & 0.484 & 0.483 & 0.174 & -0.146 & -0.002 \\
\hline 93 & $D 1 G$ & 2 & 3.23 & 4.58 & 0.449 & 0.448 & 0.156 & -0.074 & 0.031 \\
\hline 125 & AlG & 3 & 3.20 & 1.30 & 0.259 & 0.790 & 0.127 & -0.160 & -0.040 \\
\hline 115 & A2G & 3 & 3.24 & 1.30 & 0.262 & 0.699 & 0.132 & -0.119 & -0.015 \\
\hline 40 & BG & 3 & 3.21 & 2.46 & 0.133 & 0.693 & -0.018 & -0.126 & -0.087 \\
\hline 33.2 & BIG & 3 & 3.16 & 2.02 & 0.139 & 0.536 & -0.011 & -0.162 & -0.099 \\
\hline 50 & B2G & 3 & 3.27 & 2.09 & 0.191 & 0.399 & 0.052 & -0.135 & -0.057 \\
\hline 73 & $\mathrm{CG}$ & 3 & 3.25 & 4.29 & 0.082 & 0.530 & -0.079 & -0.179 & -0.140 \\
\hline 63 & $\mathrm{ClG}$ & 3 & 3.25 & 3.61 & 0.240 & 0.412 & 0.106 & -0.171 & -0.066 \\
\hline 83 & $\mathrm{C} 2 \mathrm{G}$ & 3 & 3.22 & 3.61 & 0.268 & 0.364 & 0.140 & -0.121 & -0.003 \\
\hline 104 & DG & 3 & 3.23 & 5.44 & 0.140 & 0.444 & -0.014 & -0.194 & -0.125 \\
\hline 94 & DlG & 3 & 3.24 & 4.62 & 0.276 & 0.467 & 0.148 & -0.104 & 0.003 \\
\hline
\end{tabular}


TABLE A-5 (Continued)

\begin{tabular}{|c|c|c|c|c|c|c|c|c|c|}
\hline \multirow[b]{2}{*}{$\begin{array}{l}\text { Test } \\
\text { No. }\end{array}$} & \multirow[b]{2}{*}{ Config. } & \multirow[b]{2}{*}{$\begin{array}{c}\text { Heated } \\
\text { Col. } \\
\text { No. }\end{array}$} & \multirow[b]{2}{*}{$\begin{array}{c}\text { Flow } \\
\text { Rate } \\
(1 \mathrm{~b} / \mathrm{sec})\end{array}$} & \multirow[b]{2}{*}{$\begin{array}{c}\text { Koverall } \\
\text { Arith. Avg. }\end{array}$} & \multirow{2}{*}{$\begin{array}{c}\theta_{\text {sensor }}^{\prime} \\
\max \\
(\mathrm{Cij})\end{array}$} & \multirow{2}{*}{$\begin{array}{c}{ }^{\theta} \text { CSBexit } \\
\max \\
(\mathrm{Cij})\end{array}$} & \multicolumn{3}{|c|}{$\theta(A i j)$ for Sensor Centerline } \\
\hline & & & & & & & 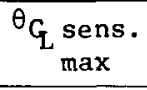 & $\begin{array}{c}{ }^{\theta} \mathrm{G} \text { sens. } \\
\text { min }\end{array}$ & $\begin{array}{c}\theta_{\mathrm{G}} \text { sens. } \\
\text { avg. }\end{array}$ \\
\hline 126 & AIG & 4 & 3.25 & 1.29 & 0.846 & 0.642 & 0.110 & 0.122 & -0.006 \\
\hline 116 & A2G & 4 & 3.28 & 1.25 & 0.543 & 0.657 & 0.075 & -0.146 & -0.031 \\
\hline 42 & BG & 4 & 3.25 & 2.38 & 0.844 & 0.544 & -0.006 & -0.108 & -0.044 \\
\hline 34.1 & $\mathrm{~B} 1 \mathrm{G}$ & 4 & 3.15 & 2.10 & 0.866 & 0.689 & -0.047 & -0.140 & -0.088 \\
\hline 51 & $\mathrm{~B} 2 \mathrm{G}$ & 4 & 3.27 & 2.07 & 0.484 & 0.521 & -0.060 & -0.146 & -0.094 \\
\hline 74 & CG & 4 & 3.25 & 4.05 & 0.852 & 0.447 & 0.057 & -0.118 & -0.048 \\
\hline 64 & $\mathrm{ClG}$ & 4 & 3.26 & 3.63 & 0.652 & 0.556 & 0.035 & -0.143 & -0.060 \\
\hline 84 & $\mathrm{C} 2 \mathrm{G}$ & 4 & 3.20 & 3.62 & 0.391 & 0.409 & 0.042 & -0.144 & -0.050 \\
\hline 105 & DG & 4 & 3.21 & 5.33 & 0.888 & 0.359 & 0.066 & -0.137 & -0.044 \\
\hline 95 & D1G & 4 & 3.21 & 4.72 & 0.555 & 0.471 & 0.026 & -0.159 & -0.070 \\
\hline
\end{tabular}


TABLE A-6

SUMMARY OF SELECTED PRELIMINARY INFLUENCE COEFFICIENTS (with Increased Reflector Block Height)

\begin{tabular}{|c|c|c|c|c|c|c|c|c|c|}
\hline \multirow[b]{2}{*}{$\begin{array}{l}\text { Test } \\
\text { No. }\end{array}$} & \multirow[b]{2}{*}{ Config. } & \multirow{2}{*}{$\begin{array}{l}\text { Heated } \\
\text { Col. } \\
\text { No. }\end{array}$} & \multirow{2}{*}{$\begin{array}{c}\text { Flow } \\
\text { Rate } \\
(1 \mathrm{~b} / \mathrm{sec})\end{array}$} & \multirow[b]{2}{*}{$\begin{array}{c}\mathrm{K}_{\text {overall }} \\
\text { Arith. Avg. }\end{array}$} & \multirow{2}{*}{$\begin{array}{c}\theta_{\text {sensor }}^{\prime} \\
\max \\
(C i j)\end{array}$} & \multirow{2}{*}{$\begin{array}{c}\theta^{\theta} \text { ĆSBexit } \\
\text { (C1j) }\end{array}$} & \multicolumn{3}{|c|}{$\theta(\mathrm{Aij})$ for Sensor Centerline } \\
\hline & & & & & & & ${ }^{\theta} \mathcal{E} \underset{\max }{\text { sens. }}$. & 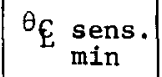 & ${ }^{\theta} \begin{array}{c}\text { sens. } \\
\text { avg. }\end{array}$ \\
\hline 31.2 & BIG & 1 & 3.25 & 2.13 & 0.174 & 0.156 & 0.096 & -0.025 & 0.023 \\
\hline F1 & 3BIG & 1 & 3.17 & 2.80 & 0.110 & 0.143 & 0.027 & -0.078 & -0.031 \\
\hline F5 & 4BIG & 1 & 3.20 & 2.68 & 0.102 & 0.111 & 0.019 & -0.050 & -0.018 \\
\hline 32.0 & BIG & 2 & 3.16 & 2.13 & 0.220 & 0.590 & 0.050 & -0.134 & -0.056 \\
\hline F2 & 3BIG & 2 & 3.10 & 2.49 & 0.270 & 0.568 & 0.038 & -0.131 & -0.058 \\
\hline F6 & 4B1G & 2 & 3.13 & 2.66 & 0.302 & 0.541 & 0.011 & -0.151 & -0.078 \\
\hline 33.2 & BIG & 3 & 3.16 & 2.02 & 0.139 & 0.536 & -0.011 & -0.162 & -0.099 \\
\hline F3 & $3 B I G$ & 3 & 3.14 & 2.62 & 0.159 & 0.492 & 0.012 & -0.168 & -0.091 \\
\hline F7 & 4BlG & 3 & 3.20 & 2.30 & 0.133 & 0.511 & -0.029 & -0.191 & -0.123 \\
\hline 34.1 & BIG & 4 & 3.15 & 2.10 & 0.866 & 0.689 & -0.047 & -0.140 & -0.088 \\
\hline F4 & $3 \mathrm{~B} 1 \mathrm{G}$ & 4 & 3.20 & 2.67 & 0.677 & 0.636 & -0.011 & -0.161 & -0.092 \\
\hline F8 & 4BIG & 4 & 3.19 & 2.24 & 0.658 & 0.578 & 0.027 & -0.175 & -0.086 \\
\hline 61 & $\mathrm{CIG}$ & 1 & 3.31 & 3.65 & 0.123 & 0.121 & 0.039 & -0.056 & -0.010 \\
\hline F9 & $3 \mathrm{CIG}$ & 1 & 3.19 & 3.88 & 0.097 & 0.103 & 0.016 & -0.071 & -0.028 \\
\hline F13 & $4 \mathrm{CIG}$ & 1 & 3.17 & 3.71 & 0.094 & 0.099 & 0.010 & -0.068 & -0.033 \\
\hline 62 & CIG & 2 & 3.28 & 3.58 & 0.372 & 0.492 & 0.066 & -0.138 & -0.051 \\
\hline F10 & $3 \mathrm{ClG}$ & 2 & 3.17 & 3.46 & 0.294 & 0.450 & -0.040 & -0.162 & -0.106 \\
\hline F14 & $4 \mathrm{ClG}$ & 2 & 3.17 & 3.56 & 0.306 & 0.415 & -0.034 & -0.151 & -0.095 \\
\hline 63 & $\mathrm{CIG}$ & 3 & 3.25 & 3.61 & 0.240 & 0.412 & 0.106 & -0.171 & -0.066 \\
\hline F11 & $3 \mathrm{ClG}$ & 3 & 3.21 & 3.56 & 0.092 & 0.419 & -0.077 & -0.174 & -0.133 \\
\hline F15 & $4 \mathrm{CIG}$ & 3 & 3.16 & 3.70 & 0.118 & 0.454 & -0.059 & -0.172 & -0.124 \\
\hline 64 & $\mathrm{CIG}$ & 4 & 3.26 & 3.63 & 0.652 & 0.556 & 0.035 & -0.143 & -0.060 \\
\hline F12 & $3 \mathrm{ClG}$ & 4 & 3.20 & 3.49 & 0.567 & 0.521 & 0.032 & -0.151 & -0.073 \\
\hline F16 & $4 \mathrm{CIG}$ & 4 & 3.21 & 4.26 & 0.528 & 0.511 & -0.024 & -0.158 & -0.098 \\
\hline
\end{tabular}


TABLE A-7

SUMMARY OF SELECTED PRELIMINARY INFLUENCE COEFFICIENTS - 4-CAL. REGION

\begin{tabular}{|c|c|c|c|c|c|c|c|c|c|c|c|c|}
\hline \multirow[b]{2}{*}{$\begin{array}{l}\text { Test } \\
\text { No. }\end{array}$} & \multirow[b]{2}{*}{ Config. } & \multirow{2}{*}{$\begin{array}{c}\text { Heated } \\
\text { Col. } \\
\text { No. }\end{array}$} & \multirow{2}{*}{$\begin{array}{c}\text { Flow } \\
\text { Rate } \\
(1 \mathrm{~b} / \mathrm{sec})\end{array}$} & \multirow[b]{2}{*}{$\mathrm{K}_{\text {overal1 }}$} & \multicolumn{5}{|c|}{$\theta^{\prime}(\mathrm{Cij})$ for Sensor and Exit Rake } & \multicolumn{3}{|c|}{$\theta(A i j)$ for Sensor $E$} \\
\hline & & & & & $\theta_{\text {max }}^{\prime}$ & $\underset{\max }{\theta \dot{C} \text { SBexit }}$ & $\begin{array}{c}\theta_{\text {sensor }}^{\text {min }} \\
\text { mand }\end{array}$ & ${ }^{\theta}{ }_{\text {min }}^{\text {ĆsBexit }}$ & $\begin{array}{c}\theta_{\text {calc. }}^{\text {cavg. }} \\
\text { avg. }\end{array}$ & ${ }^{\theta_{\mathrm{E}}} \underset{\max }{\text { sens. }}$ & ${ }^{\theta} \in \underset{\text { min }}{\text { sens. }}$ & $\overline{{ }^{\theta}} \begin{array}{l}\text { sens. } \\
\text { avg. }\end{array}$ \\
\hline 128 & BIG & 1 & 4.49 & 6.46 & 0.191 & 0.231 & 0 & 0.087 & 0.161 & -0.16 & -0.20 & -0.17 \\
\hline 129 & BIG & 2 & 4.35 & 6.27 & 0.834 & 0.663 & 0.043 & 0.115 & 0.278 & -0.24 & -0.31 & -0.28 \\
\hline 130 & $\mathrm{BIG}$ & 3 & 4.43 & 6.21 & 0.552 & 0.435 & 0.028 & 0.173 & 0.279 & +0.38 & -0.31 & -0.04 \\
\hline 131 & BIG & 4 & 4.53 & 6.13 & 0.613 & 0.507 & 0.010 & 0.074 & 0.282 & -0.02 & -0.32 & -0.20 \\
\hline 132 & BIG & 1 & 4.71 & 6.23 & 0.091 & 0.207 & 0.003 & 0.119 & 0.163 & -0.16 & -0.19 & 0.17 \\
\hline 133 & BIG & 2 & 4.52 & 5.81 & 0.769 & 0.612 & 0.031 & 0.160 & 0.277 & +0.60 & -0.27 & +0.13 \\
\hline 134 & BIG & 6 & 4.28 & 5.99 & 0.215 & 0.501 & 0 & 0.074 & 0.279 & -0.36 & -0.42 & -0.40 \\
\hline 135 & $B I G$ & 7 & 4.02 & 5.98 & 0.723 & 0.432 & 0.058 & 0.192 & 0.281 & +0.28 & -0.27 & -0.06 \\
\hline 136 & BIG & 7 & 4.17 & 6.43 & 0.675 & 0.567 & 0.002 & 0.070 & 0.283 & -0.26 & -0.39 & -0.32 \\
\hline 137 & BIG & 1 & 4.23 & 6.72 & 0.155 & 0.183 & 0.013 & 0.080 & 0.159 & -0.13 & -0.17 & -0.16 \\
\hline 138 & $B I G$ & 2 & 4.30 & 6.62 & 0.802 & 0.561 & 0.046 & 0.205 & 0.280 & +0.72 & -0.22 & +0.17 \\
\hline 139 & BIG & 3 & 4.22 & 6.27 & 0.619 & 0.560 & 0 & 0.080 & 0.279 & -0.32 & -0.38 & -0.35 \\
\hline
\end{tabular}


TABLE A-8

PRELIMINARY COST OPTIMIZATION OF CORE SUPPORT BLOCK CONFIGURATIONS

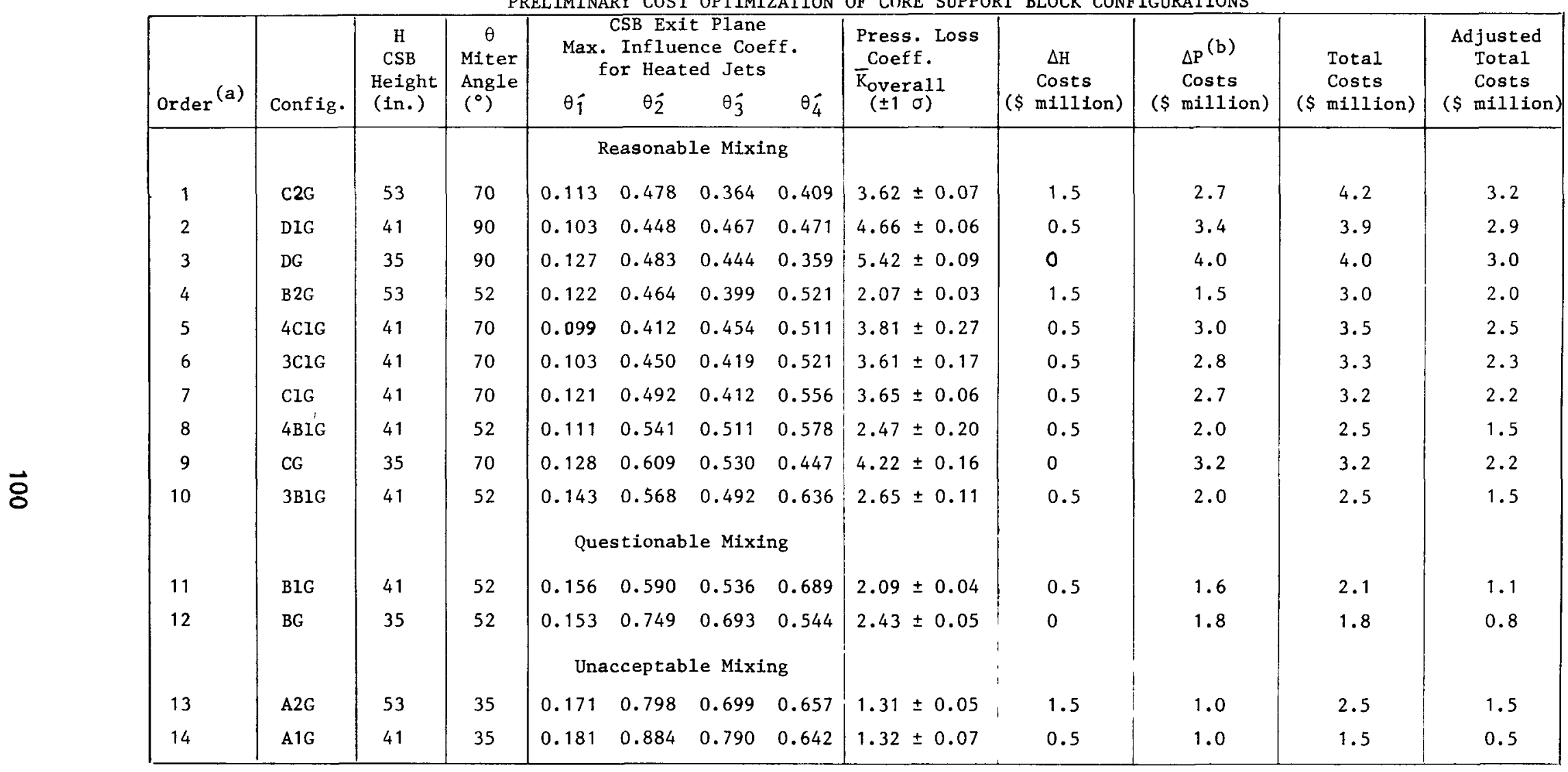

Assumptions: 1.0 psi $\Delta \mathrm{P}$ costs $\$ 2$ million; $1.0 \mathrm{ft} \Delta \mathrm{H}$ costs $\$ 1$ million

$$
\Delta \mathrm{P}_{\max , \text { reactor }}=\frac{\dot{\mathrm{m}}^{2} \mathrm{~K}}{2 \rho \mathrm{gA}^{2}}=0.365 \mathrm{~K} \text { psi }
$$

(Notes:) a. 1 is best mixing; 14 is worst mixing.

b. CSB exit loss has been excluded from these estimates. 